\title{
Exploring Performance Management of Volunteers in Non-Profit Organisations in New Zealand's Human Service Sector
}

by

Magdalena Sophia Weber

\author{
A thesis \\ submitted to the Victoria University of Wellington \\ in partial fulfilment of the requirements of the degree of \\ Master of Commerce in Management
}

Victoria University of Wellington

2017 


\begin{abstract}
Many non-profit organisations (NPOs) are highly dependent on volunteers to achieve their mission, and while volunteers tend to be motivated by altruistic reasons, performance management (PM) likely plays a key role in facilitating their commitment and directing their efforts to achieving their goals and the organisation's mission. Therefore, the purpose of this study is to investigate the PM process as applied to volunteers in an NPO in New Zealand. Moreover, the similarities and differences between PM practices used for employees and volunteers are examined.
\end{abstract}

Extant non-profit research has focused on individual management practices, but largely ignored the holistic PM process, whereas existing for-profit literature has concentrated on performance appraisals and evaluations, rather than PM. This study contributes to the limited research on PM processes by drawing together research from both sectors to develop an updated PM process model which is based on current PM trends and includes the steps goal-setting, feedback, training/development, and rewards/recognition. Due to the dearth in research on volunteer PM, a qualitative approach was deemed appropriate for this study to gain a deeper understanding of contextual factors and the research problem. A single case study was chosen to collect rich and in-depth data about the perceptions and experiences of managers and volunteers regarding PM. The New Zealand Cancer Society's Otago Southland Division (OSD) was selected as case study organisation and 19 semi-structured interviews were conducted with ten managers and nine volunteers. The interviews were held in late 2016 in four locations, the Cancer Society's national office in Wellington and the OSD's three main offices, Dunedin, Invercargill, and Queenstown.

The findings show that managers and volunteers struggle with the concept of PM in relation to volunteers because of its poor reputation and perceived unsuitability due to the special characteristics of volunteering. The individual practices, however, generated interest among participants as most practices are already used for volunteers in the OSD, albeit in an informal, ad-hoc manner and under the designation 'volunteer management'. The interviews revealed a pattern of accepted (rewards/recognition), unaccepted (goal-setting) practices and a "grey area" of practices which allow for further development (feedback, training/development). 
Volunteers' motivation and the frequency of use of the practices in the OSD influence if participants perceived them as accepted, unaccepted or as practices with potential (grey area). Based on the outcomes of this study, the updated PM process model was adapted to reflect the OSD's PM practices for volunteers.

Some inconsistencies in the participants' perceptions and experiences of PM and a lack of clear volunteer PM procedures were detected. The findings revealed that managers are reluctant to formalise the management practices for volunteers out of fear of losing them and, thus, hide certain practices behind social events which blurs the boundaries between the practices. The findings, therefore, suggest that PM is a valuable concept for the management of volunteers in NPOs, but that a semantic problem exists which prevents the further engagement with PM. Resulting implications are proposed which include a terminology change of PM in NPOs to conceal the managerial character of this concept. 


\section{Acknowledgements}

I am very grateful to a number of people who helped me with great encouragement, support, and input on the journey to completing this thesis.

First and foremost, I would like to thank Prof. Karen Smith who patiently guided me through the research process and always offered thoughtful advice, feedback, and consoling words.

Thanks to the managers and volunteers at the Cancer Society's Otago Southland Division and the National office who shared their perceptions and ideas with me and without whose support this research would not have been possible.

My heartfelt gratitude goes to my family who, although far away, always stood by me through thick and thin and who believe in me.

Finally, my greatest thanks and appreciation I would like to express to Dominik who was always there for me and whose love, support, and patience encouraged me when I felt overwhelmed with this research project. 


\section{Table of Contents}

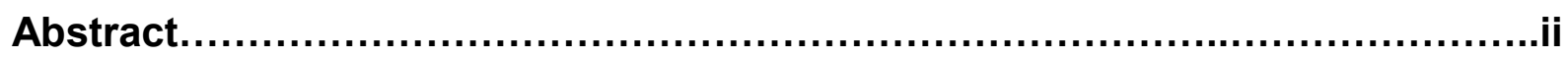

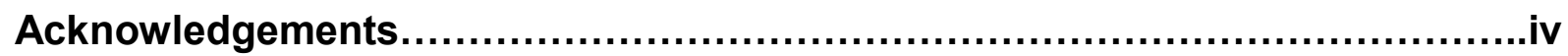

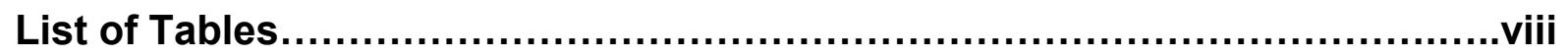

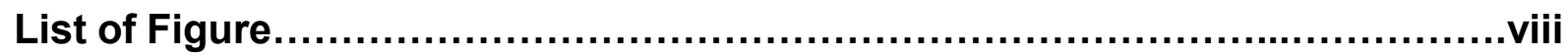

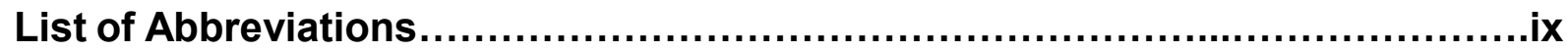

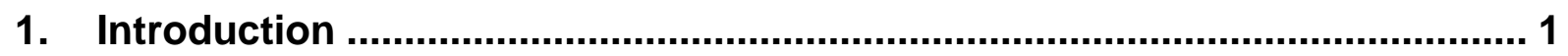

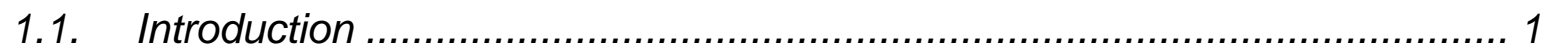

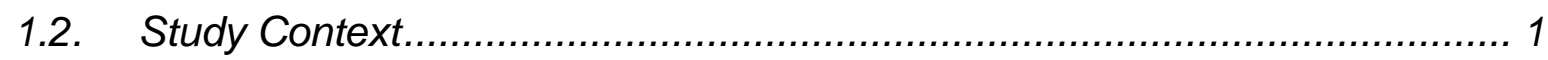

1.3. Aim of the Study and Research Design ................................................... 2

1.4. Research Question and Objectives .................................................... 3

1.5. Background to the Case Study .......................................................... 4

1.6. Roadmap through the Thesis .......................................................... 5

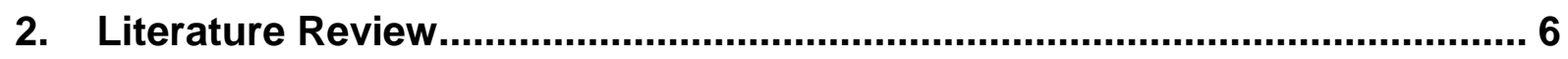

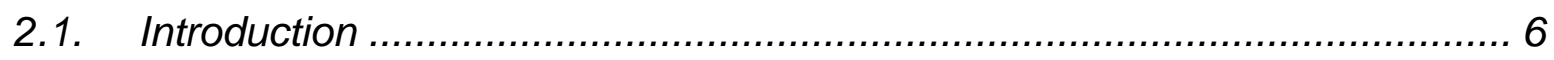

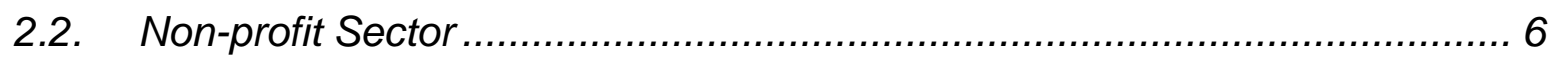

2.2.1. Characteristics of Non-profit Organisations ......................................... 7

2.2.2. Differences between For-profit and Non-profit Organisations ................... 8

2.2.3. Professionalization of Non-profit Organisations .................................... 9

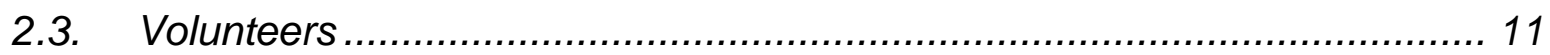

2.3.1. Definition of "Volunteerism"............................................................ 11

2.3.2. Differences between Volunteers and Employees ............................... 12

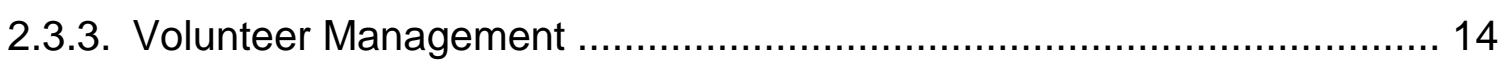

2.4. Performance Management ................................................................ 16

2.4.1. Definition "Performance Management" .............................................. 17

2.4.2. The Performance Management Process ........................................... 18 
2.4.3. Challenges in Performance Management........................................... 21

2.4.4. Performance Management Developments ............................................ 23

2.4.5. The Updated Performance Management Process ................................ 24

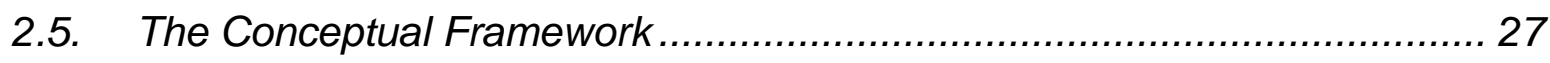

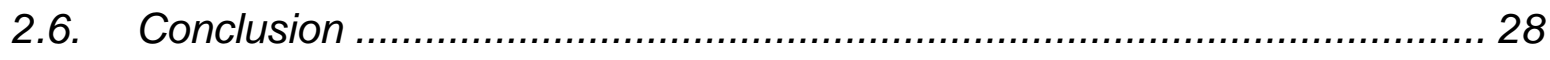

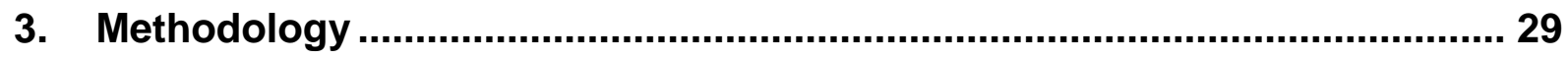

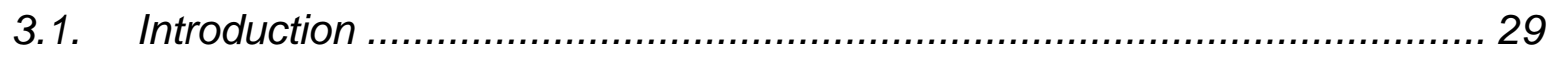

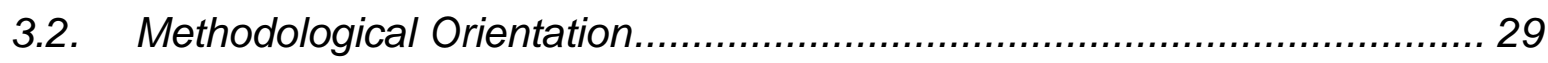

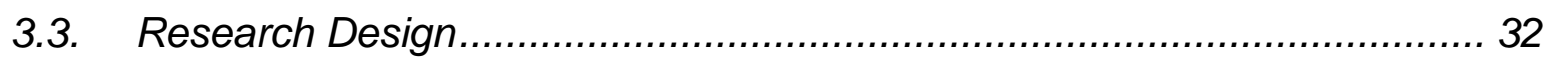

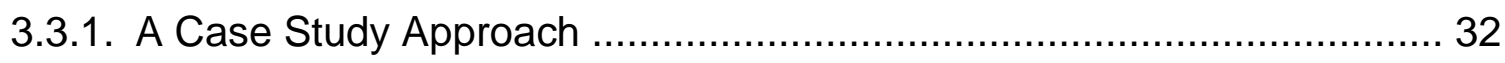

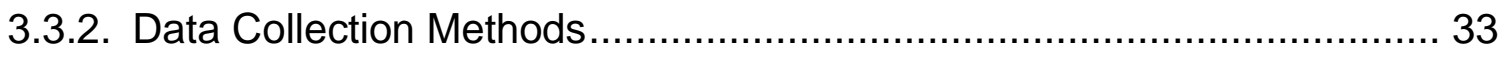

3.3.3. Case Study and Participant Selection................................................. 33

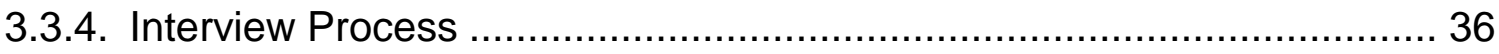

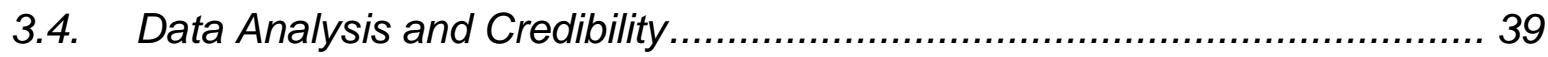

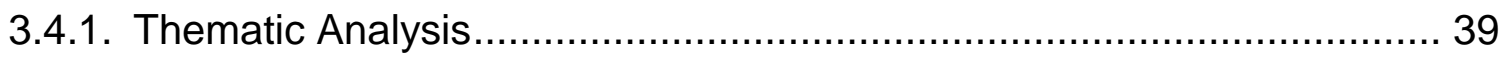

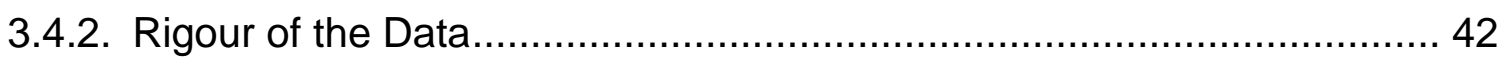

3.5. Ethical Considerations...................................................................... 43

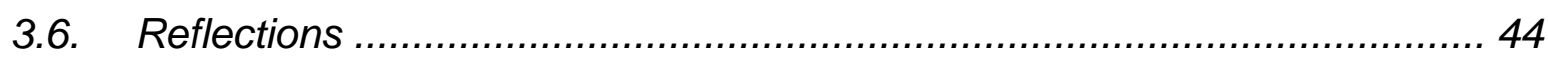

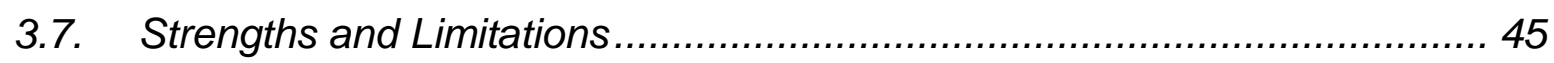

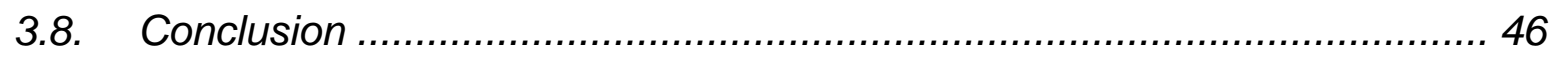

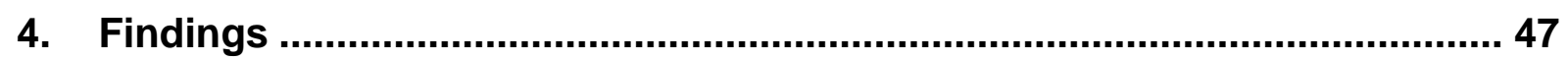

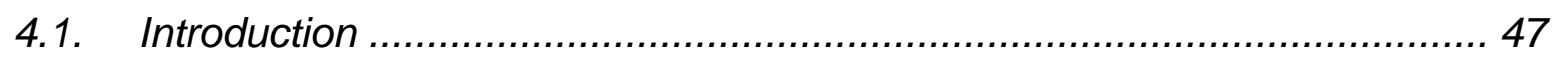

4.2. Performance Management in the Otago Southland Division ..................... 47

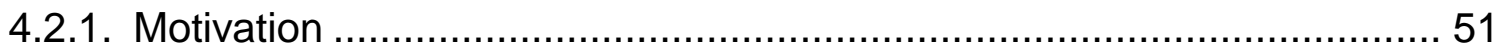

4.2.2. Performance Management Practices..................................................... 53

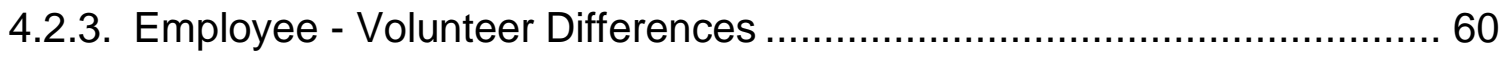

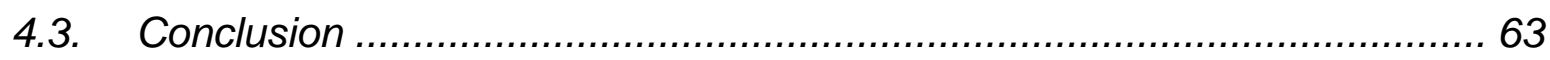




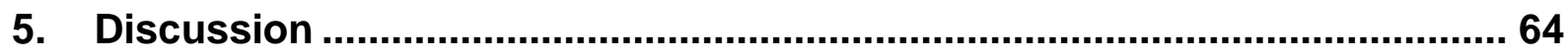

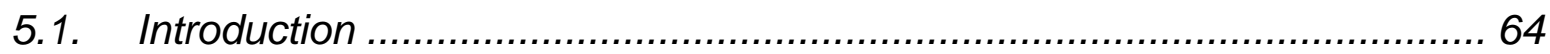

5.2. Volunteer Management and Performance Management Perceptions........ 64

5.3. Revisiting the Performance Management Practices............................... 66

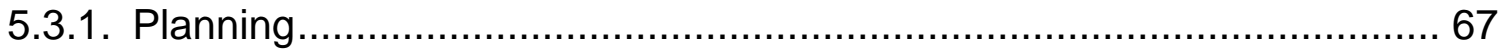

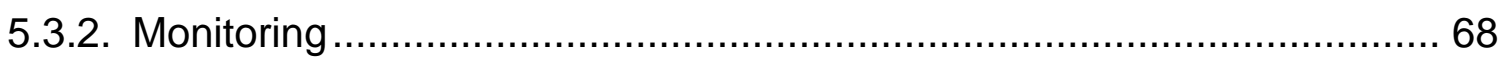

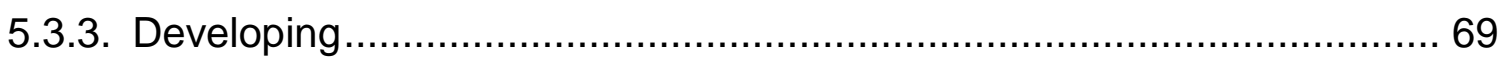

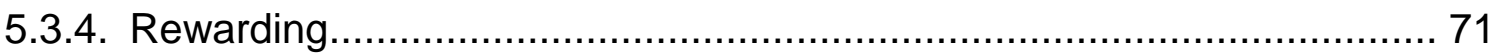

5.4. The Otago Southland Division's Performance Management Practices ..... 72

5.5. Performance Management of Employees and Volunteers ....................... 74

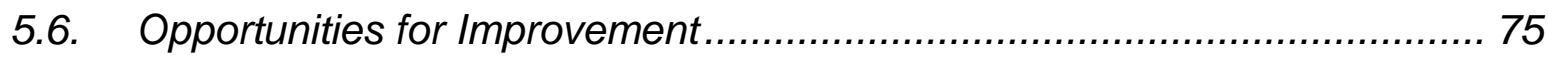

5.7. Unprofessionalism and Inconsistencies ........................................... 76

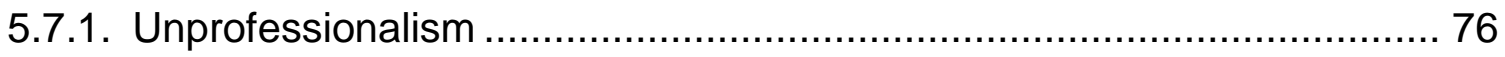

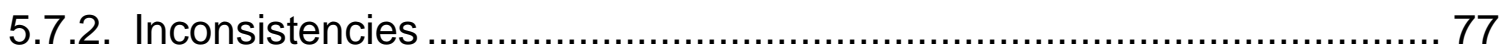

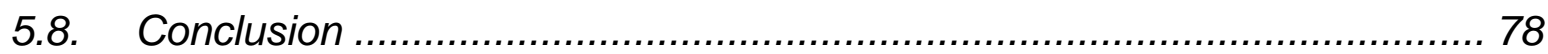

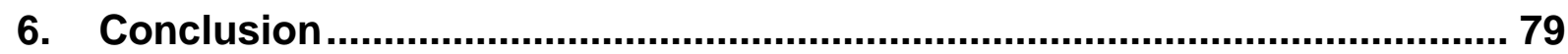

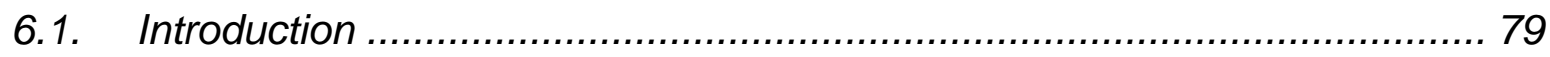

6.2. Revisiting the Research Question and Objectives................................. 80

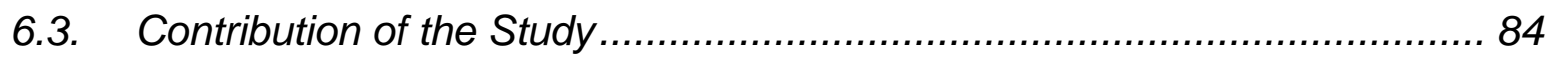

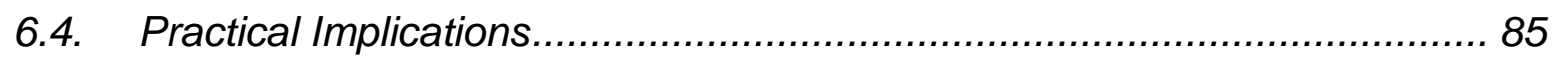

6.5. Suggestions for Future Research ..................................................... 86

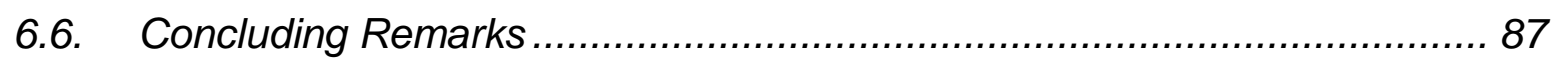

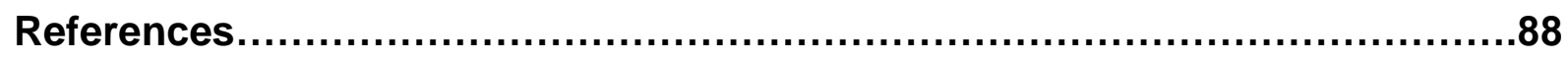

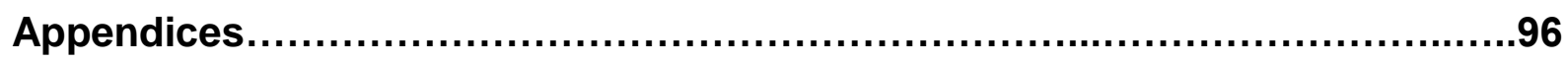




\section{List of Tables}

Table 1: Differences between NPOs and For-Profit Businesses ............................. 8

Table 2: Differences between Volunteers and Employees .................................. 14

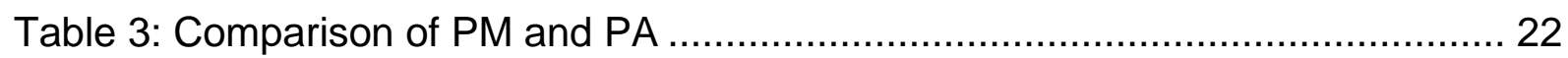

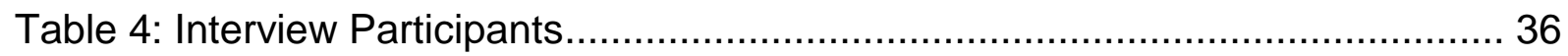

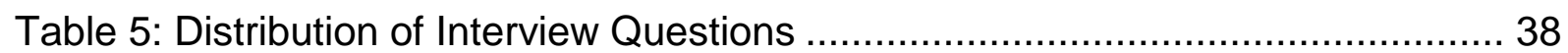

Table 6: Methods used to Enhance Rigour....................................................... 43

Table 7: Similarities and Differences of PM for Volunteers and Employees ............. 63

\section{List of Figures}

Figure 1: Distribution of NPOs in Industries ........................................................ 7

Figure 2: Integrated PM Process ................................................................. 19

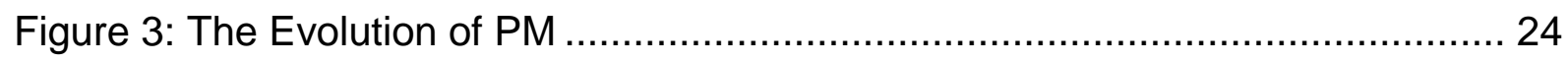

Figure 4: The Updated PM Process and Practices Model ................................... 25

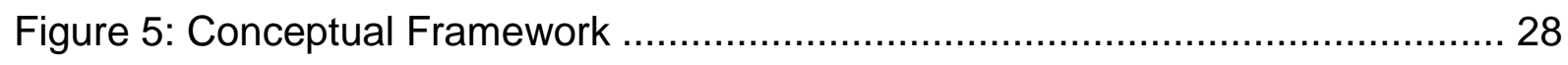

Figure 6: Overview of the Methodological Approaches ....................................... 31

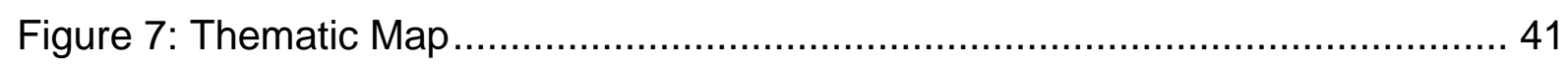

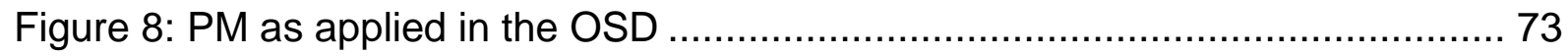




\section{List of Abbreviations}

$\begin{array}{ll}\text { CS } & \text { Cancer Society } \\ \text { NPO } & \text { non-profit organisation } \\ \text { OSD } & \text { Cancer Society's Otago Southland Division } \\ \text { PM } & \text { performance management } \\ \text { PAs } & \text { performance appraisals } \\ \text { VM } & \text { volunteer management }\end{array}$




\section{Introduction}

\subsection{Introduction}

This study aims to explore how performance management (PM) can be applied to volunteers in the non-profit human service sector. Through researching perspectives of both managers and volunteers this thesis offers insights into the effectiveness of volunteer PM and its impacts on managers and volunteers.

This chapter introduces the key components of why and how the research was conducted. The research question and objectives are discussed and the case study organisation is presented. Finally, the contributions of this research and the structure of the remainder of the thesis are outlined.

\subsection{Study Context}

Non-profit organisations (NPOs) frequently depend on volunteers as major resources of labour to achieve their missions (Bussin, 2013). According to Taylor, Mallinson, and Bloch (2008), volunteers devote their time and resources to NPOs and thereby allow the organisations to pursue their goals which would not be possible otherwise. Global statistics show a growing number of volunteers, but simultaneously the data shows a decrease in the amount of time spent volunteering. In 2013, New Zealand's volunteers spent 42\% less time working for NPOs than in 2004 (Statistics New Zealand, 2015). Additionally, NPOs are increasingly pressured by their stakeholders to act more professionally and to efficiently allocate their resources (Akinlade \& Shalack, 2016).

Thus, NPOs depend upon highly motivated volunteers and the most efficient use of scarce resources, which can be achieved through management practices (Bussin, 2013). One valuable management practice capable of improving, sustaining and monitoring volunteers' motivation and performance is PM. PM is an on-going, dynamic process and relates to multiple activities which are designed to offer encouragement, guidance, and support and, thereby, positively impacts an individual's behaviour (Aguinis, 2009; DeNisi, 2011; Ochurub, Bussin, \& Goosen, 2012). While there is some non-profit literature which looks at certain PM practices, to the author's knowledge, there is no non-profit research dealing with the holistic PM system in regards to 
volunteers. Therefore, PM systems used in NPOs for the successful motivation and retention of volunteers requires further investigation. Moreover, current changes in PM that focus on motivation rather than evaluation-focused practices imply the need for studies which examine this revamped PM process and find new ways of conceptualising PM.

\subsection{Aim of the Study and Research Design}

According to Cuskelly, Taylor, Hoye, and Darcy (2006) the HRM literature has mainly concentrated on HR practices for employees, while the volunteer management (VM) literature has been dominated by research on volunteer motivation and satisfaction. Hence, only limited research has examined the adoption and effectiveness of a PM system for volunteers, as most PM studies take place in a for-profit and/or employee context (Bartram, Hoye, \& Cavanagh, 2014; O’Boyle \& Hassan, 2015; Selden \& Sowa, 2011) or are concerned with the individual practices of $P M$, rather than the whole system. Therefore, scholars have suggested that further research about the effective management of volunteers is needed (Akinlade \& Shalack, 2016; Alfes, Shantz, \& Bailey, 2016). Moreover, current trends in PM are mostly ignored by academic literature and therefore need to be investigated further.

This study addresses these gaps in the PM, volunteer, and non-profit literature by exploring PM for volunteers in one NPO in the New Zealand human-service sector to surface potential sector-specific characteristics, challenges, and practices. This was done by conducting a case study with the Cancer Society's Otago Southland Division (OSD) which employs both paid and unpaid staff. 19 in-depth interviews were conducted with the national CEO and capacity \& development manager, and the OSD's CEO, volunteer managers, and a sample of employees and volunteers. For reasons of simplicity, the CEOs, volunteer managers and employees will be collectively referred to as "managers" in this thesis. Documents derived from public sources or provided by the organisation provided background information on the case study organisation.

The findings were compared to an updated PM model (section 2.4.5) which illustrates a new way of conceptualising PM and is based on the literature and current trends in 
PM in the for-profit sector. Additionally, this thesis identifies divergences in the perceptions of managers and volunteers on the PM practices used, which provides insights into how PM practices influence the attitudes and behaviours of volunteers and managers. By putting the PM practices used for volunteers in relation to the ones applied to employees, possible links between those are delineated. Although the analysis of employees' PM practices and their perceptions is restricted by the limited scope of this study, contextualising PM for volunteers with PM for employees represents a new perspective in non-profit and PM research, as they are normally considered in isolation.

The terminology in this thesis is will be kept consistent to avoid any ambiguity, for example volunteers are referred to as "volunteers" or "unpaid staff", while employees are designated as "employees" or "paid staff". However, interviewees often used the term "staff" when talking about paid employees which was maintained in the quotes, as it might reflect how participants regard volunteers/employees.

\subsection{Research Question and Objectives}

This thesis seeks to address the discussed gaps in non-profit, volunteer and PM literature by answering the following research question:

How can performance management be applied to volunteers in non-profit organisations?

The research objectives are to:

1. Identify how the Otago Southland Division of the Cancer Society reviews the performance of volunteers.

2. Compare how volunteers and managers perceive the Otago Southland Division's performance management practices.

3. Evaluate managers' and volunteers' perceptions on how performance management can be improved. 


\subsection{Background to the Case Study}

The case study organisation for this thesis was the Cancer Society's Otago Southland Division (OSD). The Cancer Society (CS) is a large, national NPO, which is concerned with supportive care services, health promotion and information, and funding the largest non-governmental cancer research programme in New Zealand. It is an independent charity which receives no governmental funding and is therefore in a good position to lobby the government for achieving its mission of "reducing the incidence and impact of cancer" (Otago Southland Cancer NZ, 2017).

The CS was formed in 1929 as a branch of the British Empire Cancer Campaign and operates on a national as well as divisional level within New Zealand. The OSD is one of six divisions of the CS in New Zealand. All six divisions operate autonomously and have their own governance and board. The OSD is geographically widely dispersed and has offices in Dunedin, Invercargill, and Queenstown. To be able to provide its services, the OSD involves more than 1,000 volunteers for a variety of roles, such as driving, supportive care, fundraising and working in the CanShop ${ }^{1}$. In 2016, for example, the OSD's supportive care team visited over 1,200 homes and more than NZD 200,000 were invested into cancer research. The OSD's gross income amounted to about NZD 2.551 million, whereby $37.7 \%$ of the income was raised through donations and grants, followed by bequests $(25.8 \%)$ and fundraising events $(17.5 \%)$. Other sources of income were retail (9.6\%), accommodation (7.7\%), and investments (1.7\%).

The data collection was undertaken in November 2016, which was during a transformation phase of the OSD. A new CEO had just been appointed who was not yet familiar with the OSD's management practices and who planned to implement a new PM system in 2017. There has also been a change of CEO at the National Office since the interviews. Therefore, the research may not represent how volunteers' and employees' PM will look like in the future.

${ }^{1}$ CS's retail shop which sells quality second hand goods 


\subsection{Roadmap through the Thesis}

This chapter outlined the aim and context of this thesis, identified the research question and objectives and introduced the case study organisation.

The second chapter is concerned with the academic literature on NPOs, volunteers, and PM. In this chapter definitions, characteristics, and challenges of these three topics are examined and current developments are presented. Lastly, a framework of all factors explored in this thesis is created.

Chapter Three discusses the research design and methods used in this study. The paradigm underlying this thesis is outlined and the possible research biases are delineated. The reasons for choosing a case study approach are presented and the data collection methods are identified. Moreover, the procedure for data analysis, rigour and reliability strategies are explained and ethical considerations of this thesis are highlighted. Additionally, some of the researcher's reflections are discussed and the strengths and limitations of the thesis are considered.

The subsequent chapters, Chapter Four and Five, present the findings and a discussion of the case study. The PM practices used by the OSD are identified and the perceptions of managers and volunteers are discussed, including their ideas on how PM can be improved. The extent to which the findings of the case study confirm or contradict the established literature is reviewed and an adapted PM process model which reflects the PM practices used in this NPO for volunteers is presented. The findings are compared to PM of employees.

The final chapter provides a conclusion to the study, answers the research question and identifies areas for future research. Furthermore, practical implications and contributions of this study are presented. 


\section{Literature Review}

\subsection{Introduction}

This chapter outlines the context of this research on PM of volunteers in the humanservice sector. Firstly, the non-profit sector is reviewed to understand where the research is situated and how NPOs differ from for-profit businesses. Secondly, some context on volunteers is provided to better understand what they do, their positions in organisations and their motivations. Moreover, the defining characteristics of volunteers opposed to employees and the resulting consequences on the management of volunteers are explored. Thirdly, PM is introduced and PM literature is examined for the purposes of understanding the background and issues of PM and the subsequent developments which currently take place in for-profit businesses. Then, the theoretical framework of the PM process, as used by various scholars and practitioners, is described. Finally, PM developments are discussed and a modified PM framework is introduced which serves as basis for the primary research conducted.

\subsection{Non-profit Sector}

The non-profit sector is diverse and complex and ranges from large organisations to small self-help groups (Lyons, 2001). The terminology "non-profit sector" originated in the USA and relates to organisations which have emerged from the desire to serve a greater public or common good (Bussin, 2013) and which are not allowed to distribute their profits (Lyons, 2001). According to the New Zealand Government (2016) an NPO is

"any society, association or organisation (incorporated or not) that is not carried on for the profit or gain of any member, and whose rules do not allow money, property or any other benefit to be distributed to any of its members."

NPOs have a great effect on the society as well as the economy in New Zealand. In 2013, 114,110 NPOs contributed about NZD 9.4 billion (4.4\%) to the total GDP, including volunteer labour (Statistics New Zealand, 2015). Non-profit providers in the human service sector made the highest contribution to the NPO's GDP with about NZD 1.42 billion (24\% of NPO's GDP). 


\subsubsection{Characteristics of Non-profit Organisations}

The United Nations and various governments worldwide agreed on a conceptual framework which defines NPOs, facilitates the comparison of NPOs with each other and specifies their basic structure and operation (Tennant, Sanders, O'Brien, \& Castle, 2006). According to the framework, an NPO is

- Organised (can be separately identified)

- Private (institutionally different from the government)

- Non-profit distributing

- Self-governing

- Non-compulsory (membership and participation is voluntary)

(Statistics New Zealand, 2007; Tennant et al., 2006)

NPOs in New Zealand are primarily engaged in culture and recreation, social services and health (can be equated to the human service sector), education and research, development and housing, and religion. The highest amount of organisations (44.2\%) are in the arts, culture and recreation sector, followed by social services and health (15.6\%) (Statistics New Zealand, 2015) (figure 1). NPOs do not just differ in industries and contexts they are active in, but also in size, age, activities, structure, objectives, and legal form (Lyons, 2001; Tucker \& Thorne, 2013). As well as diversity within the NPO sector, these organisations also differ immensely from for-profit businesses.

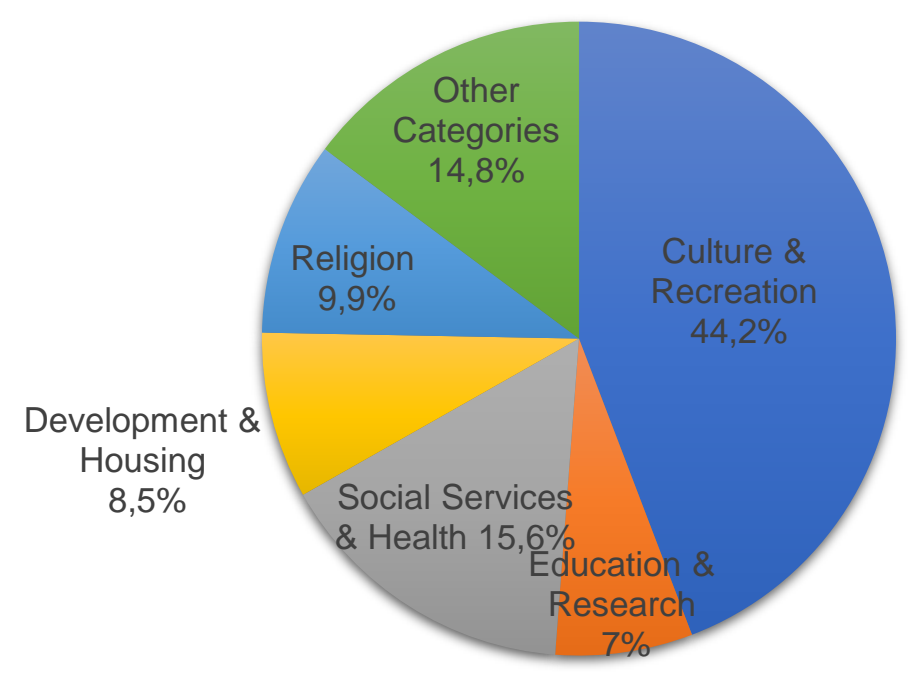

Figure 1: Distribution of NPOs in Industries

(Statistics New Zealand, 2015) 


\subsubsection{Differences between For-profit and Non-profit Organisations}

Distinct features between for- and non-profit organisations include their mission, source of revenue, governance structure, internal structure, organisational culture, value creation, profits, and legislation, as outlined in table 1.

\begin{tabular}{|c|c|c|}
\hline Characteristics: & Non-profit organisation: & For-profit business: \\
\hline Mission & $\begin{array}{c}\text { Social objectives and } \\
\text { mission }\end{array}$ & Earn profits \\
\hline Secondary Mission & $\begin{array}{l}\text { Ensure ongoing } \\
\text { funding/donations to be able } \\
\text { to maintain and extend the } \\
\text { services provided }\end{array}$ & Sell products or services \\
\hline Sources of Revenue & Funds, donations, fees & $\begin{array}{l}\text { Income from products and } \\
\text { services sold, investment } \\
\text { returns }\end{array}$ \\
\hline Governance Structure & No owners & Owners \\
\hline Internal Structure & $\begin{array}{c}\text { Frequent reliance on } \\
\text { volunteers, some also have } \\
\text { employees }\end{array}$ & Mostly employees \\
\hline Organisational Culture & Value-driven & Profit-driven \\
\hline Value Creation & $\begin{array}{l}\text { Achievement of social } \\
\text { mission; Donor satisfaction }\end{array}$ & $\begin{array}{l}\text { Financial returns; Use value } \\
\text { delivered to customers }\end{array}$ \\
\hline Profits & $\begin{array}{c}\text { Profits are re-invested in } \\
\text { organisation }\end{array}$ & $\begin{array}{l}\text { Profits are distributed to } \\
\text { shareholders or spent, } \\
\text { retained or reinvested }\end{array}$ \\
\hline Legislation & $\begin{array}{l}\text { Various legal forms, can } \\
\text { have tax concessions or be } \\
\text { tax-exempt }\end{array}$ & Various legal forms \\
\hline
\end{tabular}

Table 1: Differences between NPOs and For-Profit Businesses

(adapted from Bussin, 2013)

Paton and Cornforth (1992) have identified that non-profit and for-profit organisations differentiate themselves through NPO's social mission, the unique way of acquiring resources, achieved primarily through funding and donations, and the distinctive, value-driven organisational culture. Bussin (2013) assert that NPOs have a different governance structure than for-profit businesses. For-profit organisations are either 
owned by individuals or shareholders, whereas NPOs do not have real owners, but are rather owned by society at large (Ben-Ner, 2004). Furthermore, NPOs do not seek to gain profits for owners or investors, but rather re-invest earnings in their own organisation to carry out their purposes (Bussin, 2013). In comparison, for-profit businesses can keep their profits, distribute, reinvest, or spend them.

Another difference between non-profit and private sector lies in the measurement of the value created through the products or services offered. The NPOs' main value delivered is the attainment of their social goals and the donor's satisfaction and desire to continuously contribute to the organisation's cause. The primary value created by for-profit businesses is profits and the use-value brought to their customers (Moore, 2000). Moreover, there are also differences in legislation, as an NPO can take on various legal forms contingent on its mission and structure (O'Brien, Sanders, \& Tennant, 2009). The legislation shapes the NPO's legal forms, tax handling and action possibilities and regulates the way and extent of funding. In New Zealand many policies and statues exist which influence the non-profit sector's organisational forms and affect among others the Treaty of Waitangi obligations, employment, and health and safety requirements (O’Brien et al., 2009).

Other distinctive features of NPOs are the frequent reliance on volunteers and donor funding (Bussin, 2013; Statistics New Zealand, 2015). Taylor et al. (2008, p.390) corroborate that "organizations rely on volunteers to effectively pursue or meet their charge or mission, and without them, many organizations would not survive." About $90 \%$ of NPOs depend on volunteers and do not hire employees (Statistics New Zealand, 2015).

\subsubsection{Professionalization of Non-profit Organisations}

Due to growing competition, technological advancements, and globalization, companies in the private sector are pressured to reassess the management of their capabilities and resources to gain a competitive advantage (Akinlade \& Shalack, 2016; Cuskelly et al., 2006). NPOs face similar challenges as the competition for donors rises and donor and government funding decreases. Moreover, NPO's stakeholders, which comprise donors, members, partners, and the government, increasingly urge NPOs to become more professional and "business-like" and to use their resources efficiently 
(Akinlade \& Shalack, 2016). Governments, for instance, impose strict requirements on NPOs who want to apply for funding, including reporting conditions and operation specifications (O'Brien et al., 2009). A lack of sound governance within NPOs, which has led to several cases of fraud and scandals in the past, has caused lasting damage to the reputation of the non-profit sector (Lockyer, 2014) and fuelled the professionalisation calls.

The complexity of NPO's accountabilities, increased competition and poor reputation need to be dealt with through effective management practices (Bussin, 2013). However, often NPOs do not have the required financial resources, knowledge or capabilities to implement these practices (Lockyer, 2014). Additionally, management practices also imply higher workloads for NPOs which can be burdening considering that most non-profit institutions rely to a great extent on volunteers to carry out their mission (O'Brien et al., 2009). Therefore, it is essential to maintain or increase the volunteer's motivation and satisfaction in order to retain them (Boezeman \& Ellemers, 2009). NPOs must design a PM system for employees and volunteers to motivate them and to guarantee an efficient use of resources and organisational sustainability (Bussin, 2013). NPOs which do not motivate, retain, and raise the performance of their staff, cannot compete in today's market and are likely to fail.

However, not all scholars agree with the trend towards more effective management tools in the non-profit sector. Frumkin and Andre-Clark (2000) emphasize that as private sector businesses and social enterprises also operate in non-profit dominant industries, for-profit businesses, social enterprises, and NPOs have to compete for the same resources. If NPOs become more business-like, the competition will take place on the basis of cost, speed and quantity of almost identical services, which NPOs are likely to lose due to their limited human and financial resources, less political influence and limitations owing to NPO's social missions. Hence, Frumkin and Andre-Clark argue that NPOs need to find ways to compete in the market by drawing from their unique characteristics, missions, and capacities. 


\subsection{Volunteers}

Volunteers are frequently NPOs' main human resource and have a large effect on society, politics, and the economy (Alfes et al., 2016; Statistics New Zealand, 2015). They are of great value for organisations due to the time, free labour, and resources, such as knowledge and expertise, they bring. Volunteers are employed in a variety of environments and take on many different roles (Barnes \& Sharpe, 2009; Bussell \& Forbes, 2002). Typically, volunteerism comprises either administrative or service activities (Dwiggins-Beeler, Spitzberg, \& Roesch, 2011), whereby most volunteers are engaged in the service delivery and, thus, function as community ambassadors. In this role volunteers link the organisation to the community, facilitate fundraising and the recruitment of other volunteers (Handy \& Srinivasan, 2004; Holmes, 2009) and improve the satisfaction of NPOs' service receivers (Hotchkiss, Fottler, \& Unruh, 2009).

Volunteers are a heterogeneous group which varies in age, skills, experiences and backgrounds (Bussell \& Forbes, 2002). However, Bussell and Forbes (2002) found that women tend to volunteer more than men, apart from political non-profit work. This is in accordance with the findings from the Department of Internal Affairs (2014) where about $59 \%$ of volunteers in New Zealand were female, the largest volunteer group were 30-39 years old, and people between 10-19 years volunteered least. Additionally, people who work part-time are more likely to volunteer than those working full-time or who are unemployed (Bussell \& Forbes, 2002; van Ingen \& Wilson, 2016). According to Wilson (2000), level of education is the most accurate predictor of voluntary work, because education raises the awareness for suffering and heightens the level of empathy. Other aspects which impact the willingness to volunteer are motivation, type of paid work, and family obligations (Taylor et al., 2008). Therefore, it is both important and complex to have a system which effectively engages and retains such a diverse range of people.

\subsubsection{Definition of "Volunteerism"}

Both volunteers' heterogeneity and the differences in volunteer work make it difficult to find a clear and coherent definition of "volunteerism". While some researchers take a more simplistic approach, defining volunteering activities solely as unpaid and altruistic, others provide more complex conceptualisations (Barnes \& Sharpe, 2009). 
Boezeman and Ellemers (2007), for instance, defined volunteering broadly as unpaid work for an institution which is without obligations and benefits the society. Kenny, McNevin, and Hogan (2008, p. 46), on the other hand, took a more complex approach and described volunteering as an activity which benefits the community, is carried out willingly, and without receiving monetary rewards, but can include reimbursements for actual expenses and must be undertaken in designated volunteer positions in an organized context only.

Even within the different dimensions, researchers' opinions vary. Although most researchers exclude volunteer activities which are carried out for low pays or stipends, some scholars, such as Ellis and Noyes (1990), argue that people who receive monetary reimbursements can still be considered as volunteers. Cnaan, Handy, and Wadsworth (1996) developed a continuum which ranges from the purest to the broadest definitions of a volunteer and includes the four dimensions of free choice, remuneration, structure and intended beneficiaries. The authors concluded that people's perception of the costs and benefits to a volunteer are the main factors which decide if a person is a volunteer. The higher the costs and the lower the benefits to the individual, the "purer" is the volunteering activity (Cnaan et al., 1996).

For the purpose of this study, the definition by the UN General Assembly in 2002, which Volunteering New Zealand also refers, will be adopted:

"[T] he terms volunteering, volunteerism and voluntary activities refer to a wide range of activities, including traditional forms of mutual aid and self-help, formal service delivery and other forms of civic participation, undertaken of free will, for the general public good and where monetary reward is not the principle motivating factor." (United Nations General Assembly, 2002; Volunteering NZ, 2016)

\subsubsection{Differences between Volunteers and Employees}

Although NPOs depend on volunteers to be able to effectively pursue their goals and mission (Taylor et al., 2008), they often hesitate to spend the same amount of resources on volunteers as on employees or to involve volunteers in their decisionmaking processes. This can be traced back to organisations not being able to exert the same amount of control over volunteers as over employees (Dwiggins-Beeler et al., 2011). Additionally, the volunteer-NPO relationship is beneficial for both sides, but 
if challenges occur volunteers may be less engaged to solve these issues than employees and may leave rather than trying to solve the issue with the organisation (Garner \& Garner, 2011).

Another difference between employees and volunteers concerns their motivation. Volunteers' motivations are multifaceted (Dhebar \& Stokes, 2008; Taylor, Darcy, Hoye, \& Cuskelly, 2006), but, according to Dwiggins-Beeler et al. (2011), they are more intrinsically motivated than employees through the opportunity of personal fulfillment, networking with others and building social relationships or prospective job offers. Other reasons to volunteer can include altruism, the hope for a better world, reciprocation for help received, the extension or improvement of skills, prospective job offers, the desire to meet new people or to spend time with family and friends who also volunteer (UN Volunteers, 2015; Wilson, 2000). Moreover, Boezeman and Ellemers (2009) conducted a study on job satisfaction of volunteers and employees and found that employees derived their job satisfaction and intention to remain in the company mainly from meeting their needs for autonomy, whereas for volunteers satisfying the need for relatedness was the key. There are also variations between employees' motivations, as non-profit employees are often motivated more intrinsically, for example by their contribution to social change, than for-profit employees (Devaro \& Brookshire, 2007) and, therefore, need to be rewarded more intangibly through for example recognition, flexibility schemes etc. (Mohiuddin \& Dulay, 2015).

Table 2 was developed by the researcher to summarize the defining differences between volunteers and employees as outlined in the literature. 


\begin{tabular}{|c|c|c|}
\hline Characteristics: & Volunteers: & Employees: \\
\hline Motivation & Intrinsically motivated & $\begin{array}{c}\text { Often more extrinsically } \\
\text { motivated }\end{array}$ \\
\hline Rewards & $\begin{array}{c}\text { Normally no monetary } \\
\text { rewards; achievement of } \\
\text { personal goals } \\
\text { Similar to the role of } \\
\text { employees or } \\
\text { supplementary roles } \\
\text { Role }\end{array}$ & $\begin{array}{c}\text { Salary, benefits, bonuses, } \\
\text { leave etc. }\end{array}$ \\
\hline Work Amount & $\begin{array}{c}\text { Work days \& hours by } \\
\text { agreement }\end{array}$ & \\
\hline Legislation & No Contract of Service & Full / Part-time \\
\hline required & $\begin{array}{c}\text { Contract of Service as } \\
\text { defined in the }\end{array}$ \\
\hline
\end{tabular}

Table 2: Differences between Volunteers and Employees

(developed by the author)

\subsubsection{Volunteer Management}

There are diverging views on how volunteers should be managed (Cnaan \& Cascio, 1998; Studer \& von Schnurbein, 2013). Some scholars argue that volunteers can be compared to employees and should be supervised similarly (e.g. Drucker, 1989; Leat, 1993). Other researchers contend that volunteers and employees differ from each other and, therefore, should be managed differently (e.g. Cnaan \& Cascio, 1998). Authors who take the view against an analogous management indicate that people who volunteer only want to contribute to society and do not want to be managed or supervised (Cnaan \& Cascio, 1998). Some researchers corroborate that management practices contradict with the values of volunteering (Kellner, Townsend, \& Wilkinson, 2016; Kreutzer \& Jäger, 2011; Leonard, Onyx, \& Hayward-Brown, 2004). Moreover, apart from receiving no income, volunteers vary from employees in terms of work days and hours, contractual situation, organisational communication and motivation (table 2) (Creative NZ, 2014; Dwiggins-Beeler et al., 2011; Studer \& von Schnurbein, 2013). Hence, many factors, such as income and job security, which demonstrably influence the job attitudes of employees do not play a role for volunteers (Boezeman \& Ellemers, 2009). 
Although volunteers and employees differ from each other in many ways, it has been acknowledged by researchers from both positions that human resource management (HRM) practices can be beneficial for the management of volunteers, as long as the special qualities of volunteering are maintained (Paull, Holloway, \& Burnett, 2010). For instance, research shows that effective VM has significant benefits for NPOs (e.g. Machin \& Paine, 2008), whereas the lack of competent management can result in increased difficulties to retain volunteers (e.g. Taylor et al., 2006). This presents a problem, as researchers, such as Carvalho and Sampaio (2017) and Machin and Paine (2008), have found that VM rarely follows a strategic focus approach. Additionally, Brewis, Hill, and Stevens (2010) and Nesbit, Rimes, Christensen, and Brudney (2016) discovered that volunteer managers often have significant experience in dealing with volunteers, but not necessarily managerial education.

Nevertheless, many guides for volunteer managers (e.g. Creative NZ, 2014) suggest to introduce HRM practices, such as carefully planned recruitment, orientation, supervision and reward systems. Lynch and Smith (2009) examined 12 cultural heritage attractions in the UK and found that national, large NPOs were more likely to use a formalised recruitment process than smaller NPOs. Contrarily, Carvalho and Sampaio (2017) investigated five NPOs and discovered that the majority of these organisations use an informal, ad-hoc approach to VM. Also other researchers found that most NPOs, depending on the organisational context, deem informal VM as sufficient (Hager \& Brudney, 2004; Machin \& Paine, 2008). Hager and Brudney (2004) showed that NPOs with a higher volunteer involvement made greater efforts to manage them effectively, but also found that with an increasing number of volunteers, individual supervision gave way to standard management practices.

Moreton (2006) noticed that professional HRM practices for volunteers are influenced by external factors and organisational growth and that volunteers perceive these practices differently. He states that "it is not the management style that is of paramount importance, but the perception of the management style in the mind of the volunteer" (p.8). Moreover, he concludes that volunteers do not resist HRM practices in general, but that the way these practices are executed and communicated is more important than the practices themselves. Furthermore, Nencini, Romaioli, and Meneghini (2016) investigated volunteer motivation and satisfaction by asking 247 volunteers from four 
different NPOs to fill out a self-report questionnaire. The researchers ascertain that the volunteer environment is less important for their satisfaction and commitment than the volunteers' perceptions of their relationships with the organisation's other un/paid staff. They conclude that effective, supportive VM that is based on good relationships between volunteers and employees plays an essential role in determining volunteer satisfaction, commitment, and intention to stay. Other research also confirms that good relationships between volunteers can increase retention rates, improve the organisational climate and the volunteers' satisfaction (Haski-Leventhal \& Bargal, 2008; Vecina, Chacón, Sueiro Abad, \& Barrón, 2012).

\subsection{Performance Management}

In recent years, NPOs have increasingly recognized the potential of HRM to positively affect volunteer well-being (Bartram et al., 2014). However, the nature of HRM differs in each organisation depending on its specific needs, structure, size, level of volunteer involvement, and context (Bartram et al., 2014; Hager \& Brudney, 2004). Also the industry in which an NPO operates influences the implementation of VM practices, as health and human service NPOs are generally more likely to adopt HRM practices than NPOs from other fields (Hager \& Brudney, 2004). Human service NPOs rely heavily on employees and volunteers to provide their services and, thus, the quality, satisfaction, and motivation of their un/paid staff are key factors in determining the organisation's success (Walk, Schinnenburg, \& Handy, 2014).

One important HRM practice is $\mathrm{PM}$, which is an on-going, dynamic process and relates to multiple activities designed to offer encouragement, guidance, and support and, thereby, shall positively impact an individual's behaviour (Aguinis, 2009; DeNisi, 2011; Ochurub et al., 2012). PM for volunteers is significant not just to increase their performance, but also to offer volunteers support in dealing with the emotional and physical strains of their voluntary work, for example in a hospital setting (Wilson, 2012). PM also helps to give volunteers a clear work structure and communicate expectations and role descriptions which can increase volunteer satisfaction and retention (e.g. Kreutzer \& Jäger, 2011; Souza \& Dhami, 2008). Several scholars have corroborated that PM can significantly contribute to a volunteer's intention to stay with an NPO (e.g. Hager \& Brudney, 2004; Machin \& Paine, 2008). Therefore, it is an essential 
management practice which can help NPOs to effectively manage, motivate and retain their valuable human resources.

Most PM literature to date focuses on for-profit companies and, hence, there is a dearth of research dealing with PM systems in the non-profit sector (e.g. Bartram et al., 2014; O'Boyle \& Hassan, 2015). However, some non-profit literature exists which looks at certain individual PM practices. Therefore, the subsequent sections are primarily based on research of PM in the for-profit sector and only include non-profit literature when talking about individual practices.

\subsubsection{Definition "Performance Management"}

PM has no precise definition within the literature (O'Boyle \& Hassan, 2015). According to Nankervis and Stanton (2010), a distinction can be made between three PM definitions. Some definitions incorporate all organisational performance indicators, others include only performance outcomes on an individual level, and still others understand PM as an umbrella term which comprises, among others, job design, training and development opportunities and rewards. Consequently, the definitions used often depend on factors such as the aim and theoretical framework of a study (Nankervis \& Stanton, 2010).

According to DeNisi and Smith (2014), PM's goal is to develop practices which will assist un/paid staff in meeting their personal objectives, but which will also improve the organisation's effectiveness. Managers fulfil this mission by implementing PM practices which focus on managing and raising the performance at an individual, team and organisational level, so that employees and volunteers are rewarded and the organisation raises its performance (Aguinis, 2009; DeNisi, 2000; DeNisi \& Smith, 2014). Armstrong (2006, p.9) specifies PM as

"a continuous and much wider, more comprehensive and more natural process of management that clarifies mutual expectations, emphasizes the support role of managers who are expected to act as coaches rather than judges and focuses on the future".

Moreover, within PM literature, an effective PM system includes several practices that align the organisational processes and employee, team and department objectives 
with the NPO's strategic goals (Aguinis, 2009). This system then has to be supported by a performance enhancing organisational culture, effective leadership and continuous feedback and learning (O'Boyle \& Hassan, 2015).

For this thesis, a comprehensive definition of PM is adopted. Thus, PM will initially be understood as comprising various activities in an organisation that aim at improving the individual and team/group performance with the ultimate goal of increasing the organisation's effectiveness (DeNisi, 2000). Hence, the primary purpose of PM is to facilitate the effective collaboration of the organisation and its subsystems (employees, departments, volunteers etc.), so that the organisational objectives can be achieved (Castka, Bamber, \& Sharp, 2003).

\subsubsection{The Performance Management Process}

Several PM process models have been developed by scholars, and include different stages, levels of specificity and complexity (e.g. Aguinis, 2009; Pulakos, 2009). Even so, most models share certain key managerial behaviours which are needed in an effective PM system. In their study, Kinicki, Jacobson, Peterson, and Prussia (2013) aimed at developing a measure of PM behaviour by using multisource data from inductive as well as deductive approaches and thereby also integrated several existing PM process models to show the core behaviours of an effective PM system. This model is used in this thesis as it reflects and summarizes traditional PM process models which were introduced by several scholars. Figure 2 depicts the integrated PM process, as proposed by Kinicki et al. (2013). 


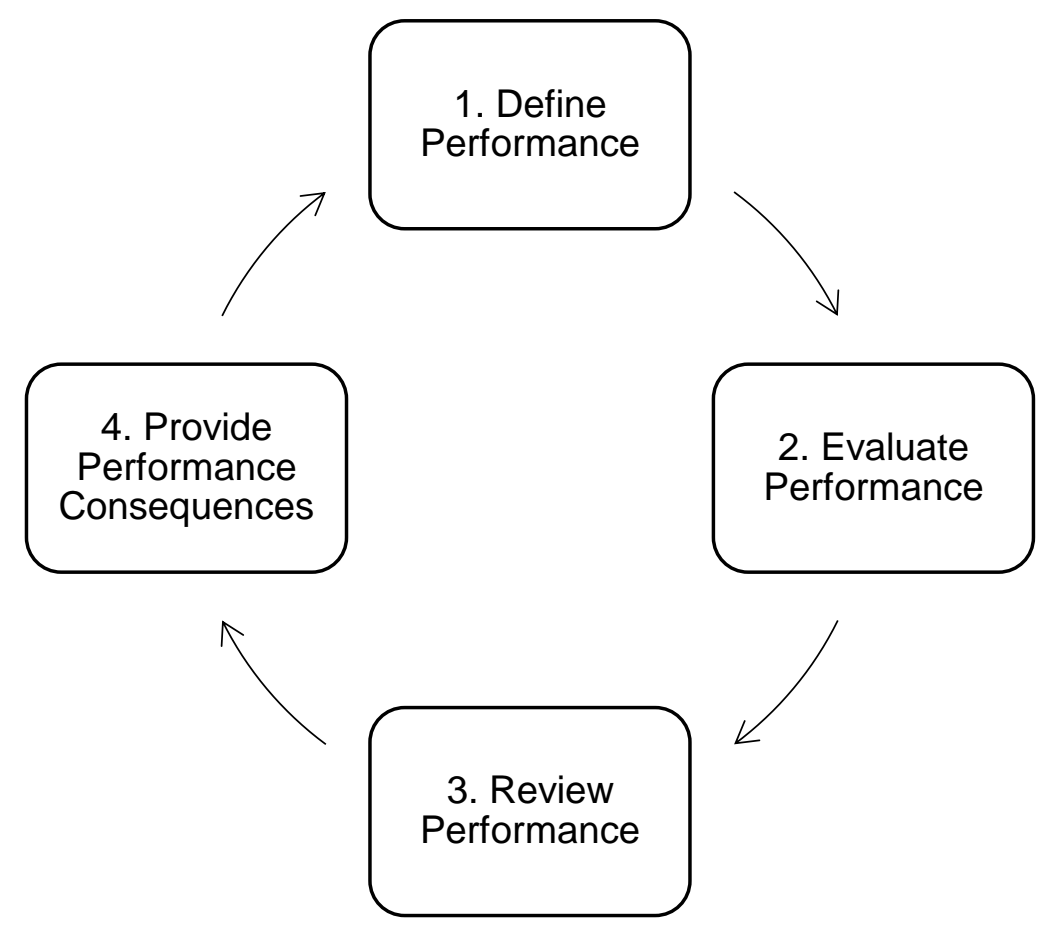

Figure 2: Integrated PM Process (adapted from Kinicki et al., 2013)

The stages outlined in figure 2 are umbrella terms for the underlying behaviours. The first step, defining or "planning" performance, includes practices such as goal-setting processes and communicating the employee's and organisation's performance expectations and objectives (Gruman \& Saks, 2011; Kinicki et al., 2013). This is a key stage in the PM process, because un/paid staff need to know what they are working towards and how the organisation's objectives can be achieved. Effective communication is the most important ingredient for this stage (Kinicki et al., 2013). Furthermore, set goals need to be aligned to the organisation's strategic goals and vision to have a positive influence on individual and organisational performance (Pulakos, 2004). Joint goal-setting, where employees are involved in the goal-setting process or even set the goals themselves, are becoming increasingly popular, as research has shown that employee commitment to set goals and being able to attain the set goals is significant for goal achievement (Kinicki et al., 2013; Pulakos, 2004).

The second step is about evaluating individual performance and comprises activities which serve the purpose of monitoring, facilitating and assessing performance, e.g. overseeing if goals are achieved and finding out about the employee's strengths and weaknesses (Bititci, Cocca, \& Ates, 2016; Kinicki et al., 2013). Additionally, this stage 
involves informal feedback when poor or exceptional performance is observed to encourage continuous performance. Yet, managers often avoid giving feedback, because they are not trained in feedback delivery and therefore do not know how to provide constructive feedback that motivates employees rather than makes them feel uncomfortable and treated unfairly (Pulakos, 2004).

Step three involves reviewing and possibly rating the employee's performance, which is primarily done using performance appraisals (PAs). During this stage, managers provide formal feedback to individual employees, rate them against certain performance criteria and help them to develop for future success (Kinicki et al., 2013). Feedback can take on many forms and is dependent on the perspective, objectives, setting and the person who gives and the person who receives the feedback (Carey, Philippon, \& Cummings, 2011). Although at this stage the ultimate goal is to improve employee performance, PAs often have the opposite effect (section 2.4.3.).

The last stage in the PM process deals with performance consequences and encompasses behaviours which either reward and reinforce employees, offer development and improvement opportunities or, in the worst case, entail negative employment decisions (Kinicki et al., 2013).

Although these four or similar stages are present in most PM systems, the practices and the extent to which each step is executed varies in every organisation. There is no one-size-fits-all PM system, but they rather need be tailored to the organisation's needs, culture, and strategic objectives (Pulakos, 2004). Moreover, PM systems can have several purposes, such as the support on decisions concerning payment, promotions, or employee development. It is important to consider, however, that PM aims of decision-making and employee development, although related, frequently do not support each other well. PM systems which focus on decision-making use PA information to determine pay raises, promotions and other administrative actions which influence the individual's career development. PM systems which are designed for employee development, have a strengthened emphasis on coaching, mentoring, training and other activities which support employees in the development of their capabilities (Pulakos, 2004). 


\subsubsection{Challenges in Performance Management}

PM, although critical for gaining a people-based competitive advantage (Wolfe, Wright, \& Smart, 2006), is highly criticised by scholars, managers and employees alike who claim that PM is ineffective (Bouskila-Yam \& Kluger, 2011), outdated (Buckingham \& Goodall, 2015), costly and time-intensive (The Economist, 2016) and jeopardizes work relationships (Bouskila-Yam \& Kluger, 2011). There are several reasons for this.

First, PM emerged in the late $19^{\text {th }}$ century, when work was mainly physical and worker's performance could be measured by the quantity produced or similar outputs (Risher, 2011; Sillup \& Klimberg, 2010). However, over time employees changed substantially from primarily blue-collar workers to a more knowledge-based labour force which needs different skills and competencies, such as the abilities to work in teams, create value for stakeholders or solve problems (Gruman \& Saks, 2011). Due to the different work demands and skill requirements for knowledge workers, it is increasingly difficult for managers to accurately evaluate the employees' performances (Risher, 2011).

Second, most of the criticism above is directed at PAs which are only one of many practices that can make up a PM system. PAs and PM are frequently confused which is understandable considering that these notions tend to be used interchangeably (McHargue, 2003). Both terms are widely used in the HRM literature, but to date more research has dealt with PAs and performance measurements rather than management (DeNisi \& Smith, 2014; Kinicki et al., 2013). Table 3 summarizes the differences between PM and PAs. PAs is a formal, (bi-)annual event which involves the evaluation of employees' or volunteers' performance against certain performance criteria and the subsequent rating of their job performance (DeNisi \& Smith, 2014; Kinicki et al., 2013). PA's aim is to provide data which will help managers and HR professionals to improve employee performance and can therefore be used as part of the PM system. 


\begin{tabular}{|c|c|c|}
\hline Characteristic & Performance Management & Performance Appraisals \\
\hline Form: & Set of activities & $\begin{array}{l}\text { Evaluation of performance } \\
\text { against certain criteria + rating }\end{array}$ \\
\hline Frequency: & On-going & Annual or biannual \\
\hline Goal: & $\begin{array}{l}\text { Motivate employees with the } \\
\text { goal of raising employees' } \\
\text { performance and subsequent } \\
\text { organisational performance }\end{array}$ & $\begin{array}{l}\text { Provide information on } \\
\text { employees' performance to } \\
\text { manage employees in a } \\
\text { performance enhancing way }\end{array}$ \\
\hline Scope: & $\begin{array}{c}\text { All activities which enhance } \\
\text { employee motivation }\end{array}$ & Can be one of the PM practices \\
\hline
\end{tabular}

Table 3: Comparison of PM and PA

(based on DeNisi \& Smith, 2014)

However, PAs and ratings often backfire due to reasons such as rater errors, managers distorting poor results, or managers focusing solely on the administrative purpose of PAs by gathering data on employee performance to be able to make critical decisions, such as the dismissal or the allocation of promotions (DeNisi \& Smith, 2014; Risher, 2011). Additionally, practitioners are frequently not trained in providing performance feedback, which makes it harder for them to deliver constructive feedback and leads to distortions of performance ratings (Pulakos, 2004) and employees feeling treated unfairly (Spence \& Keeping, 2011; The Economist, 2016). Furthermore, PAs are conducted once or twice a year and therefore look at employees' past performances instead of current issues and developments. Hence, PAs tend to be incoherent with employees' daily work and do not take into account the activities that actually drive performance, e.g. continuous communication about expectations, ongoing, real-time feedback and development opportunities, although research has shown that on-going, constructive feedback is more valuable and empowering for employees, as it is forward-looking and employees can immediately react on it (Pulakos, 2004; Pulakos, Hanson, Arad, \& Moye, 2015).

To summarize, in contemporary work environments, performance is increasingly difficult to measure which further contributes to PA issues such as distorted ratings and employees feeling treated unfairly. Hence, organisations are pressured to adapt their PM systems to reflect the roles of their employees and the fast-changing and dynamic business environment. 


\subsubsection{Performance Management Developments}

Due to the PM challenges (section 2.4.3), some researchers suggested to eliminate PM (Pulakos et al., 2015; The Economist, 2016), while others take the stand that PM should be kept, but revamped entirely to adopt a more motivating and developmentenhancing focus (Risher, 2011; The Economist, 2016). Several organisations which agree with the second view started to focus on employee motivation and commitment, rather than measuring, evaluating and ranking performance (e.g. Buckingham \& Goodall, 2015). Pulakos et al. (2015) argue that it is possible to abolish PAs and ratings, when compensations are not allocated based on these ratings. Ratings are also important for documentation, fairness and defensibility and, thus, should only be abandoned if other possibilities of recording data are found which can stand up to legal ramifications (Pulakos, 2004).

Although there is not one ideal PM system which fits all organisations and although ratings can also be effective, if executed properly, PM processes with the purpose of employee development are starting to outnumber PM systems aimed solely at decision-making (Pulakos, 2004; Pulakos et al., 2015). Reasons for this development are that engaged and motivated employees perform better and simultaneously the need for PAs is reduced (Mone \& London, 2009). Employee motivation and engagement is regarded as source of competitive advantage, because of its positive influence on individual performance and retention and the reduction of absenteeism (Walk, 2012). PM processes which focus on raising employee engagement might even achieve greater performance improvements than PM processes which only look at performance itself (Gruman \& Saks, 2011). They argue that in today's work environment, where performance is increasingly difficult to measure, managers should draw their attention to facilitating rather than evaluating performance which can be done by creating performance-driving conditions. Therefore, contemporary PM systems must take contextual factors into account which can facilitate or impair employee motivation. The Corporate Leadership Council (2004) conducted some research on PM practices and found that employees' performance and engagement was significantly higher when the PM system included certain key activities, such as constructive, continuous feedback, development opportunities and support, and the communication of clear expectations. Figure 3 was created by the author to summarize the development of PM. 
Traditional PM Process

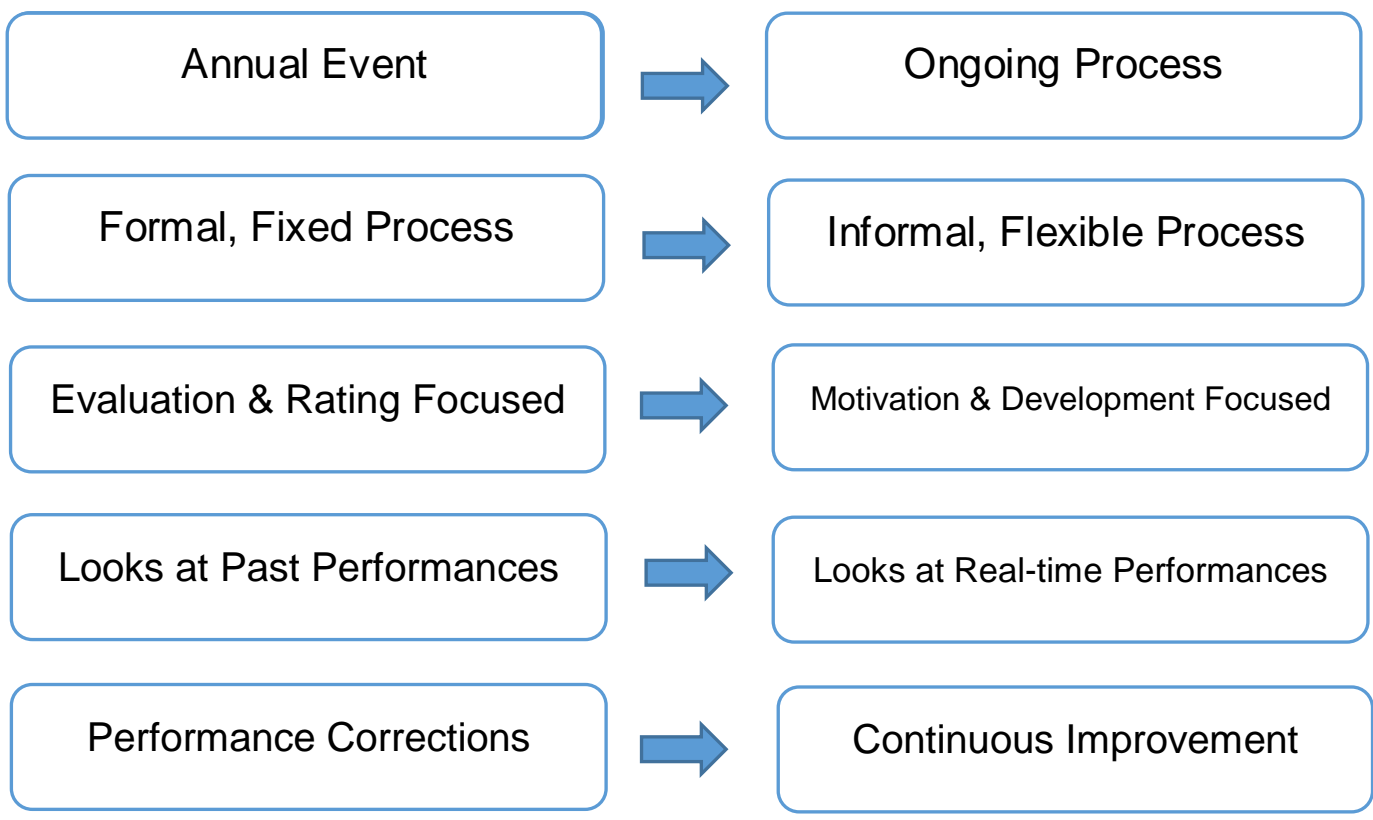

New PM Process

\section{New PM Process}

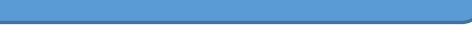

\section{Ongoing Process} $\int$

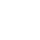


needed which takes key changes, namely the move towards more motivational tools and the abolishment of PAs and ratings, into account. The updated PM process and practices cycle will be used as a basis for the case study. The model (figure 4) is made up of four stages, namely planning, monitoring, developing and rewarding, which are similar to the original PM process model, however, they concentrate more on motivational aspects and on positively influencing people, as can already be seen in the labelling of the four phases. Furthermore, the practices which belong to each phase are depicted as well. Figure 4 illustrates the updated PM process and practices cycle, as proposed by the author of this thesis.

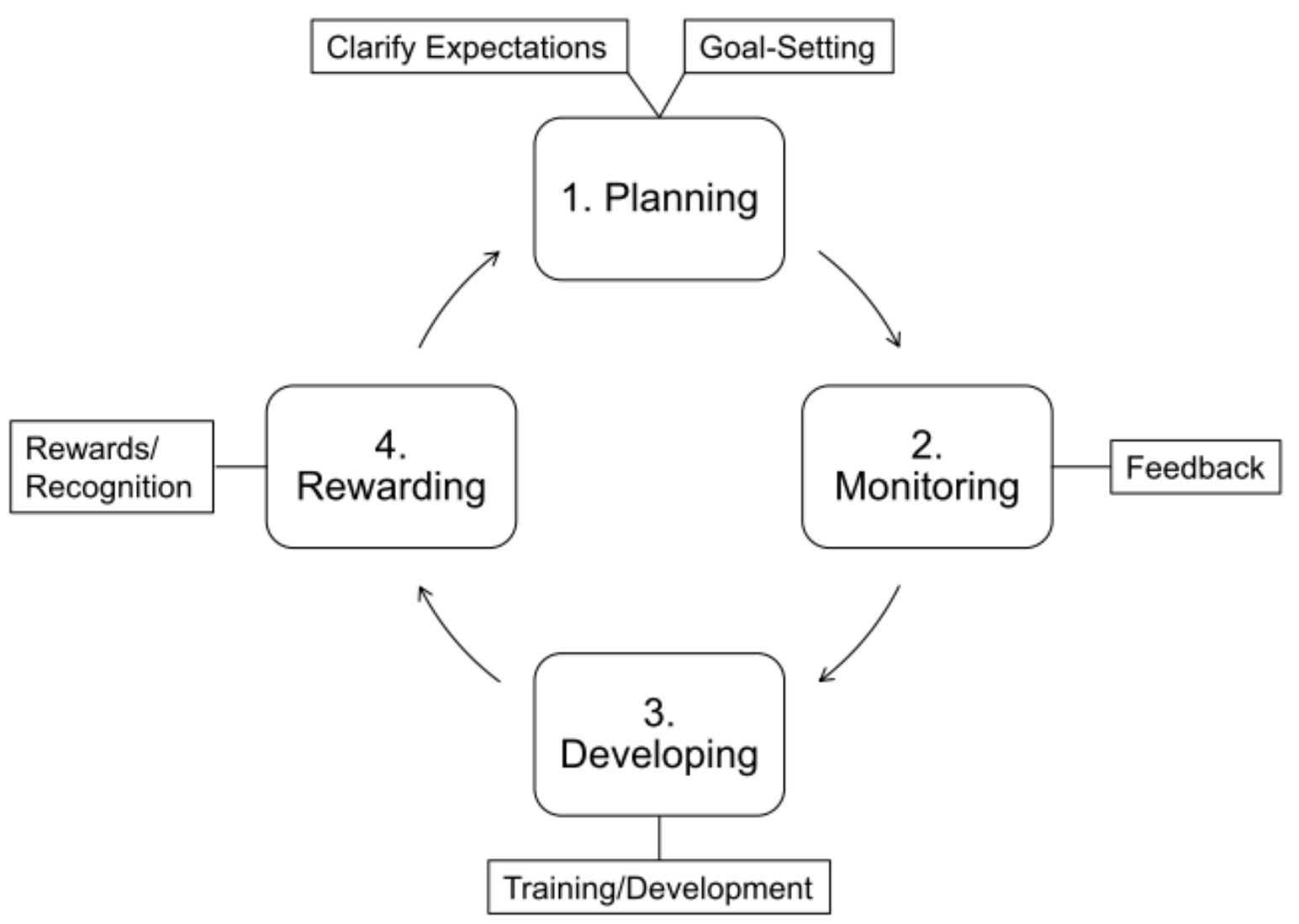

Figure 4: The Updated PM Process and Practices Model (developed by the author based on the literature)

The first stage, planning, equals the "defining phase" of Kinicki et al. (2013)'s model and involves the PM practices goal-setting and communicating the organisational objectives. To the author's knowledge, currently no non-profit literature about goalsetting for volunteers exists. 
The second phase, monitoring, is also similar to the original PM process model, however an emphasis is put on continuous and real-time feedback and facilitating performance rather than evaluating it. Research has shown that on-going, informal, real-time feedback is highly significant for employees and positively influences their immediate performance, job attitude and also future performances (Pulakos, 2004). Feedback has also been studied by non-profit literature and found that volunteers appreciate constructive, regular feedback and communication with their supervisors and that it increases the volunteers' performance (e.g. Cnaan \& Cascio, 1998; Dhebar \& Stokes, 2008; Leonard et al., 2004). Hager and Brudney (2004) conducted a survey in the American NPO sector and noted that most organisations regularly supervise their volunteers. Moreover, Brewis et al. (2010) surveyed 1,004 volunteer managers in England and discovered that $60 \%$ of them offer one-on-one supervision to volunteers.

The third step, developing, differs fundamentally from most previous PM process cycles. Whereas originally it involved PAs and ratings, recent PM developments show a higher concentration on developing and coaching employees (Pulakos, 2004; Risher, 2011). During this stage, managers still provide feedback to their subordinates, however in an informal way and with more focus on the employee's strengths and development possibilities. Managers do not have to rate employees anymore which also takes the fear out of feedback-giving or -receiving. Nevertheless, managers still have to get trained on constructive feedback-giving. Pulakos and O'Leary (2011, p. 156) state that the key for managers to successful feedback is

"learning how to (a) build trust through creating supportive and open relationships, (b) engage in continuous informal performance conversations, (c) diagnose and productively address performance issues and (d) deliver and react to feedback conversations constructively."

Non-profit researchers have extensively studied training/development for volunteers. Most argue in favour and outline that training volunteers is highly beneficial to organisations, as it leads to better performance and motivation and achieves higher retention rates (e.g. Bussell \& Forbes, 2006; Hager \& Brudney, 2011; Waikayi, Fearon, Morris, \& McLaughlin, 2012). Taylor and McGraw (2006) even found that some organisations arrange more trainings for volunteers than employees. Brewis et al. (2010) discovered that about $50 \%$ of NPOs in England have a training/development 
plan for their volunteers in place and that most training is informal. The main obstacles for offering training opportunities are a dearth of funding, a low uptake by volunteers, the perception that volunteers are not interested in participating in trainings and the unavailability of suitable trainings. Moreover, some researchers, such as Hughes (2006), claim that training might put volunteers with certain skills off and Hartenian (2007) noted that volunteers might find training an unnecessary waste of valuable resources. Relating thereto, Newton, Becker, and Bell (2014) investigated volunteers' motives and their correlation with trainings and learnt that the volunteers' motivations have a large influence on their commitment to learning and development.

The final phase, rewarding, is again similar to Kinicki et al. (2013)'s model, but with a more positive label, which also reflects the aim of this stage, namely rewarding and recognizing positive attitudes and performance. This does not mean that there cannot be any negative consequences on poor performance as well, but human resources are scarce and managers increasingly try to find ways how poor performers can improve by coaching, developing and rewarding them and giving them job tasks which motivate them and where these employees can thrive (Mone \& London, 2009; Risher, 2011).

\subsection{The Conceptual Framework}

To visualize the key concepts and factors which are investigated in this study and the links between those, a conceptual framework was developed which will be used as a basis for examining the PM practices used for volunteers and employees in the OSD. Figure 5 depicts the conceptual framework of this thesis. 
NPO Context
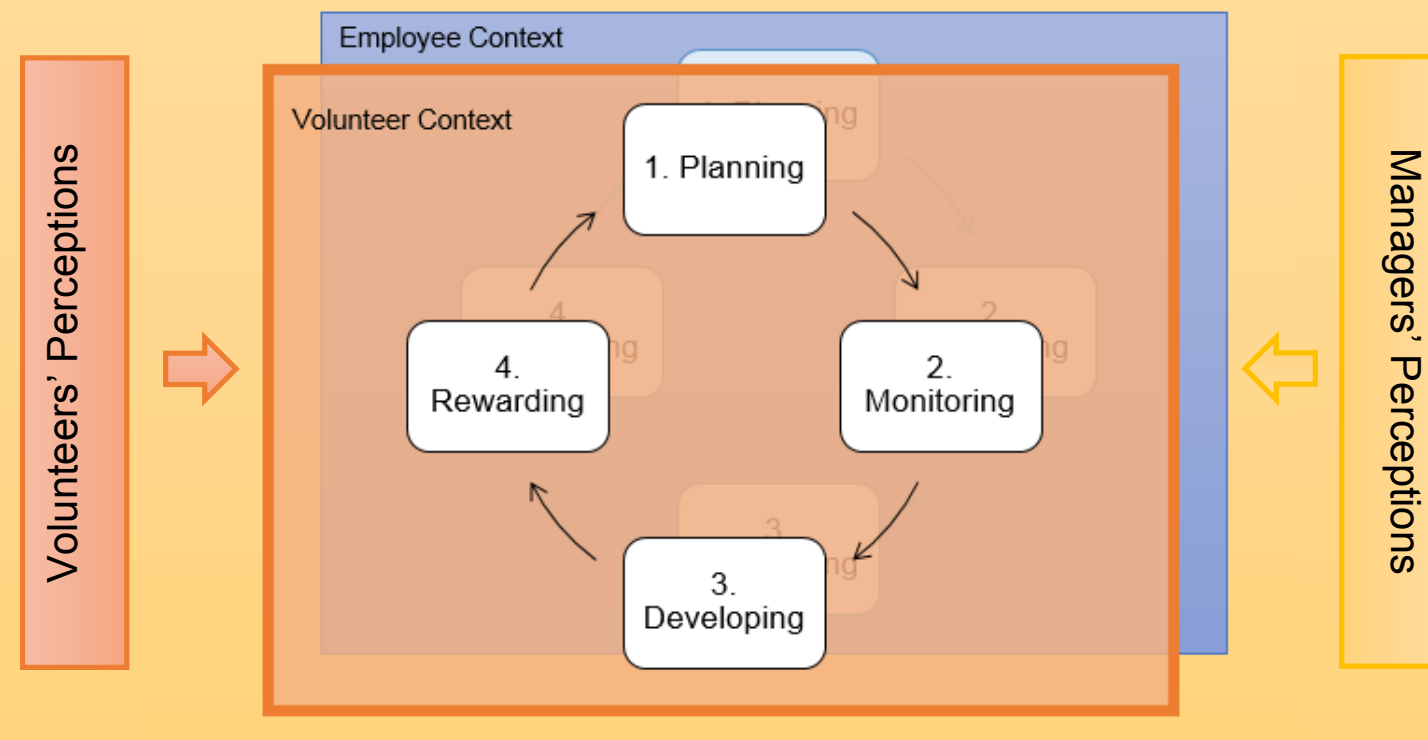

Figure 5: Conceptual Framework

The study takes place in a non-profit context, which is displayed by the yellow background in the framework. In this overall context, especially the volunteer-focused PM practices will be explored (red background), however, this will be contextualized with the PM practices used for employees (blue background). According to current developments in PM in the for-profit sector, the newly proposed PM process and practices model (figure 4) will be used as a basis for the PM practices examined in this study. The volunteers' and managers' perceptions on the PM practices applied by the OSD will be investigated. Whereas volunteers are asked about their ideas, experiences, and opinions about the PM practices (red background), managers are questioned about the PM practices for volunteers as well as employees (yellow background to reflect overall context).

\subsection{Conclusion}

This review has examined the literature concerned with NPOs, volunteers and PM. The background of the non-profit sector and volunteers have been discussed. Moreover, PM has been introduced and current PM challenges and developments have been pointed out. The lack of academic research on volunteer PM and the current PM developments were the decisive stimuli for this thesis and informed the conceptual framework (figure 5). The subsequent chapter will outline the methodology used to explore the research question. 


\section{Methodology}

\subsection{Introduction}

This chapter discusses the research design and methods used in this study. It is organised into seven sections, starting with this introduction, followed by an outline of the paradigm underlying this thesis. The ensuing section describes the methods used and the rationale for choosing a case study approach and employing interviews and document reviews as data collection methods. Then, the interview process is outlined and the participants are briefly introduced. Subsequently, the data analysis strategy as well as the measures enhancing the rigour are explained. Following this, the ethical considerations of this study are highlighted. This chapter concludes with presenting some of the researcher's reflections and discussing the strengths and limitations of the research.

\subsection{Methodological Orientation}

The researcher takes on an interpretive paradigm which emphasizes experiences and interpretations (Henning, Van Rensburg, \& Smit, 2004). The interpretivist paradigm adopts a relativist ontology which suggests that several realities exist due to reality being socially constructed (Hudson \& Ozanne, 1988; Jennings, 2001). The primary goal of interpretivist researchers is to examine and comprehend the constructed world as it is understood by a certain person or group (Cavana, Delahaye, \& Sekaran, 2001). This paradigm requires a research approach that allows participants to describe their subjective, time- and context-bound feelings, understandings and experiences about a topic (Hudson \& Ozanne, 1988). The researcher's assumption that people construct their own reality and the research question and objectives suggest that an interpretivist orientation, which seeks to understand the human behaviour, is well suited for this research topic. It is assumed that the meaning of PM is constructed by managers and volunteers based on their interactions, subjective feelings, understandings and experiences.

The epistemology is subjectivist and signifies that individuals construct their own meanings through interactions between people and therefore every individual derives meaning differently (Gray, 2013; Jennings, 2001). For the credibility of the research, it 
should be acknowledged that scholars with a social constructionist orientation understand that researchers construct their own interpretations (O'Leary, 2014).

The researcher acknowledges that the context of PM differs in each of the Otago Southland Division's locations and with every volunteer and manager who is involved in these practices. Furthermore, PM and what it involves could be interpreted differently by the interviewees. The researcher is aware that the data derived from the interviews is based on the participants', but also the researcher's, subjective opinions and experiences. Additionally, the researcher's background might have influenced the collection and interpretation of the data. An example is that she was raised in a nonEnglish speaking environment which will have influenced the interview process due to a language barrier, and assumed difference of interpretation of responses. Several strategies were employed to ensure that this influence did not overwhelm the participants' voices or constructions of their experiences (section 3.4.2.).

Figure 6 was developed by the researcher to provide an overview of the research approach taken in this thesis. 


\section{Paradigm: Interpretivism}

\section{Ontological \\ Orientation}

\section{- Relativist}

- aims to examine and understand volunteers' and managers' perceptions about performance management practices

\section{Epistemological Orientation}

\section{- Subjectivist}

- aims to construct meaning about performance management practices through the interactions of the participants and the researcher

Theoretical Approach

\section{- Inductive}

- aims to explore how the organisation applies performance management to volunteers and the perceptions of managers and volunteers on these practices

\section{Methodology}

\section{- Qualitative}

- aims to develop a holistic perspective of performance management practices for volunteers by interpreting the perceptions of managers and volunteers

Research Method

\section{- Case Study}

- Single case study of a New Zealand based, human service non-profit organisation

\section{Data Collection Method}

\section{- Semi-structured Interviews \& Reviewing Documents}

- aims to collect in-depth data about the perceptions of managers and volunteers in relation to performance management practices at their organisation

\section{Data Analysis Method}

\section{-Thematic Analysis}

- aims to systematically analyse the data by transcribing, summarising and coding the interviews and then identifying emerging themes from this data

Figure 6: Overview of the Methodological Approaches 


\subsection{Research Design}

For this Master thesis, exploratory research was conducted which is based on an inductive reasoning. Qualitative research seeks to collect data in its natural form and, thereby, to receive in-depth insights into the sense-making of people's experiences (Ogden \& Cornwell, 2010). In qualitative research only a small sample size is used which allows the researcher to ask follow-up questions and, thus, get a more thorough understanding of people's thinking (Gill, Stewart, Treasure, \& Chadwick, 2008). However, there are also limitations of qualitative methods, which include lack of objectivity, subjective interpretation of the data, and limited generalizability (Bryman, 2003; Ogden \& Cornwell, 2010).

\subsubsection{A Case Study Approach}

In recent years, the interest in case studies as a research tool for management research has gained popularity (Lee, Collier, \& Cullen, 2007; Platt, 2007). Yin (2009, p.2) outlines that "in general, case studies are the preferred strategy when (a) "how" or "why" questions are being posed, (b) the investigator has little control over events, and (c) the focus is on a contemporary phenomenon within a real-life context".

As all three criteria match the proposed research, a case study method was deemed appropriate. Moreover, since the purpose of this study is to examine the concept of volunteer PM in the non-profit sector, a case study is useful to gain a better understanding of the unique context within which PM is executed. Understanding the context is important due to the disparities of non-profit and for-profit organisations and volunteers and employees. Another reason for choosing a case study approach is to obtain a holistic picture of the PM practices used in the organisation and the perceptions about these practices by gathering multiple opinions and experiences from managers and volunteers involved in PM at the organisation.

A single case study was conducted which allows the researcher to immerse herself in the organisation and provides a more thorough understanding of the way PM is used for volunteers, the perceptions of the participants and the organisational context in which PM occurs. Although the study is not representative for the non-profit sector and cannot be viewed as definitive, it provides an in-depth analysis of the PM practices 
used in this organisation and the opinions of the participants and, therefore, is beneficial to NPOs and PM and VM scholars.

\subsubsection{Data Collection Methods}

Interviews were chosen as a research method, because they let interviewees tell stories which allows the researcher to generate contextual and historical information which elicits richer data (Hollway \& Jefferson, 1997). As the researcher wanted participants to reflect on their experiences and perceptions of PM in the organisation, the interview guide needed to be partly structured, but also leave enough room for follow-up questions. Hence, a semi-structured interview guide provided a starting point from which the interviewees elaborated on their responses. Open-ended questions were mainly used, as "open-ended research produces nonstandardized information that allows researchers to make full use of differences among people" (Reinharz \& Davidman, 1992, pp.18-19).

Moreover, it was decided that face-to-face interviews were suited best for this study, so that the researcher can establish a relationship and build up trust with the participant, which leads to better insights into the experiences and feelings of the interviewee. It also allowed the researcher to gather more data in form of observations of the participant's body language and the physical settings. As Shuy (2001, p.548) highlights, being physically present during the interview allows the researcher to receive "communicative clues to the respondent's confusion, reluctance to answer, or discomfort" and to react on them. Furthermore, documents, such as the annual reports and volunteer role descriptions, provided by the CS were used to gather background information on the case study, but were not incorporated in the main analysis.

\subsubsection{Case Study and Participant Selection}

When choosing the case study organisation, it was important to find an appropriate organisation which could provide the needed data to answer the research question. Hence, the following criteria were chosen by which it was decided if an organisation was suitable for this study or not:

1. The organisation is an NPO.

2. The organisation operates in the field of human services. 
3. The organisation is located in New Zealand.

4. The organisation employs volunteers as well as employees.

5. The organisation uses PM practices for their volunteers.

The search focused on large organisations which operate on a national level, as it was assumed that these organisations are most likely to employ volunteers and employees and to adopt PM practices for their volunteers. Moreover, organisations in the field of human services, which is broadly defined as organisations working towards enhancing, maintaining and protecting human well-being (National Organization for Human Services, 2016), were chosen, because they are most likely to use PM (Hager \& Brudney, 2004). It was acknowledged that by studying a large organisation not all aspects can be examined in detail, however, the intention was not to be representative, but to gather rich data.

The selection of the organisation was mainly influenced by the criteria stated above and by the organisation's willingness to participate. The first organisation approached declined participation due to a restructuring of their VM. The second organisation was the CS who at a national level agreed to take part, if one of their divisions was interested in participating. Three divisions showed interest, one of those three was considered inappropriate, because they had no volunteer manager at that time. From the other two divisions, the OSD was selected, because they fulfilled all the selection requirements and had been the first to raise their hand to participate.

The sample for this study comprised 19 interviews, split between the $\mathrm{CEO}^{2}$ and the capacity \& development manager on a national level and the CEO, volunteer managers, employees, and volunteers on a divisional level. While the interview participants from the national office discussed their understanding of volunteer PM and their knowledge of the PM of other divisions, the interviewees of the OSD offered a more in-depth view of the PM practices for volunteers used and their perceptions about those. The researcher interviewed the volunteer manager, an employee and three volunteers in each of the OSD's offices in Dunedin, Invercargill, and Queenstown. All employees came from different departments within the organisation and varied in how closely they worked with volunteers. The volunteers were heterogenous in terms of

\footnotetext{
${ }^{2}$ The national CEO has now left the CS, but is still referred to as CEO in this thesis
} 
demographics and volunteer roles, but similar in that all of them worked regularly for the OSD, rather than on an ad-hoc or episodic basis. The service time of the volunteers interviewed ranged from about one year to 20 years.

Volunteers and managers were interviewed to gather data about their perceptions, ideas, and suggestions about the PM practices in the organisation, whereas the CEOs were consulted to get a better understanding of the CS's policies, culture, and values. There was neither a dedicated HR professional in the OSD nor in the national office and no specific employee was responsible for HR or PM matters. Therefore, the CEOs and the managers were interviewed about PM for employees.

It should be acknowledged that no gender balance among the interviewees was achieved, as the majority of employees and volunteers at the OSD are women, which reflects the situation in the NPO sector in general (e.g. Baines, Charlesworth, \& Cunningham, 2014). Whereas the researcher determined the number and positions of people who would be interesting to talk to, the volunteer manager nominated the volunteer and employee sample based on the criteria of their involvement in PM, their positions, and demographics and directly asked the participants to participate. Table 4 depicts the interview participants and their positions. 
Interview Participants:

\begin{tabular}{l} 
National Level: \\
\hline National Chief Executive (CEO) \\
\hline Capacity \& Development Manager \\
\hline Support Officer
\end{tabular}

\section{Divisional Level:}

Divisional Chief Executive (CEO)

Volunteer Manager 1

Volunteer Manager 2

Volunteer Manager 3

Daffodil Day Coordinator

Supportive Care Manager

Health \& Promotion Manager

\begin{tabular}{|l|l|}
\hline Volunteers: & Position: \\
\hline Alice & CanShop \\
\hline Janice & Administrational Tasks \\
\hline Lilly & Events Volunteering \\
\hline Lorraine & Administrational Tasks \\
\hline Sam & Administrational Tasks \\
\hline Marie & CanShop and Supportive Care \\
\hline Monica & CanShop and Supportive Care \\
\hline Phoebe & Events Volunteering and Supportive Care \\
\hline Sandra & Administrational Tasks and Events Volunteering \\
\hline
\end{tabular}

Table 4: Interview Participants

\subsubsection{Interview Process}

The interviews were conducted in the order of Wellington, Dunedin, Invercargill, and Queenstown. Initially it was expected that the individual interviews would take up to one hour, however they ranged in length from 23 minutes to 86 minutes. The volunteer interviews were often shorter, as the volunteers did not experience much PM in their volunteer roles, whereas the interviews with managers sometimes exceeded one hour. All interviews took place at the OSD's premises, either in a meeting room or in the personal offices of the interviewees. 
The interview schedule was designed based on PM and volunteer literature. Three interview schedules (Appendix $\mathrm{C}$ ) were written, one for the CEOs, one for managers, and one for volunteers. All interviews started with an easy-to-answer opening question, which should allow participants to become more comfortable with the researcher and with the interview process. In the course of the interview, the questions became more focused and more PM related. Table 5 displays the main interview questions relating to PM and their distribution between the schedules. The aim of these schedules was to create a logical flow and to maintain a consistency between the interviews, which would allow the researcher to compare key aspects of PM and the perceptions of the interviewees. Moreover, some prompts were prepared for each question to assist during the interview and remind of the data that needed to be collected.

The interview schedule for the CEOs and managers comprised questions about the VM of the organisation, the PM practices and policies used, their perceptions about these practices and their improvement suggestions. Moreover, questions about PM for volunteers in relation to PM for employees were included. The volunteer interview schedule was designed to ask about the volunteer's experience with the OSD concerning PM. In all interview schedules, first participants were asked about their ideas of what PM entails and then especially four PM practices were asked for based on the updated PM process and practices model (figure 4). Issues and ideas raised during the interviews were used to inform subsequent meetings. By refining some of the questions, the researcher could react to the unique context of the OSD and simultaneously elicit some underlying issues. 


\begin{tabular}{|c|c|c|c|}
\hline Questions: & CEO: & $\begin{array}{l}\text { Volunteer } \\
\text { Coordinators/ } \\
\text { Staff Member }\end{array}$ & Volunteers \\
\hline Understanding of PM & & & $\checkmark$ \\
\hline $\begin{array}{l}\text { Purposes of PM practices in } \\
\text { organisation }\end{array}$ & $\checkmark$ & $\checkmark$ & \\
\hline $\begin{array}{l}\text { Type of PM policies and practices } \\
\text { in organisation }\end{array}$ & $\checkmark$ & $\checkmark$ & \\
\hline $\begin{array}{l}\text { Obligations under the Treaty of } \\
\text { Waitangi influence PM practices }\end{array}$ & $\checkmark$ & $\checkmark$ & \\
\hline Objectives \& Goal Setting & $\sqrt{ }$ & $\sqrt{ }$ & $\sqrt{ }$ \\
\hline Feedback \& Training Opportunities & $\checkmark$ & $\checkmark$ & $\checkmark$ \\
\hline Rewards \& Recognition & $\checkmark$ & $\checkmark$ & $\checkmark$ \\
\hline $\begin{array}{l}\text { Benefits and strengths of PM } \\
\text { practices }\end{array}$ & $\checkmark$ & $\sqrt{ }$ & \\
\hline Limitations of PM system & $\checkmark$ & $\checkmark$ & \\
\hline $\begin{array}{l}\text { Handling poorly/highly performing } \\
\text { volunteers }\end{array}$ & $\checkmark$ & $\checkmark$ & \\
\hline $\begin{array}{l}\text { Similarity of PM for volunteers to } \\
\text { PM for employees }\end{array}$ & $\checkmark$ & $\checkmark$ & \\
\hline $\begin{array}{l}\text { Positive \& negative experience with } \\
\text { PM }\end{array}$ & & & $\checkmark$ \\
\hline $\begin{array}{l}\text { Possible opinions of volunteers on } \\
\text { PM }\end{array}$ & $\checkmark$ & $\checkmark$ & \\
\hline Possible improvements to PM & $\checkmark$ & $\checkmark$ & $\checkmark$ \\
\hline $\begin{array}{l}\text { Opinion on what good PM for } \\
\text { volunteers would look like }\end{array}$ & $\checkmark$ & $\checkmark$ & $\checkmark$ \\
\hline
\end{tabular}

Table 5: Distribution of Interview Questions 


\subsection{Data Analysis and Credibility}

All interviews were personally conducted, audio recorded, and transcribed by the researcher. As indicated in the research agreement (Appendix B), the interviewees had the possibility to review their transcript (section 3.4.2). Subsequently, the data analysis was started. Hatch (2002, p.148) emphasized that "data analysis is a systematic search for meaning. It is a way to process qualitative data so that what has been learned can be communicated to others".

\subsubsection{Thematic Analysis}

The data analysis method chosen for this study was "thematic analysis". Thematic analysis is well suited for research which seeks to understand and examine the way people conceptualise a certain phenomenon (Joffe, 2012). Braun and Clarke (2006, p.79) describe thematic analysis as "a method for identifying, analysing and reporting patterns (themes) within data".

The first phase included the repeated reading of the transcribed interviews to familiarize with the information and get an overview of the responses (Braun \& Clarke, 2006). Afterwards, the transcripts were reread, notes were taken and the information was coded using NVivo. The codes were derived by analysing the data against a list of factors deduced from the literature (deductive coding) and by identifying new codes from the raw data (inductive coding). The codes extracted from the literature were developed in accordance with the research question and included, e.g. the PM practices goal-setting, feedback, training/development and rewards/recognition. For the inductive coding, the researcher read the interviews first based on respondent group (starting with CEOs and managers, followed by the volunteers), then by location and lastly by themes. Subsequently, patterns were identified and organised into categories. Finally, broader themes were determined and refined. When starting to write-up the findings, some of the themes changed again and new themes were developed. The final themes are depicted in the thematic map (figure 7).

The thematic map depicts three main themes which are grouped as PM, inconsistencies, and unprofessionalism. The first theme, PM, is concerned with the existing PM system in the OSD and the perceptions of managers and volunteers about 
PM, motivation, and PM practices. The respective findings are presented in chapter 4 and primarily aim at answering the "how" and "what" of PM in the OSD. The other two themes, inconsistencies and unprofessionalism, are discussed in chapter 5 and explore the background of the OSD and reasons for the managers' and volunteers' behaviour and perceptions and, therefore, the "why" of PM in the OSD.

The structure of the findings (chapter $4 \& 5$ ) is based on integrating the information from managers and volunteers from the start. This way, the opinions, perceptions, and experiences of the participants within their role and also across the various roles can be compared and contrasted. For confidentiality reasons, there was some selectivity involved when choosing quotes for the findings and discussion sections. In some cases, quotes were not selected because it would clearly identify the interviewee or person discussed. In other instances, parts of quotes were deliberately taken out to prevent the identification of a person. Reasons to choose a quote were the topic and the level of expertise on it. Moreover, quotes were selected that best convey the meaning of the paragraph which often came from managers working closely with volunteers. 


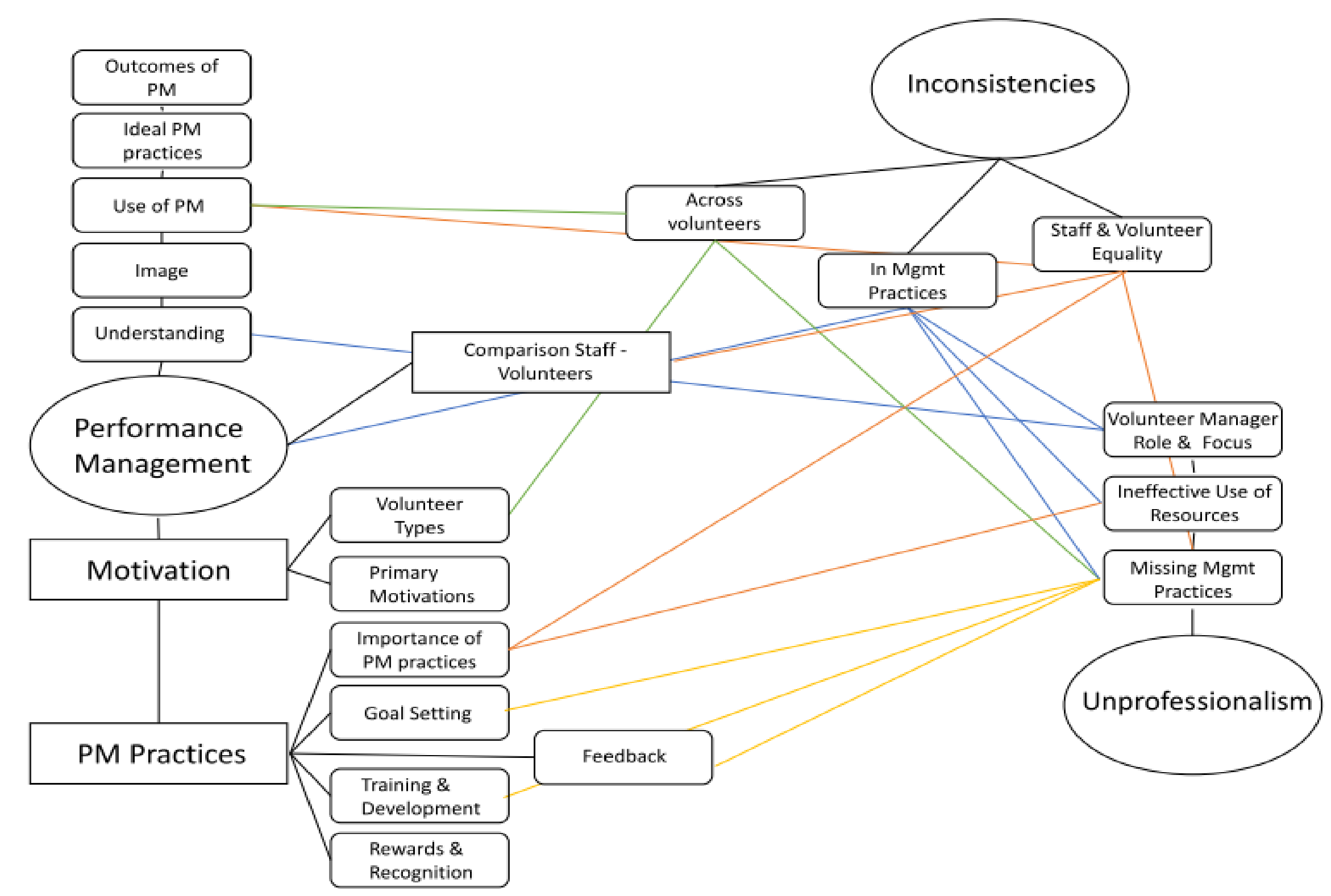

Chapter 4

Figure 7: Thematic Map

Chapter 5 


\subsubsection{Rigour of the Data}

Researchers increasingly acknowledge that qualitative research cannot be judged in the same manner as quantitative research (Carter \& Porter, 2000), which is why different criteria are used. Most commonly applied are the four factors suggested by Lincoln and Guba (1985): dependability, confirmability, credibility and transferability.

Dependability refers to the stability of the data and is closely related to confirmability (Shah \& Corley, 2006). Confirmability involves collecting and using accurate and neutral data (Houghton, Casey, \& Murphy, 2012). Credibility is associated with the believability of the study outcomes and comprises two phases, namely the credible conduct of the research and the demonstration of believability (Lincoln \& Guba, 1985). Finally, transferability is concerned with the degree of applicability of the findings to a similar context, population, or group, while maintaining their meaning and inferences (Houghton et al., 2012).

According to Creswell (2013), any research should adopt a minimum of two rigour criteria. This study has attempted to achieve all criteria. It was strived to meet the criteria of credibility by interviewing enough people to achieve saturation and no new concepts emerged from the interviews. A process of data triangulation was added by interviewing individuals from different positions, such as the CEOs, managers and volunteers. Moreover, if requested by participants in the research agreement (Appendix B), they were invited to review their interview transcription to ensure the accuracy of their opinions, thoughts, and suggestions. Interviewees were then given the option to confer with the researcher about any questions or issues which arose regarding the transcript. Eight of 19 interview participants made use of this offer, however only two managers changed some of their wording. The others did not report any concerns about the content of the transcript.

The use of NVivo for the data analysis enhanced the rigour of the study, as it allowed for transparency in decision making (Houghton et al., 2012). Furthermore, the researcher's self-awareness is significant for ensuring credibility of the research (Creswell, 2013). Therefore, the researcher kept a reflective diary throughout the research process in which challenges, decisions, ideas, and thoughts were documented. This step served to add confirmability and dependability to the study. 
Concerning transferability, the research methods and findings were described in detail and direct quotations from the interviews were provided in a way that allows the readers to judge on the transferability of the findings.

\begin{tabular}{|l|l|}
\hline Criteria for Rigour & Methods Used \\
\hline Credibility & $\begin{array}{l}\text { Data Saturation } \\
\text { Data Triangulation } \\
\text { Participants were invited to review their transcript }\end{array}$ \\
\hline Dependability & $\begin{array}{l}\text { Audit Trail } \\
\text { Reflexivity }\end{array}$ \\
\hline Confirmability & $\begin{array}{l}\text { Audit Trail } \\
\text { Reflexivity }\end{array}$ \\
\hline Transferability & Thick Descriptions \\
\hline
\end{tabular}

Table 6: Methods used to Enhance Rigour (adapted from Houghton et al., 2012)

\subsection{Ethical Considerations}

Ethical approval was gained from the Victoria University Pipitea Human Ethics Committee (approval number: 23441) before starting the data collection. The research participants were informed of the purpose of the study by receiving an information sheet (Appendix A). Participants were asked to sign a research agreement (Appendix B) prior to the participation in the research, acknowledging their awareness of the purpose, procedures, and confidentiality terms.

The divisional CEO agreed to the OSD being identified in this thesis. Participants were informed about it and accepted it by signing the research agreement. To reduce the likelihood of individual interviewees being identified, self-selected pseudonyms were used for volunteers and self-identified job titles for managers. It was made clear to the CEOs and managers that they might be identifiable through their job titles. The direct quotations used in this thesis were selected carefully and data was aggregated where necessary to ensure confidentiality of individuals.

All possible steps were taken to ensure that no harm came to the participants. No data about individual performance was reported. Moreover, preceding the interviews, the 
interview questions were reviewed and piloted to make sure that the questions are impartial and pertinent for answering the research questions.

\subsection{Reflections}

This section offers some of the contemplations of the researcher which are recorded in the reflective diary (section 3.4.2). Although the research went well and a wealth of data was collected, some reflections about the interviews should be highlighted, as these might have influenced the research.

\section{Reflection 1: Interviewee Behaviour}

Different language was used for managers and volunteers. Whereas a management terminology was applied when talking to the CEOs and managers, a simpler wording was used for volunteers. Yet, there was a reluctance from some volunteers to engage with the concept of PM and to dwell on the interview questions. An example for this reluctance is this excerpt from the interview with Lorraine, an administrational volunteer:

I: What kind of feedback do you receive from staff?

$V$ : They just say "Thank you and you've done a good job. It's been good to have you here".

I: Do they also tell you about things you could improve next time?

V: No.

I: Do you think it would be helpful?

V: Sometimes it would be.

I: Can you give me an example?

V: Ugh...goodness...caught me there...no, not really. Well, I take back that answer: No, it's not really.

These interviews were quite frustrating for the researcher who tried a variety of paraphrases and prompts to tease out some more information from the volunteers. Although, when discussing the individual practices, some of those volunteers seemed interested, they still remained rather quiet and introverted. When listening to the interviews afterwards, the researcher realised that after a while, when the volunteers did not open-up, she unconsciously changed to asking closed questions to ease the interview process for the participants which might have influenced the remaining interview and needed to be considered when analysing it. Examples for closed questions asked can be seen in the excerpt above. 
It is interesting to reflect about the reasons for the volunteers' behaviour. One possible background for the unwillingness to reply to questions could be that the volunteers did not understand the concept, but were reluctant to show their incomprehension. Another reason could be that those volunteers had negative associations with PM and refused to consider the possibility of the OSD using those practices for volunteers. A third option might be that those volunteers, having little or no experience with PM, did not want to seem judgmental towards the OSD and their processes.

\section{Reflection 2: Interviewee PM Cognition}

Another observation made was that participants often had contradictory ideas and perceptions about PM throughout the interview. This especially applied to the volunteers and some of the managers and might be attributed to the fact that they had not engaged much with the concept of PM before and only started the thinking process during the interview. As their thinking developed, ideas or concepts they had rejected before, seemed more appealing.

A further reason could be that those interviewees had negative associations about the concepts and, therefore, disliked the idea of introducing them in the OSD. These negative associations were triggered when using a managerial terminology by the researcher. However, when rewording the questions and ideas, the participants showed interest in the concepts. One example is the word "feedback" which was often perceived negatively, whereas "check-up" seemed to prompt more positive reactions and even sparked some interest in the participants. Although this might involve some deception, it also shows how important the framing of management practices is and how easily people's perceptions can change depending on how it is presented.

\subsection{Strengths and Limitations}

The case study approach allowed for the collection of in-depth data from a variety of stakeholders of the CS's OSD and therefore provided scope for comparison between them. By interviewing participants from several positions and locations, a wealth of data could be gathered. Most of the data relates to the perceptions and experiences of the participants with volunteer PM, but also much information of the background, organisational culture, and other managerial practices at the OSD could be collected. 
Limitations of the research include the single case study approach which limits the transferability of the findings. However, it is argued that the findings from this research are still relevant, valuable, and possibly even applicable to other NPOs (section 6.2).

A second limitation is that the study was restricted to a specific timeframe and, hence, the findings only reflect a snapshot in time. The interviews were conducted in November 2016, which was during a time of change in the OSD. Thus, the findings from this thesis may not represent the present situation in the OSD. Although a longitudinal study of the OSD would have been interesting, it requires a substantial increase in interviews and resources which are beyond the scope of a Master thesis.

Another limitation concerns the choice of volunteers participating in the research. The interviews did not accurately reflect all the volunteers of the OSD, as the volunteer managers themselves selected volunteers they deemed appropriate. When asked what volunteers they had chosen, they replied that they had tried to recruit volunteers from a variety of different volunteer roles who worked for the OSD on a regular basis. The selection of the volunteers influenced the study, as only volunteers who had a good relationship to the organisation may have been chosen. Additionally, the knowledge from managers about who participated might have had an impact on the volunteers and their openness during the interview. Furthermore, no volunteers from areas outside the three main locations (section 3.3.3) nor ad-hoc volunteers had been interviewed.

\subsection{Conclusion}

This chapter discussed the methodology chosen for this thesis. Moreover, the use of an interpretivist paradigm was introduced and the research design was justified. A qualitative approach was taken for this study to gain in-depth insights into the perceptions of managers and volunteers on the PM practices used in the OSD. The interview process and the selection of participants and the case study was outlined. Thereafter, the procedure of the data analysis and rigour of the data was presented and a thematic map (figure 7) was created which depicts the main themes that have emerged in the interviews and which will be discussed in the following chapters. Finally, ethical considerations, reflections of the researcher and strengths and weaknesses of the study were presented. 


\section{Findings}

\subsection{Introduction}

This chapter discusses the findings of the case study and provides first answers to the research question. Referring to the thematic map (figure 7), the main focus of this chapter is the theme PM which gives insight into how and with which practices the OSD manages the performance of its volunteers. The structure of this chapter is based on key emerging themes which arose from the interviews. Within those themes the different perceptions from managers and volunteers are intertwined.

In the following, the participants' perceptions about PM and its image are outlined and first insights into the OSD's PM are presented. Thereafter, the chapter proceeds by discussing the volunteers' motivations, as these can influence the effectiveness of the PM practises. Subsequently, each of the four practices is examined in more detail. Finally, the PM practices used for volunteers and employees are compared.

\subsection{Performance Management in the Otago Southland Division}

In the literature, PM is a management practice with many definitions which is often confused with PAs (section 2.4.3). Similar observations were made in the CS's national office and the OSD. The CEOs had a good understanding of what PM is and entails, but moving down the hierarchical structure of the organisation, fewer managers made distictions between PM and PAs. Among volunteers, only two had a clear idea of PM, as they had experienced it in their paid jobs. Two articulate descriptions of PM came from the divisional CEO and volunteer manager 1 :

"I think one big part is about personal development [...]. And then it's an opportunity to review not just a performance of the staff member, but also the relationship as a whole and how that is facilitating the achievement of strategic goals. [...] I should also say that performance management is...I think, about dealing with... issues that might come up. If there is a major behavioural issue or something like that. It's a system for working through those issues in a way that is fair to staff members and managers."

(Divisional CEO)

Volunteer manager 1 elucidated PM in a similar way, but especially emphasised the importance of PM for the OSD: 
"It [PM] is going to be ensuring that everything is in line with our values, [...] people whether they are being paid staff or volunteers are doing something on behalf of the Cancer Society. So, it's got to be aligned with our values and we have to think about our credibility. Secondly is to ensure that the work is done and thirdly is to make sure that the volunteer experience is meaningful to them."

Some other key words managers and volunteers used to describe the purpose of PM for volunteers were "support", "personal development", "process for poor performers", "ensuring that everything is in line with the organisation's values", "ensuring a meaningful volunteer experience", and "relationships are important in PM". Most of these phrases seem rather positive and reflect their understanding of how important $\mathrm{PM}$ is for ensuring that volunteers as well as the organisation benefit from their relationship. Most managers explained that $P M$ is an important part of every organisation and having an effective PM system for volunteers is crucial, because it creates loyalty, retention, better job performance, commitment, and motivation, as outlined by the national office's capacity and development manager:

"It [PM] contributes to the engagement of the volunteers. If you are able to match people and their resources, they are recognized for their work and have the opportunity to grow and develop, they stay engaged in the job. And with increased engagement, you get a better performance, you reduce your health and safety risks and your sick leave and all those things. So, it's not only that people are happier employees, but that'll also have other positive effects."

Moreover, PM helps to manage relationships with volunteers who do not meet the expectations of the organisation and ideally promotes personal development, which contributes to meaningful volunteer experiences. However, while the concept of PM is perceived as positive and important, the interviewees still had negative connotations towards it. The image of PM is rather admissive with managers' responses ranging from "formal and planned" to "negative", "judgmental" and "scary", as reflected in this extract from the interview with volunteer manager 1: "Performance management sounds really scary; it is a bit like performance appraisals..."

The volunteers also often reacted in a dismissive manner and were unwilling to engage with the concept of PM. In the volunteers' perception, PM was associated with PAs, pressure, negative feedback, and control by managers and therefore not desirable. Volunteer manager 2 explained that most people do not like the term PM, but that the practices itself are beneficial to the organisation and the volunteers: "Performance 
managing, I think, people associate with being told what they are doing wrong, whereas coaching and goal-setting is a positive thing. I think, it's depending on what we call it."

At first neither of the participants believed that the OSD engages in PM for volunteers. The managers justified the supposedly missing PM practices by emphasizing the scarcity of resources and the challenging tasks of managing volunteers with heterogenous motivations and characteristics and of retaining them:

"It's hard when they [volunteers] are a big part of the workforce. They go on holidays, they go overseas for three or four months, so therefore it affects your business, and then they come back and want to be engaged. It's a challenging workforce to work with. And in this sort of environment when it's dealing with people."

(Supportive Care Manager)

Contrarily, the volunteers talked about their positive volunteer experiences and were reluctant to discuss negative experiences or to offer improvement ideas. Only later in the interviews the managers and some of the volunteers identified that most of the practices, namely feedback, training/development and rewards/recognition, were used for volunteers already, albeit in a more informal, ad-hoc and subtle way. An example is volunteer manager 2 :

"It's interesting when I was thinking about it, I didn't really think we did performance management, but I think it's just very subtle and just really comes up, it's not a "we do it every 6 months", it's just if I happen to see something, it's more sort of off the cuff."

It turned out that PM had not been in the managers' and volunteers' minds, because they had not perceived it as a managerial practice, but rather as support for volunteers. Especially the volunteer managers identified that they subconsciously use PM practices to guide their volunteers. Moreover, as a review of documents provided by the OSD shows, the volunteer managers have a thorough induction process for volunteers and have already started volunteer PM by handing out role descriptions and information about the expectations of the OSD to their volunteers. The role descriptions and list of expectations can thereby be seen as "goals" for volunteers, which need to be met. The divisional CEO and volunteer managers outlined their plan for the next years which is to create a framework for employees that makes them feel safe to engage with volunteers and subsequently to involve volunteers in all areas of 
the OSD. This way they hope to offer a more diverse volunteer profile, especially to younger people who seek to gain job experience, and to assist employees in all departments.

When discussing the individual practices, most volunteers opened up and seemed interested in the concepts. However, managers and volunteers stressed that PM for volunteers should be designed as an informal, subtle process, because people do not want to spend their leisure time in an environment similar to their paid work, as emphasised by Marie:

"When I am volunteering, I don't want to feel any pressure on volunteering. We have so much of that in our paid work...sometimes it's just nice to go out and feel like you are helping someone and not... having to...strive to do something better or to achieve something."

Furthermore, there are concerns amongst managers of getting bad word-of-mouth from volunteers and impacting the CS's reputation. Volunteer manager 3 noted that "in a small community, the worst thing we could do is actually go in there and confront it head on. We would have a lot of negative feedback from that."

To keep PM informal and due to time constraints, managers use strategies such as performance managing a group rather than individual volunteers, taking a more guiding than managing approach, and building good relationships with volunteers to make communication easier. The managers highlighted the importance of concealing management practices behind social events or group meetings and to hide the fact that the volunteers are managed from the volunteers themselves, as this would exert pressure on them. Hence, in the OSD volunteer PM often takes place in a groupsetting and is inconspicuous and informal, except when problems with a volunteer occur. However, there are no set policies, processes, or frameworks for dealing with poor performers, which makes it harder for managers to act. Volunteer Manager 2 explained:

"We struggle to performance manage people who do something wrong, cause they are volunteers and we don't want to lose them and that's kind of...yeah, it's really tricky to performance manage people who...(thinking)...yeah, we've had complaints before...it's almost like we can't do it. [...] We can't possibly get bad press and there is that threat that the volunteer could leave..." 
A similar issue exists for volunteers who exceed expectations, as there are no processes or policies on how to reward those volunteers. Some managers argued, though, that volunteers who are particularly committed and excel in their job are asked to work more often and therefore receive more recognition from the volunteer managers, but this only applies to volunteers in the main locations, not to volunteers in more distant areas. The PM practices will be discussed in further in section 4.2.2.

When discussing strengths and limitations of the OSD' PM practices, the opinions of the managers were congruent. The managers saw the strengths of their management in getting the best out of volunteers, in their recruitment process, in clarifying their objectives and in recognising volunteers. Limitations revolved mainly around geographical spread, time and resource constraints, dealing with poor performance, the informality of the practices and the reluctance to formalise practices as this could lead to negative word-of-mouth and may even result in negative press coverage. Some of the managers' responses are illustrated below:

"Because it [PM] is informal it's really easy to miss out on conversation with individuals. Because you basically look for the opportunities when that person is actually around and you have a chat. But...it's hard to make sure that you do that with everyone on a regular basis. So that's definitely a downside."

(Capacity and Development Manager)

"I think...the positive stuff we are good at, the negative stuff is a lot harder."

(Volunteer Manager 2)

\subsubsection{Motivation}

Volunteer motivation was originally planned to be only an entry point into the interview, rather than a large part of this thesis, but it became a reoccurring theme during the interviews which proved to significantly influence the management of volunteers:

"If we understand why people are there...then it can help us think about how we...you know, how do we engage with them, how do we help deliver what they want, but also how do we help them to deliver what we want as well."

(Divisional CEO)

Many managers emphasized the importance of motivation behind volunteering and the challenges of managing such a diverse group (p.49). Some of the managers 
proposed the idea of two different types of volunteers, namely the main volunteer workforce and the ad-hoc volunteers:

“You're almost creating two different workforces. You're creating a volunteer workforce and ad-hoc volunteers, which are two different groups that require different management."

(Volunteer Manager 3)

The volunteer workforce is seen as volunteers who work for the OSD on a regular basis, whereas the ad-hoc volunteers are comprised of people who only volunteer once or twice a year for certain events. The managers argued that due to the limited availability of ad-hoc volunteers and the different motivations of the two volunteer groups, they need different management practices, namely the volunteer workforce needs to be managed more than ad-hoc volunteers and similarly to employees. The divisional CEO explained:

\begin{abstract}
"It's a bit different for different types of volunteers, so the ones that are brought in for...say around Daffodil Day ${ }^{3}$, I think...having the preparation, training and... a review of what went well and what could be improved, is possibly enough, cause it's a day that they are there...well, and a few days either side basically. For longer-term volunteers, I think, having regular check-ins with other volunteers that are part of that community building that they can share issues, that they can get feedback from managers, is really useful."
\end{abstract}

Some managers also stressed that volunteers' motivations within those two volunteer groups vary, which makes managing them even more complex. The interviews showed, though, that a lot of long-term ${ }^{4}$ volunteers have similar primary motivations. Six volunteers indicated their main motive for volunteering for the CS to be the effect cancer had on their lives, because either they, their partner or close relatives had suffered from cancer. Many of these volunteers had initially been clients of the CS and had later become volunteers to be able to give back to the CS and help other people who are in a similar situation as they had been.

\footnotetext{
${ }^{3}$ Cancer Society's annual fundraising event

${ }^{4}$ All volunteers interviewed (even Lilly, the events volunteer) were involved in on-going as well as event roles at the OSD. Thus, no implications can be made for ad-hoc volunteers.
} 


\subsubsection{Performance Management Practices}

Four PM practices, namely goal-setting, feedback, training/development, and rewards/recognition, were introduced to the participants in the interviews. Additionally, two managers suggested exit interviews as supplementary processes, as they agreed that this is part of the feedback process. Training/development and rewards/recognition were seen as the most important practices for volunteers by volunteer managers and the divisional CEO claimed goal-setting and rewards/recognition were central. The volunteers all agreed with at least one practice and were satisfied with how they are executed. Most volunteers were even interested in furthering at least one practice.

In the following, each practice will be discussed in more detail. Rather than follow the PM cycle, which is how the questions were asked, the subsequent sections are ordered by the level of acceptance of the practice to the participants. Acceptance refers to the degree of positivity and interest from interviewees when talking about the individual practices.

\section{Rewards/Recognition}

Both managers and volunteers understood recognition to be various forms of saying thank you, such as in person, thank you emails, thanking the volunteers on the OSD's website or facebook page, inviting volunteers for drinks and nibbles at Christmas or similar social events. Seven out of nine volunteers indicated that the OSD recognises its volunteers sufficiently and that they feel appreciated, as illustrated by the quote below:

"They make it very...very much clear that without their volunteers, they couldn't do what they do and you feel like they mean you personally, but they mean everybody. [...] And all the people are just, you know, "what would we do without you volunteers" and you are made aware of the fact that you are definitely appreciated..."

(Alice, Volunteer)

Only one interviewee indicated that she is not recognised enough, while another participant stated that she receives enough acknowledgement but that she would not mind receiving more. The volunteers' overall acceptance of and satisfaction with the practice rewards/recognition is in line with responses from the managers who felt confident that this is the PM practice used most often and done best in the OSD. 
A general agreement by the volunteers was that recognition is more important than rewards due to the OSD's limited resources and the altruistic nature of voluntary work. Most managers were aware that their volunteers preferred recognition over rewards, but some felt that a lot of volunteers, especially the more mature ones, appreciate occasional small rewards, such as pins or pens, even though, or because, they do not expect them. However, many managers also pointed out the challenges of rewarding volunteers. First, it is difficult to find rewards that are appreciated by volunteers of all types, age, and motivations. Second, many managers were afraid of forgetting volunteers who then feel not valued and stop volunteering. Third, managers argued about the type of behaviour that should be rewarded, either the length of the volunteer's service time or the frequency of engagement:

"We had a system when I came here, we had badges for 5, 10, 15 years etc., but there was the feeling amongst the staff that that wasn't fair because you might have someone who has been on a book as a volunteer for 25 years but actually has not done a lot of work."

(Volunteer Manager 1)

Some managers explained that they prefer to forego all rewards to avoid making any mistakes and prefer methods which recognize the whole volunteer community.

\section{Training/Development}

After rewards/recognition, training/development was the easiest practice to discuss for the participants, as it is commonly used for the OSD's volunteers. Every new volunteer runs through an induction process which includes essential information, such as confidentiality clauses, and some theoretical training. Depending on the volunteer's role, there is also on-the-job training, e.g. in the shop. Moreover, in some locations and for some volunteer roles, there is the possibility to occasionally attend guest lectures, conferences, or in-house trainings. Yet, managers argued that their training/development programme could be improved, as trainings are only offered irregularly due to financial and time limitations and are often not attended well. Moreover, no refresher trainings exist to update or remind volunteers of important information. Challenges of organising trainings were the difficulty of finding a suitable time for volunteers, finding low-cost trainings or voluntary guest speakers and finding topics which interest volunteers, so that the training uptake is higher. 
Volunteer manager 1 describes the difficulty of motivating volunteers to attend trainings:

"People won't come in, there is the mindset of I am giving my time don't ask me to give up more time to come in and sit here and be taught anything or be trained, and yet when people do come to the likes of the one we had recently, they had a really nice time, people were chatting getting to know each other."

(Volunteer Manager 1)

The volunteer managers considered making some important refresher trainings compulsory. This, though, leads to another issue, namely that volunteers often feel demeaned and believe they are seen as incompetent, if they have to attend trainings:

"There is some feedback from volunteers that we have had about...training and communication and that they can feel talked down to sometimes. They are volunteers, but they are all very competent people and they want to be treated that way. So, I think we need to be mindful with how we present information."

(Volunteer Manager 3)

Thus, managers started to conceal trainings as coffee mornings or social function to distract volunteers from the educational purpose, e.g. volunteer manager 3 explained: "We previously had difficulties to actually run trainings, so what we'll do is run a series of, we just call them coffee mornings." Nevertheless, managers find themselves in a dichotomy between offering training/development, which is important for the organisational advancement and is also asked for by some volunteers, and ceasing the trainings, as they are often sparsely attended and let some volunteers feel undervalued and talked down to. The volunteers' responses were more in favour for training/development:

"I just feel it would be beneficial definitely to have...ugh... a bit more information from outside speakers for volunteers. It just keeps you interested. Otherwise you'll start to think... you know, why are you doing this? Well, I know why I'm doing it, because I like helping people, but it still keeps you...it's another part of it. Just... keeping informed, I think. And that's a bit vital really."

(Phoebe, Volunteer)

Seven volunteers would like to receive further training/development or lectures, mainly on the OSD's work, current cancer research and similar topics. Primarily the supportive care volunteers also want more on the job training. Only two volunteers are content with the current situation and do not want to receive any more training. 
Moreover, almost all volunteers, often in connection with rewards/recognition and training/development, requested more social events to meet other volunteers and employees:

"With volunteers, it would be good to have a bit more social activities or something. Just as a get-together. (thinking)...We need to sometimes just have a group of us here and just have a cup of tea and a chat of what we do...that would be helpful."

(Lorraine, Volunteer)

The volunteers regard social events a significant part of their volunteer experience, as it allows them to get in contact with employees and other volunteers, which in turn increases their commitment and sense of belonging to the organisation. Currently, such social events take place about twice a year in the OSD and serve to "officially" recognize volunteers. The volunteer interviews revealed that trainings are seen as another opportunity to meet and catch up with other volunteers which links with the managers' idea to present trainings as a social rather than an educational event. According to the volunteers, two to four social events a year, which include employees, would be ideal. Some volunteers from across the division also emphasised the importance of meeting the new CEO, who is based in the main office in Dunedin, in one of those meetings and to receive more information from the main office, as they felt somehow less engaged due to the geographical distance.

\section{Feedback}

Most clarification was needed for the practice feedback. Firstly, many managers and volunteers immediately thought of bottom-up feedback (feedback from volunteers to managers), e.g. volunteer manager 3 who explained:

"When I think feedback, I always think about volunteers giving us feedback, but we need to give feedback to them too. It is really hard when someone has done something out of the goodness of their heart."

Only few managers, and hardly any volunteers, talked about top-down feedback (feedback from managers to volunteers) right away. The participants corroborated that volunteers are highly encouraged to give managers feedback and that debriefing sessions take place after each event where improvement ideas are discussed. Moreover, the participants stressed that all three volunteer managers have an opendoor policy which allows volunteers to contact them at any time: 
"When volunteers come in, the first thing I say to them is that I have an opendoor policy, so anytime anyone wants to talk, they can come in. As frequent as they want. I think that is really important that they feel supported and that they can be honest with me."

(Volunteer Manager 2)

Secondly, although all participants had a certain understanding of what top-down feedback is, the opinions on what it entails differed significantly between managers and volunteers. The managers considered feedback for volunteers as a similar process to the one for employees which involves a one-on-one meeting, where expectations of both parties are discussed, the employee's work is reflected upon and improvement ideas are given thought to. Some managers emphasised the significance of regular one-on-one meetings or phone calls with the individual volunteers, as it can improve the volunteer's commitment and sense of belonging to the organisation, especially for volunteers in more dispersed areas who have less contact with the main offices and volunteer managers:

"It is important to meet them [volunteers], it makes a big difference. [...] It's much easier to work with someone when you have got a face to a name and they know who they are talking to. And then you can just have email or phone communication, that's fine. It's something that...I think that's something we should do."

(Volunteer Manager 3)

Most managers declared that they do not give feedback to volunteers due to time and resource constraints. Only later some managers, especially the volunteer managers, realised that they gave feedback to volunteers, even though there is no process or policy around it and it does not take place on an individual and regular basis. Feedback for volunteers in the OSD is dependent on volunteer role, availability, and location, e.g. supportive care volunteers in Dunedin receive more feedback than administrative volunteers in rural areas. Furthermore, managers often had difficulties to differentiate between feedback and the other three practices, because for them feedback is also included in goal-setting, training/development and reward/recognition. As there are no clear volunteer PM processes in the OSD, managers mainly use the practices rewards/recognition and training/development and put their feedback in-between.

In contrast to managers, volunteers indicated from the beginning that they received feedback. However, what volunteers understood as feedback was more recognition, which substantiates the mix-up of practices. None of the volunteers felt that they receive constructive feedback from managers, but affirmed that they would like to get 
some and also have a one-on-one meeting or phone call with their volunteer manager at least once a year. Six volunteers asked for more feedback, two were satisfied with the present situation and one would not like to receive any constructive feedback at all. Phoebe and Monica are both interested in receiving more feedback:

"[Feedback] Makes you feel connected and if you've got any thoughts that you're not doing the right thing...I think that would be helpful. Often the meetings we have we'll talk around those sort of things, but sometimes people aren't keen to talk about...ugh...problems in a group setting, so it might be easier for people to meet and talk about them [individually]."

(Phoebe, Volunteer)

The lack of constructive feedback in the volunteers' perception is in line with the managers' admittance of avoiding giving negative feedback or improvement ideas out of fear of losing volunteers and because they feel it is not respectful. Yet, some managers indicated that as a volunteer they would like to receive honest feedback, but do not want to give it to volunteers themselves. Therefore, feedback in the OSD primarily happens in groups and is focused on recognizing volunteers for their work. If managers hear about a volunteer who did not comply to the OSD's expectations, they often send out an email to all volunteers or organise a group meeting rather than talking to that person individually. Concealing the feedback for this one person as an update for all volunteers has the positive effects of making communication with the volunteer easier, avoiding the negative feelings of being summoned into the office for an individual talk, and is a good way of reminding the other volunteers as well that the OSD has certain expectations of its volunteers:

"I don't try ever to isolate someone and say "Come into my office, we need to talk about something", because I don't think that is a good way of doing it. And you know what, there could be someone else in the room who has done it but just hasn't been caught doing it, so why not tell everyone."

(Volunteer Manager 2)

Only in case of a severe violation of the OSD's expectations, volunteers are asked for a private conversation with their managers. Concerning the supervision of volunteers, managers affirmed that the communities in Otago and Southland are so small that no supervision is necessary, as violations are passed on to the managers anyway.

Goal-setting

Goal-setting revolves around the planning stage of PM and involves two phases: the 
mutual communication of expectations and objectives and the decision on goals for the employee/volunteer. When discussing the first phase of goal-setting, the volunteers stated that they feel confident about their tasks and know about the OSD's expectations. The managers also ensured that they clarify the OSD's objectives in the first interview with the volunteer and that volunteers receive a role description.

The goal-setting phase had less acceptance among volunteers. During the interviews, financial (e.g. raising a certain amount of money in fundraising or in the shop) as well as personal goal-setting (e.g. learning to operate the till) were discussed. Three volunteers did not want to engage with the concept of goal-setting at all, while four volunteers were satisfied with the current situation. In these volunteers' perceptions goal-setting is an unsuitable practice for their volunteer occupation, as their role has no measurable indicators, e.g. supportive care volunteers whose job is to weekly visit clients. Only two volunteers were interested in developing the practice further.

The managers' opinions about goal-setting were divided. Some managers perceived goal-setting as the least important PM practice for volunteers, others argued in favour for it. All managers agreed, though, that there is no goal-setting process for volunteers in the OSD. Some managers reported that, for example in fundraising, financial goals developed quite naturally amongst volunteers, as they strive to collect more donations than in the previous year. One Daffodil Day manager explained:

"When we send them out the note of how much they've raised, they almost do that [goal-setting] themselves. So we raised this much last year, we can try and better it next year. So they set their own goals really."

Although goals motivate some volunteers, managers are reluctant to create a process around goal-setting to not pressure the volunteers who do not like set targets. Moreover, if goal-setting takes place, managers usually set personal rather than financial goals for volunteers, as they benefit volunteers more and exert less pressure on them.

Differences amongst managers were also found in their perception of goal-setting for volunteers. Some managers argued for a similar goal-setting process for volunteers and employees with monthly or annual targets that need to be met. A similarity between those managers' and volunteers' statements was that goal-setting depends 
on the volunteer's role and so not all positions are suitable for goal-setting, which is exemplified by the following quote:

"In supportive care we do not really have... a distinct sort of fact like that, all volunteers I work with are engaged with the clients and keep them in contact. So it's not really a goal-setting work if you like. Whereas fundraising [...], you sit down with the committee and you set out what you're trying to achieve and the date. You know, you have to have set goals for events."

(Supportive Care Manager)

Other managers argued that goal-setting for volunteers is less an identification of periodic targets and more about meeting the OSD's expectations. The organisation's expectations, such as showing up to an event the volunteer registered for or complying with the confidentiality agreement, thereby represent the volunteer's goals:

"Not showing up without letting anybody know would be not a good performance. Also with every shift there are certain things you need to do, so if that's not taking place, then that would be poor performance as well. We also set goals...well it's more like expectations, not so much goals, around confidentiality. That's a real big one. So, any breach of confidentiality is a total no-go. So it's not...goals, but it's more like expectations."

(Capacity and Development Manager)

Whereas the managers' first view reflects a very formal, work-environment-like process, the second position is more in line with the approach to an informal and subtle way of performance managing volunteers. Due to the strong disparities in perception, also the opinions on how much goal-setting takes place in the OSD vary. While managers with a more formal attitude towards goal-setting for volunteers believe that no goal-setting is done at all, the other managers affirm that goals are set by giving the volunteers role descriptions and information about the OSD's expectations. However, the latter managers also agree that there is a lot of room for improvement, especially in regard to dealing with poor performance and enforcing the goals/expectations.

\subsubsection{Employee - Volunteer Differences}

One of this thesis' objectives was to compare PM of volunteers and employees. Therefore, the CEOs and managers were asked about the PM practices for employees. 


\section{Equality}

Some inconsistencies were detected between managers depending on their hierarchical position. Evidence for that could already be recognized in some of the previous sections, such as goal-setting (p. 58). Whereas CEOs and managers on a higher-level took the viewpoint that basic PM principles can be applied equally to volunteers and employees, but that the extent and application of the practices varies, lower-level managers did not quite seem to comprehend their superior's ideas and took one of two positions.

The higher-level managers' arguments for similar PM principles for volunteers and employees were the resemblance of their work, and that both are an essential part of the organisation's human resources. Moreover, volunteers are often as well trained and educated as employees. The quotes below exemplify this standpoint:

"I think the practice, how you actually role it out might be slightly different, but it's around the circumstances, the environment that you create for a person to flourish in a role...but also making sure that they meet the requirements and expectations. I think those principals apply for paid staff and volunteers. The reality is we would not sit down with the same template with the volunteers and map out all the KPIs and that sort of things. But, in itself, you do follow kind of the same principals, but in a more informal way."

(Capacity and Development Manager)

"I think that... a lot of our volunteers are here because they want to do good in the world, it's not because they see it as a career move, it's not because they see themselves going somewhere...and...our efforts should be in helping them to make the biggest difference they can rather than in taking them through lots of formal processes."

(Divisional CEO)

By contrast, lower-level managers either agreed with their superiors' viewpoint, but could not explain it and got tangled up when questioned further or contradicted their superiors and pointed out that volunteers and employees are not treated equally due to the differences in payment, contract, and role:

"People say they treat staff and volunteers same but you can't, I am sorry, but you can't. Staff has a contractual employment agreement and they [volunteers] have the code of conduct."

(Supportive Care Manager) 
Both of these positions might indicate that lower-level managers did not quite understand that their superiors talked about basic principles and not the extent or application of the practices.

Other differences mentioned were, e.g. the PM practices which are more formal and less subtle for employees, as pointed out by volunteer manager 3 :

"Staff need feedback, definitely, but a volunteer...I guess for the volunteer I would always tend to talk about the positives... Whereas for the staff member I think you do need to be possibly more blunt. I think it's easier to measure an employee's performance than a volunteer's."

Some interviewees felt that at times volunteers are treated better, valued more, and receive greater support than employees. A reason for this could be the volunteer managers' need to motivate and retain their volunteers by building good relationships and offering a warm and welcoming environment, whereas continuous salaries are often seen as sufficient motivation for employees. Moreover, because employees are paid, organisations can take the liberty of implementing formal PM systems for employees to ensure the effective and efficient use of their resources.

\section{Performance Management Practices}

From all information received in the interviews, table 7 was created which depicts similarities and differences of PM for volunteers and employees. Variations in the PM systems are highlighted. Noticeable is that there are hardly any similarities between the two PM systems, except that both are ongoing and appear nascent in their development status. The differences primarily reflect the (in-)formality of practices, e.g. while PM for employees is more planned and formal and has been further developed than PM for volunteers, the "positive" and developmental practices for employees lack behind, whereas those are most used for volunteers. This shows that more effort is applied to motivate and retain volunteers than employees, as they are unpaid and need to be motivated differently, whereas employees might be expected to be aware of the organisation's resource constraints. 


\begin{tabular}{|c|c|c|}
\hline Characteristic & PM Employees & PM Volunteers \\
\hline Form: & Formal, Apparent, Planned & Informal, Subtle, Ad-hoc \\
\hline Frequency: & On-going, Annual & On-going \\
\hline Designation: & $\begin{array}{c}\text { Talent Management, } \\
\text { Performance Appraisal, } \\
\text { Performance Management }\end{array}$ & $\begin{array}{l}\text { PM often concealed behind } \\
\text { social events, group meetings }\end{array}$ \\
\hline $\begin{array}{l}\text { Policies, } \\
\text { Framework: }\end{array}$ & $\begin{array}{l}\text { Hardly any policies; More } \\
\text { uniform system planned in } \\
2017\end{array}$ & No policies or framework \\
\hline Environment: & PM takes place individually & PM takes place in a group \\
\hline Goal-setting: & KPIs, goals are enforced & $\begin{array}{l}\text { No apparent goal-setting, no } \\
\text { enforcement, volunteers can } \\
\text { set their own goals, } \\
\text { expectations can be seen as } \\
\text { goals }\end{array}$ \\
\hline Feedback: & $\begin{array}{l}\text { Expectations, improvement } \\
\text { ideas and KPIs are discussed } \\
\text { in a one-on-one meeting }\end{array}$ & $\begin{array}{c}\text { More bottom-up feedback, if } \\
\text { top-down then mostly } \\
\text { positive, no constructive } \\
\text { feedback }\end{array}$ \\
\hline $\begin{array}{l}\text { Training \& } \\
\text { Development }\end{array}$ & $\begin{array}{l}\text { Not really beyond an } \\
\text { induction process }\end{array}$ & $\begin{array}{l}\text { Irregular, induction process, } \\
\text { guest speakers etc. }\end{array}$ \\
\hline $\begin{array}{l}\text { Rewards \& } \\
\text { Recognition }\end{array}$ & $\begin{array}{l}\text { Some recognition, but no } \\
\text { formal framework for rewards }\end{array}$ & $\begin{array}{l}\text { Lots of recognition and some } \\
\text { rewards }\end{array}$ \\
\hline
\end{tabular}

Table 7: Similarities and Differences of PM for Volunteers and Employees

\subsection{Conclusion}

This chapter has used the interviewees' own words to describe the OSD's PM practices and the managers' and volunteers' perceptions on those. The four PM practices outlined in the conceptual framework (figure 5) were explored and fitted within a volunteer in contrast to an employee background. It was apparent that there are some well and some less accepted practices by participants, which might be linked to how commonly the practices are used in the OSD. Chapter 5 will revisit the key themes and add some additional themes, as outlined in the thematic map (figure 7). Moreover, in the next chapter, the emerged themes will be joined by the literature examined in chapter 2 . 


\section{Discussion}

\subsection{Introduction}

This chapter makes sense of the findings (chapter 4) by looking once more at the four PM practices and relating them to two new themes, namely "inconsistencies" and "unprofessionalism", as outlined in the thematic map (figure 7). These themes provide background information and allow for a better understanding of the OSD's PM practices. Additionally, the findings are compared to the literature (chapter 2), whereby emphasis is put on exploring similarities and differences. The managers' and volunteers' perceptions will be integrated and discussed collectively, similar to chapter 4. Moreover, in contrast to section 4.2.2, where the practices were grouped according to the interviewees' acceptance, the PM practices discussed in section 5.3 follow the order of the PM cycle.

This chapter starts with an elucidation of the understanding and acceptance of PM in the OSD compared to the literature and the importance of good relationships between managers and volunteers is highlighted. Subsequently, the updated PM process model (figure 4) is revisited. This model frames the further discussion to provide a better overview on the degree and way PM practices are used in the OSD and to explain the managers' and volunteers' perceptions of these. Moreover, the practices, as used in the OSD for volunteers, are compared with the literature. Subsequently, the PM model is adapted to reflect the practices as applied in the OSD and the idea of three levels of acceptance of PM practices for volunteers is introduced. The ensuing section contrasts the PM practices for employees and volunteers and discusses possible reasons for the differences. Next, the themes "unprofessionalism" and "inconsistencies" are revisited and discussed in more detail. The chapter concludes by expanding on improvement ideas from managers and volunteers and by summarising the discussion in a brief conclusion.

\subsection{Volunteer Management and Performance Management Perceptions} Volunteers clearly enjoyed working for the OSD and their experiences with the organisation were largely positive and revolved around employees, support, and the helpful and caring atmosphere. They were well aware of the limited resources of the OSD and the few unpleasant experiences that were raised were when volunteers felt 
that the organisation had either wasted its own or the volunteers' resources. The ineffective use of resources, which will be revisited in section 5.7, is one of three subthemes that were grouped under "unprofessionalism" in the thematic map (figure 7), as it reflects the mis-management in NPOs which has led, in other NPOs, to several cases of fraud and scandals in the past and an increasing urge from stakeholders to become more "business-like" (Akinlade \& Shalack, 2016; Lockyer, 2014) (section 2.2.3)

Although researchers' opinions on the usefulness of HRM practices for volunteers diverge (section 2.3.3), it is acknowledged by authors from both positions that HRM practices can be beneficial for the organisation's effectiveness and to ensure that the volunteers' passion is directed towards achieving their goals, but only as long as the distinct characteristics of volunteering are maintained (Paull et al., 2010). Nevertheless, management practices are often overlooked by NPOs (section 2.2.3), mainly for reasons such as the scarcity of financial resources, knowledge, or capabilities (Bussin, 2013; Lockyer, 2014).

PM is a highly significant management practice (e.g. Kreutzer \& Jäger, 2011; Wilson, 2012) which has been confirmed by the interviewed managers. The understanding of what PM is and entails varied widely among the interviewees (section 4.2), depending on the hierarchical structure. Although most participants rationally perceived the concept of PM as important and helpful, emotionally they felt that PM has a negative and scary image. With this caution towards PM the participants are not alone, as PM has long been criticised (e.g. Bouskila-Yam \& Kluger, 2011; Buckingham \& Goodall, 2015) (section 2.4.3). Possible explanations for the participants' dichotomy of perceptions are the lack of understanding of PM, bad experiences with PM or PAs which are often mixed up (section 2.4.3), the resemblance with professional employment or the perceived inherent contradiction with volunteer work (section 2.3.3)

As became apparent, the OSD deployed PM practices, though, in an informal, uncoordinated and subtle way, which is in line with findings from Carvalho and Sampaio (2017). Moreover, the OSD has started to implement a formalised recruitment and induction process for volunteers, as done by many national NPOs (Lynch \& Smith, 
2009). This points to an inconsistency, namely the formalised recruitment process versus an informal PM approach for volunteers. However, the managers hesitate to further develop their PM process out of fear of losing volunteers due to PM's poor reputation, the overly formalisation of processes, and the repression of the values and spirit of volunteering, which is supported by Kreutzer and Jäger (2011) and Leonard et al. (2004) (section 2.3.3). Therefore, volunteer PM practices at the OSD are often concealed as social events to divert attention from their purpose (section 5.3.2 and 5.3.3). By contrast, formalised recruitment is perceived as acceptable by volunteers and managers, as it can be argued that volunteers are in contact with the OSD's clients and thus, need to be checked thoroughly.

Unlike the managers' assumptions, and although most volunteers had difficulties with the term PM, most volunteers showed interest in the individual PM practices, as long as they are executed in a non-pressurised way. This might indicate that managers are too cautious and that volunteers are not as disapproving of the practices as they think. Furthermore, it demonstrates the influence of terminology and of the manner in which managerial practices are communicated, as confirmed by Moreton (2006). Additionally, it was discovered that good relationships with volunteers primarily impact their acceptance of practices, while the type and degree of practices play a minor role (Nencini et al., 2016), which was also observed by volunteer manager 1 :

"It [PM] is going to come down to having good relationships, I think. So, the better your relationship is, hopefully, the easier that [PM] is going to be."

Thus, research and the findings from this study suggest that managers can further develop PM practices, as long as they are based on and foster close connections between volunteers themselves as well as between volunteers and employees.

\subsection{Revisiting the Performance Management Practices}

The four practices will be discussed, following the order of the PM cycle. Each of the practices belong to one step in the PM process. Section 2.4.5 introduced the updated PM process model which consists of the four stages planning, monitoring, developing and rewarding (figure 4). 
This model is suitable for exploring the OSD's PM practices, because it mirrors the OSD's management approach, e.g. the use of more motivational terms, the aim of motivating and developing volunteers, rather than rating them. During the interviews, no evidence was found for any evaluating of volunteer performance.

\subsubsection{Planning}

The first step, planning, revolves around communicating mutual expectations and targets between the organisation and employees and setting goals (Gruman \& Saks, 2011; Kinicki et al., 2013). The findings (section 4.2.2, "goal-setting") show that participants were satisfied with the OSD's communication of its objectives and expectations. The recent introduction of role descriptions, however, was not such a simple undertaking. Two volunteer managers mentioned that volunteers who had been in the job for several years were particularly resistant to signing the role descriptions and did not understand their usefulness. Conversely, new and younger volunteers did not take offence to the role descriptions and some even emphasised their helpfulness:

"We were given a brief role description and we were able to read through them and be like that's what is expected of me, so l'm sort of in charge of this, this and this, which was really helpful."

(Lilly, Volunteer)

The example of the role descriptions, which are a foundation stone for effective PM, substantiates the claim from section 5.2 that the perception and communication of practices are more important than the practices themselves, which is affirmed by the national CEO:

"It's about how you sell it and it's about tone and respect. If you say this is actually to protect you and here is your position description and we are really grateful for your time, but here are the parameters so that you don't get stretched and pulled too many ways and you have a real understanding of your role, then it is going to work."

While long-term volunteers might have felt threatened by the role descriptions, as they had successfully worked without them for several years, new volunteers did not know any different system and even found role descriptions helpful. A way of changing the negative perceptions of the long-served volunteers was through their good relationship with the managers. 
Role descriptions are not just important for volunteers to know what their job is, but also for organisations who use them as basis for decisions on poor performances. Dealing with people who do not follow the guidelines is a risky and difficult task for NPOs with which effective management practices and performance measures might help. At the OSD the managers believe that the handling of volunteers who do not comply with the expectations is their greatest weakness. Volunteer manager 3 explained that this was due to the patchy implementation of role descriptions and the lack of enforcement of those. Furthermore, a lack of managerial education and experience amongst managers might also be a reason for this weakness (Brewis et al., 2010; Nesbit et al., 2016). The dearth of policies and procedures around poor performances and VM, which again gives rise to the claim of being unprofessional (section 5.7), contribute to the managers' insecurity to handle such difficult volunteers.

Whereas most participants regarded the first phase of the planning stage as necessary and, therefore, partly accepted it, the goal-setting process was eyed critically. Volunteers felt uncomfortable with goal-setting, while managers' opinions were divided. The different approaches managers take and their disagreement about which one is more suitable reflect inconsistencies in the OSD (section 5.7). Moreover, it indicates that volunteers do not receive the same managerial treatment across the OSD, but that it depends on the location, manager, and volunteer position, which was confirmed in the interviews.

\subsubsection{Monitoring}

The second step involves the monitoring of performance, whereby the main emphasis is put on continuous, real-time feedback and facilitating performance. This phase differs from traditional PM processes in that it does not evaluate or rate performance.

Feedback evoked some opinion differences among participants (section 4.2.2, "feedback"), but was still mostly accepted. The participants' perceptions of top-down feedback for volunteers varied widely. Whereas managers viewed feedback for volunteers as a similar process to the one for employees and did not believe they gave feedback, volunteers indicated that they received feedback, but saw it more as a recognition process, pointing out that it did not include constructive feedback. The managers' reasons for avoiding constructive feedback revolved mainly around the fear 
to upset or lose volunteers and not knowing how to communicate improvement ideas so that volunteers do not feel undermined. This highlights another theme (figure 7), namely the lack of strategic focus among managers. Often the managers' focus lies more on the volunteers themselves than the OSD's efficiency and effectiveness, which especially applies to volunteer managers, as it seemed in the interviews that their main concern was the wellbeing and happiness of their volunteers rather than considering what is best for the organisation. This is in line with reports from the literature and might stem from a lack of strategic focus approach to VM or missing managerial skills and knowledge of volunteer managers (e.g. Brewis et al., 2010; Carvalho \& Sampaio, 2017; Machin \& Paine, 2008; Nesbit et al., 2016). Pulakos and O'Leary (2011) emphasise that managers need to be trained on constructive feedback-giving and outline four key factors (section 2.4.5) that are essential for effective, constructive feedback, one of which is creating good relationships. The OSD's managers already know the importance of building supportive relationships with volunteers, but more training on performance conversations can support them to overcome their fear of giving feedback and add a management by objectives focus ${ }^{5}$.

While managers avoid giving constructive feedback and making the process more formal, six volunteers wished for more constructive and regular feedback. This suggests that managers are too hesitant in dealing with volunteers and that more formalised PM practices would be welcomed by the majority of volunteers. The benefits of having on-going, constructive feedback sessions for volunteers are also outlined in the literature (e.g. Dhebar \& Stokes, 2008). Although the OSD offers group debriefing sessions to volunteers in some roles, such as events, and supportive care volunteers even receive one-on-one supervision, no regular feedback sessions are offered, which seems to differentiate the OSD from other NPOs (e.g. Brewis et al., 2010; Hager \& Brudney, 2004).

\subsubsection{Developing}

The third step is concerned with the employees' development based on the feedback provided and with an increased focus on the employee's strengths. This stage differs significantly from traditional PM processes (section 2.4.5).

\footnotetext{
${ }^{5}$ Management system where the organisation's goals are agreed upon by managers and employees
} 
Volunteers mostly either accepted the practice training/development or categorized it as having potential for further development (section 4.2.2, "training/development"). In contrast to feedback, the volunteers' and managers' opinions and perceptions about training/development mainly coincided. Seven volunteers would like to receive more training/development which was acknowledged by managers. However, the managers argued that although volunteers ask for more training/development, the uptake is often low and if made compulsory, some volunteers feel debased by having to attend trainings. Similar results were found by researchers, such as Hartenian (2007) and Hughes (2006) (section 2.4.5). Nevertheless, training/development of volunteers has been studied in a range of connections (e.g. motivation, performance, retention) and most researchers agree that training volunteers is beneficial to NPOs (e.g. Bussell \& Forbes, 2006; Hager \& Brudney, 2011; Waikayi et al., 2012).

The OSD shows some similarities to the outcomes of Brewis et al.'s (2010) study (section 2.4.5). For instance, while the OSD has no training or development plan for its volunteers, the training offered is informal and the barriers to further developing the trainings are equivalent to Brewis et al.'s findings: lack of funding, low uptake by volunteers, the perception that volunteers are not interested in participating, and the unavailability of suitable trainings. Hence, it seems that trainings are important for organisations and volunteers alike, but that there are barriers for the organisation of trainings which have not yet been resolved.

Moreover, the volunteer managers stressed that volunteers are driven by various motivations, which makes them such a complex group to manage. Similarly, Newton et al. (2014) discovered that volunteers' motivations have a huge influence on their commitment to learning and development. Research shows that volunteers' motivations are manifold (Dhebar \& Stokes, 2008; Taylor et al., 2006). The two main motivations of the OSD's volunteers, though, are a personal connection to cancer and wanting to give back. This might indicate that these volunteers do not need more incentives to volunteer and they are not primarily driven by a desire of personal growth which has implications for the communication of trainings to volunteers and the way trainings are managed. The volunteer interviews showed that it depends on the type of training whether they attend or not. In general, volunteers were more attracted to 
guest lectures and conferences than on-the-job training, except for supportive care volunteers.

Presently, the OSD's managers conflate trainings and feedback with social functions and coffee mornings to distract from the educational or evaluating purpose. The hiding of practices behind social gatherings that are, in the managers' perceptions, accepted and pleasant for volunteers reflects the managers' insecurity and dichotomy between introducing proper management practices for the organisation's good and avoiding them to offer an unpressurized, non-work-related volunteer environment. However, the individual practices get mixed up when used cohesively, which is why managers got confused when talking about feedback and did not see any differences between the practices (section 4.2.2). On the one hand, hiding practices might not be ideal, as most volunteers want to receive more training and constructive feedback. Moreover, the concealment of management practices could be seen as deceiving. On the other hand, disguising practices behind social functions fits well with the volunteers' request for social events. Seven volunteers would like to have more social gatherings, as meeting other volunteers and employees is an important part of the volunteer experience (e.g. Haski-Leventhal \& Bargal, 2008; Vecina et al., 2012).

Additionally, PM practices, such as training, could be made available to volunteers across the OSD by using videos, podcasts, or skype and thereby diminish the perceived distance to the Dunedin office. However, managers argued that due to resource constraints, they often do not have the time to "innovate" and find ways to improve the volunteer experience.

\subsubsection{Rewarding}

The last step comprises of recognizing and rewarding employees. In traditional PM process models this stage involves rewarding and developmental opportunities, but also negative consequences for employees who have not delivered to the expectations (Kinicki et al., 2013). In rare cases, negative conclusions also must be drawn in the OSD, but generally managers recognise their volunteers, as the expectations are different than for employees (section 2.3.2). 
Recognition/rewards was the most accepted practice among participants (section 4.2.2, "rewards/recognition"), whereby recognition is valued more than rewards due to the organisation's limited resources. While managers agreed that rewards/recognition is the PM practice they are best at, the opinions on if and how to reward volunteers diverged. Participants revealed that rewards differ according to location, role, and manager which points to inconsistencies in the OSD (section 5.7). However, in the case of rewards, inconsistencies could be appreciated by volunteers, if managers choose rewards according to the volunteer's preferences, e.g. one volunteer manager explained how volunteers from older generations often appreciate small rewards, such as pins, whereas younger generations do not value them. Moreover, volunteers' motivations are multifaceted and go beyond altruism (sections 2.3.2, 4.2.1, and 5.3.3) which makes it imperative to know and cater to the volunteers' needs to achieve higher retention rates (Dhebar \& Stokes, 2008; Taylor et al., 2006). Thus, the reward chosen should be appreciated by the recipient and motivate him/her to continue contributing to the organisation.

\subsection{The Otago Southland Division's Performance Management Practices}

In the last section, the updated PM model was used as basis for discussing the OSD's PM practices. It is apparent that the OSD does not execute all practices in the same extent and order as suggested by the PM model. Moreover, motivation turned out to be of great importance when implementing a PM system. Hence, figure 8 illustrates how PM is applied at the OSD. 


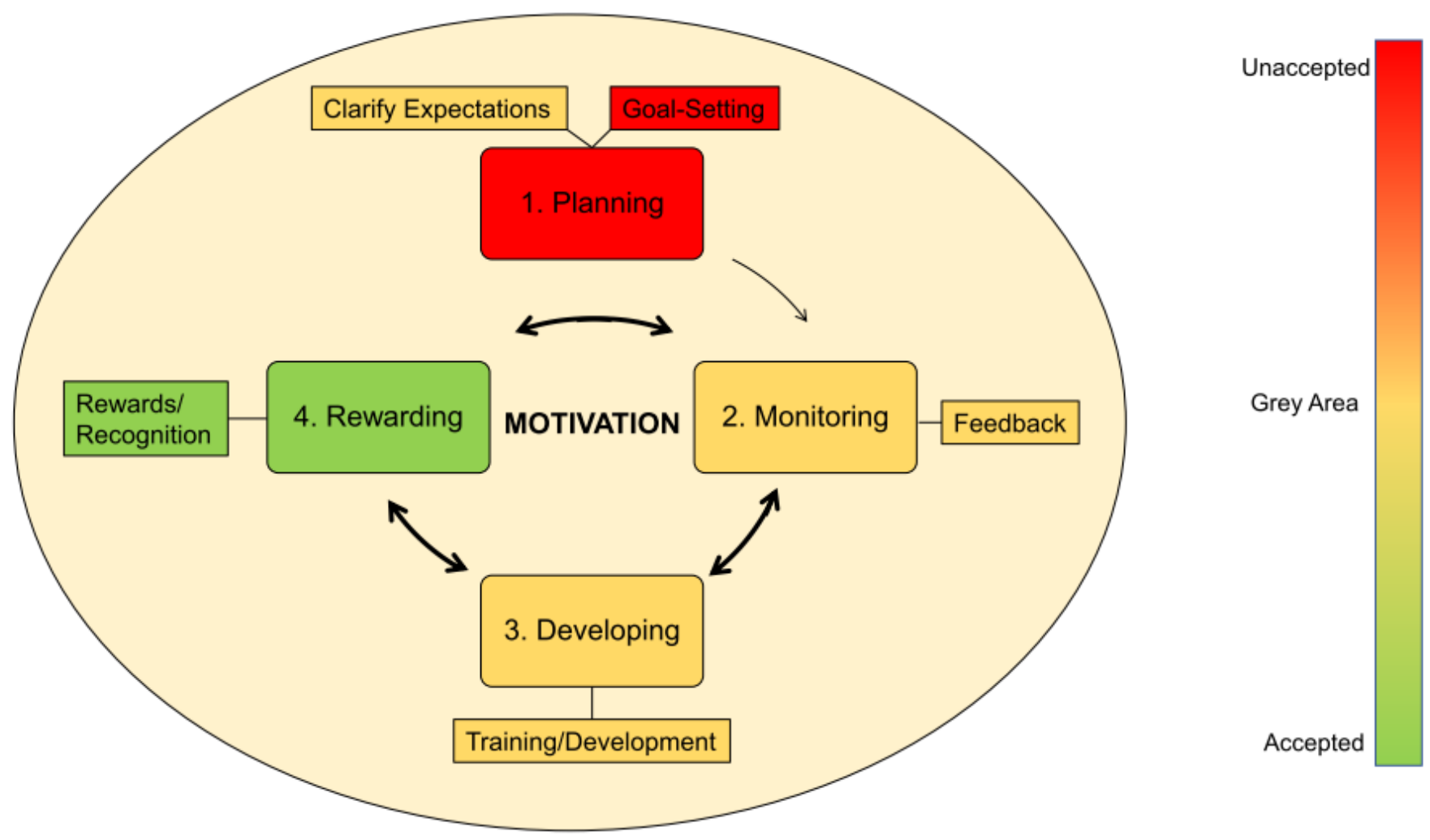

Figure 8: PM as applied in the OSD

A pattern of accepted and unaccepted practices and a "grey area" could be identified in the interviews (figure 8). People's acceptance is based on their thoughts towards the practice, but also on the frequency of its usage. The "accepted" area is the practice of rewards/recognition which most participants agreed with and is also most commonly used in the OSD. The "grey area" includes the practices of feedback and training/development which most volunteers wanted to receive more of, but managers seemed to struggle (sections 5.3.2 and 5.3.3). Nevertheless, these two practices seem to offer the most promising opportunities for PM development. The first part of planning, clarifying the expectations and objectives, is also part of the "grey area", as volunteers do not oppose, but also not totally agree with role descriptions, whereas managers see the necessity of them. The "unaccepted" area revolves around goalsetting; participants showed the least interest in this and it is also least developed in the OSD. However, depending on which goal-setting process the OSD decides on (section 5.3.1) and how it is communicated, it might move from its "unacceptable" status to the "grey area" which allows for further development. 
Looking at the segmentation of the practices, it seems that the OSD does best in the practice that comes last in the PM model, followed by the two practices which are in the middle of the process. Goal-setting, which comes first in the model, is the practice the OSD is least active in and which is also least accepted by participants. Moreover, most of the time the clarification of expectations only takes place once at the beginning of the volunteer engagement, whereas all other practices are applied more regularly, albeit not necessarily in the typical PM order and quite often at the same time (figure 8). Finally, volunteers' motivation plays an important role in their perceptions of PM practices which has implications for the PM design and implementation in NPOs (section 6.4).

\subsection{Performance Management of Employees and Volunteers}

This study's main purpose was to investigate the PM used for volunteers in the OSD, but some information about PM of employees was also sought to compare the PM practices for both paid and unpaid staff. To the researcher's knowledge, no studies exist which consider PM of volunteers in relation to PM for employees.

According to Dwiggins-Beeler et al. (2011), NPOs often hesitate to allocate the same amount of resources to volunteers as to employees and to involve them in their decision-making due to the voluntary nature of volunteering and the lack of power NPOs have over volunteers (section 2.3.2). This is not the case in the OSD, where the divisional CEO and the volunteer managers try to include volunteers in all departments, value their feedback and ask them for their input. On the contrary, it seemed that volunteers sometimes receive more resources than employees, which was confirmed by some managers who pointed out that volunteers are often treated better and valued more than employees. Practices such as rewards/recognition and training/development are less developed and seldom used for employees in comparison to volunteers which has also been confirmed by literature (Taylor \& McGraw, 2006). A possible reason for this could be that NPOs focus their efforts and resources on motivating and retaining volunteers rather than employees due to the distinctive characteristics of volunteers compared to employees (section 2.3.2). Considering the limited financial resources available and non-profit employees' high intrinsic motivation (Devaro \& Brookshire, 2007), organisations should put more effort into rewarding employees intangibly (Mohiuddin \& Dulay, 2015) (section 2.3.2). 
The lack of shown appreciation for employees might be a reason that rather vehement reactions were triggered in some operational managers, when asked to compare PM for employees and volunteers. A discussion about employee-volunteer equality came up where the CEOs and some managers from higher positions claimed that basic PM principles, as opposed to practices, apply equally to employees and volunteers, whereas some operational managers disagreed and others, in turn, complied, but could not justify their response. Both operational managers' reactions might indicate an incomprehension of their superiors' position. The disparities in the managers' views point to the "unprofessionalism" and "inconsistencies" themes (section 5.7). There are missing guidelines that determine and explain the OSD's position, philosophy, and objectives around VM. Creating such guidelines might help operational managers to better understand the position of their higher-ranked colleagues and therefore unify the managers' perceptions. Furthermore, such guidelines could be used as basis for developing policies and processes around volunteer PM which would help managers to execute PM, but also improve the consistency of practices.

\subsection{Opportunities for Improvement}

One objective of this study was to generate ideas about the managers' and volunteers' perceptions on the improvement of the OSD's PM practices. This was more difficult than expected, as volunteers were very keen on praising the OSD and its work, but more reluctant to talk about negative experiences or to offer improvement ideas. Reasons for the volunteers' hesitation to discuss PM and improvement ideas were already partially reviewed (section 3.6) and involved the incomprehension of PM, negative associations with PM and not wanting to seem judgmental towards the OSD. It could also be that volunteers had no improvement ideas or feared other people would hear about them and dislike them.

Of the improvement ideas put forward, the most popular was more social gatherings (section 5.3.3), as volunteers would like to have more opportunities to meet with other volunteers and employees. Another suggestion was an improved communication and information flow between managers and volunteers, as some volunteers mentioned that, while the communication with volunteer managers works well, managers from other departments seem inaccessible. This perception links to the current debate in the OSD about who is responsible for managing the volunteers in their job. Volunteer 
managers argue that they are only in charge of recruiting, while the supervision of volunteers needs to be done by the operational managers who work with them, whereas line managers contradict and claim that volunteer managers are responsible for everything that concerns volunteers.

Managers' improvement ideas can be categorised as ideal practices rather than improvement suggestions, because managers often were unsure how to ameliorate the practices considering the limited resources of the OSD. In general, managers stressed that every practice can be improved, but the main suggestions included more and better communication with volunteers, a better process around poor performances and creating frameworks around VM. Implications of these suggestions will be discussed in section 6.4 .

\subsection{Unprofessionalism and Inconsistencies}

In the interviews, some themes (figure 7) emerged that play an important role for understanding PM, though they are not necessarily only associated with PM. These aspects were conceptualised under "unprofessionalism" and "inconsistencies", which are related and point to similar issues. Some of these themes were already pointed out in previous sections and are revisited here.

\subsubsection{Unprofessionalism}

NPO's unprofessionalism is highly debated in current literature (section 2.2.3) and was a recurring topic in the interviews. Three main issues of "unprofessionalism" emerged in the interviews.

Firstly, NPOs often do not have proper management practices in place (section 2.2.3). Hence, it was no surprise to discover the paucity of VM practices in the OSD. Some indications for missing management practices were the lack of processes for the management of volunteers, the dearth of written policies and the inconsistent PM process for volunteers. Although the managers engage in some management practices, interviewees described them as being ad-hoc rather than policy guided and well thought through. Moreover, the only official management practice for volunteers was the recruitment and induction process which had recently been introduced. 
Volunteer manager 1 also realised the lack of management for volunteers: "In regards of volunteering, I will be honest, I think we have been over cautious and what that means is that things haven't been managed."

Secondly, a lack of management practices often results in a rather ineffective use of resources which was reflected in volunteers' perceptions that their donations (time, money etc.) were not always used effectively and their resulting worry that the OSD wastes valuable resources. Additionally, participants argued that managers could make more use of the OSD's assets if they used technology, such as social media, and thereby save time.

Thirdly, the volunteer managers seemed to mainly focus on the well-being of their volunteers, while overlooking the OSD's strategic goals. This together with the lack of PM awareness and the insecurity of using PM practices could give ground for accusations of being "unprofessional". Moreover, the debated role distribution between managers and the discussion about employee-volunteer equality suggest that there are no clear VM guidelines yet. All of this might stem from a lack of higher leadership in volunteer PM, as the national CEO cannot enforce any management practices in the divisions due to the governance structure of the CS and the divisional CEO had been newly appointed around the time of the interviews. Additionally, according to narratives from managers, VM had not been a focus for the previous CEO.

\subsubsection{Inconsistencies}

Three matters were discovered that can be categorised under "inconsistencies". Firstly, the lack of management practices and agreement between managers leads to inconsistencies in the management of volunteers depending on their location, role, and manager.

Secondly, various management practices can be found across the three primary OSD offices, the volunteer roles, but also between volunteer and employee PM. An inconsistency in management practices is also apparent in the thorough recruitment process for volunteers on the one hand and the lack of other management practices on the other hand. 
Thirdly, the debate about employee-volunteer equality and the discrepancies in the practices for both paid and unpaid staff can be seen as an inconsistency. While Garner and Garner (2011) noted that volunteers often do not receive the same amount of resources, the opposite is true for the OSD. The findings show that volunteers even receive more training/development and rewards/recognition than employees which elicited some frustration among managers.

\subsection{Conclusion}

This chapter revisited the updated PM process and each of the stages was discussed individually and compared to the literature. The idea of three levels of acceptance of PM practices was developed, namely accepted, unaccepted practices and a "grey area". Next, similarities and differences between volunteer and employee PM were outlined and showed that volunteers receive more training/development and rewards/recognition than employees. Subsequently, managers' and volunteers' improvement ideas were discussed. Finally, the themes "inconsistencies" and "unprofessionalism" (figure 7) were revisited. The final chapter will conclude the research and revisit the research question and research objectives. 


\section{Conclusion}

\subsection{Introduction}

This thesis has explored volunteer PM in an NPO in the New Zealand human service sector and has thereby developed an understanding of how NPOs can use PM practices to better achieve their objectives and to direct the volunteers' efforts so that they can accomplish theirs. A single case study was deemed appropriate to research the specific context of a rural NPO and to gain detailed insights into the PM practices used. The OSD was selected as case study organisation due to its fulfilment of the selection requirements and its willingness to participate. By focusing on both managers' and volunteers' perspectives this thesis offers an in-depth journey into volunteer PM in the OSD and examines four practices it entails. Moreover, insights into the PM of employees in the OSD allow for a comparison of paid and unpaid staff and the management practices used to guide them. A conceptual framework (figure 5) was developed which illustrates the factors explored in this thesis.

An updated PM process and practices model (figure 4) was created which moves away from traditional PM processes to depict current changes in PM in the for-profit sector. The changes include an increased focus on motivating employees and the abolishment of ratings and rankings. This "new" way of performance managing also reflects the OSD's approach which is why the model was suitable as basis for exploring the OSD'S PM.

The findings from this study show that volunteers are a complex workforce to manage and that there is no "one-size-fits-all" approach to PM, but that the organisation's objectives and the volunteers' motivations have to be considered. Moreover, managers often find themselves in a dichotomy between formalising PM practices for volunteers and disguising them as social events to divert attention from their purpose.

To add rigour to the study, some of the author's reflections on the research process were included in the thesis (section 3.6). As with any single case study there are some limitations which need to be acknowledged (section 3.7), one of them being that this study only represents a snapshot in time and that since conducting the data collection some of the OSD's practices and processes discussed will have developed and changed. 
The concluding chapter revisits key aspects discussed in the findings and discussion chapters by answering the research question and objectives. Furthermore, the thesis' contributions, implications, and suggestions for future research are presented. The chapter ends with some concluding remarks.

\subsection{Revisiting the Research Question and Objectives}

This study was concerned with exploring volunteer PM in the CS's OSD, and to thereby address the following research question:

How can performance management be applied to volunteers in non-profit organisations?

Moreover, three research objectives were chosen which shall answer the research question and which will be discussed in detail.

1) Identify how the OSD reviews the performance of volunteers

This study suggests that the OSD manages the performance of its volunteers, but managers and volunteers are often not explicitly aware of it. Although some PM practices for volunteers have been implemented, the managers and volunteers did not perceive them as a managerial technique, but rather as support for volunteers to successfully do their work. The volunteer managers admitted that they were nervous to be the case study for this thesis as they had thought that no PM for volunteers exists in the OSD, but that they wanted to reflect and improve their VM. The unawareness of PM could point to a lack of higher leadership for VM and the dearth of managers' managerial focus which is supported by the lack of policies and processes around VM and the resulting inconsistent PM approaches across the OSD. Moreover, the understanding of PM varied widely among managers with most operational managers having negative emotional associations with this process. However, managers also realised the importance of effective PM practices for the organisation as well as the volunteer experience and were interested in improving it. 
A closer look at the PM of volunteers revealed that the practices are executed in a subtle and ad-hoc manner, which is in line with managers' lack of awareness of these practices. Most PM takes place in group-settings due to time and financial constraints and a reluctance to formalise VM out of fear of losing volunteers by making the perceived cost of volunteering too high. The hesitation to formalise VM can also be seen in the choice of practices used. While practices such as goal-setting, which are associated with more work-related environments and higher efforts for volunteers and managers, are seldom applied, other practices are used regularly and in group as well as individual settings. The OSD has started to performance manage volunteers by introducing volunteer role descriptions, however, thereafter the PM process stops with goal-setting and constructive feedback mostly missing. In a later stage the PM process is resumed with some training/development offers and a lot of rewards/recognition.

More evidence of managers' reluctance to formalise VM is revealed in the practices feedback and training/development which are often concealed behind social events to hide their purpose. A reason for this is managers' worry that volunteers do not agree with the practices, but it also makes uncomfortable situations easier for managers if, for instance, negative feedback can be disguised as information update for all volunteers. The concealment of PM, though, leads to a mix up of practices, because managers give feedback, training and recognise volunteers at the same time at one social event. Moreover, while managers are comfortable with the positive side of the practices, they struggle most when negative conclusions must be drawn for volunteers who do not comply to expectations. Nevertheless, the OSD seems to neither differ in its employees' understanding of PM nor in the use of its volunteer practices from other NPOs (section 2.4.5). Thus, the OSD presents a typical NPO which allows for the assumption that this study's findings may potentially be applicable to other NPOs as well.

A comparison with the PM practices for employees show that in the OSD PM for volunteers focuses more on positive aspects and, therefore, most frequently uses the practices training/development and rewards/recognition, whereas PM for employees focuses on feedback and goal-setting and does not offer a training schedule or regular rewards/recognition. Moreover, the practices for employees are more formal than the ones for volunteers, albeit ad-hoc and inconsistent across the OSD, similarly to PM for 
volunteers. While the processes differ, discussions between managers are still going on concerning employee-volunteer equality and the similarity of the management practices used for them.

2) Compare how volunteers and managers perceive the OSD's PM practices and

3) Evaluate managers' and volunteers' perceptions on how PM can be improved

While the first objective aimed at examining the OSD'S PM process, these two research objectives look at the managers' and volunteers' perceptions and shall thereby enable a more comprehensive examination of the participants' individual perspectives, which is why the objectives are answered together.

Whereas participants perceived the term PM as negative and contradictory to volunteer work, the individual practices found mainly positive approval. The volunteers especially seemed interested and even asked for an increase of the practices' use, if they continue to be executed in a non-pressurised way. From the interviews a pattern (figure 8) of accepted, unaccepted, and partly accepted ("grey area") practices could be identified, whereby latter offers the most promising development opportunities. It is likely that the frequency of usage of a practice influenced its acceptability among participants, but also, the other way around, that the acceptability of a practice impacted on its frequency of use.

The accepted practice, rewards/recognition, is most commonly used in the OSD and the practice managers and volunteers are most comfortable with due to its positive purpose. Moreover, interviewees perceived rewards/recognition as "done best" practice for volunteers in the OSD.

The first stage of goal-setting and the practices training/development and feedback were categorised as "grey area". While participants perceived role descriptions mainly as a necessity with no need for further development, most volunteers were interested to increase the use of the other two practices. The managers acknowledged the volunteers' interest, but also presented their perspectives which ranged from the scarcity of resources to a lack of attendance from volunteers. Moreover, it was evident that the volunteers' motivations play a significant role in how they perceive PM 
practices which in turn affects how the practices can be designed to be most effective, e.g. ad-hoc volunteers need to be managed differently than continuous volunteers. Due to the vast variety of motivations there is no "one-size-fits-all" approach, but PM has to be tailored to the organisation's and volunteers' needs.

Finally, goal-setting was categorised as unaccepted practice, as most volunteers disliked the idea of setting goals which they have to perform against. The aversion of goal-setting might lie in the perception that it is most similar to a paid-work-environment and exerts the most pressure on volunteers. However, it is often not the practice itself, but rather the relationships and communication of the practice that make it acceptable to volunteers or not (section 5.3.3.). Thus, goal-setting might move to the "grey area" or even become an accepted practice depending on how managers communicate it. The managers, though, struggled themselves to agree on suitable goals for volunteers, as some wanted to use the same goals as for employees, while others argued that expectations, such as being punctual and showing up for work, are more reasonable goals for volunteers.

The treatment of and practices for volunteers in comparison to employees in general are a subject of discussion between managers, whereby some managers argue for a similar management of volunteers and employees and others contradict. Furthermore, some managers perceived that, at times, volunteers are treated better, valued more, and receive greater support than employees which originates from a different focus of PM practices for paid and unpaid staff (section 5.5).

The third objective, to learn more about managers' and volunteers' improvement ideas turned out to be harder than expected. Volunteers had difficulties coming up with improvement ideas which might stem from an incomprehension of the PM concept or a worry about seeming judgmental towards the OSD. Similarly, many managers had trouble to come up with improvement ideas, because often their ideas were not feasible with the OSD's limited resources. Nevertheless, suggestions were made mainly concerning the frequency and degree of communication between managers and volunteers, and volunteers with each other. 


\subsection{Contribution of the Study}

This study contributes to non-profit, PM and VM literature by bringing together knowledge and research from literature streams which are typically dealt with in isolation, such as for-profit versus non-profit research and volunteer versus employee literature. Moreover, to the researcher's knowledge, this study is one of the first to examine PM for volunteers, as most studies investigated PM in the for-profit and/or employee context (Bartram et al., 2014; O'Boyle \& Hassan, 2015; Selden \& Sowa, 2011) or examine the individual practices of $P M$ for volunteers, rather than the whole system. Additionally, so far, academic research mostly ignored current PM trends which therefore need to be investigated further. Hence, this study makes a first attempt to overcome the paucity of research on PM in NPOs (Selden \& Sowa, 2011) by revealing new insights on PM in the non-profit sector and by proposing a new PM process model (figure 4).

A further contribution of this study is the comparison of volunteers' and employees' PM. Although the scope of this thesis does not allow for an in-depth analysis of employees' PM, it is still one of few studies which take both volunteers and employees into consideration. Thus, the present study provides important insights into volunteer PM and managers' and volunteers' perceptions about it and compares the PM practices used for both paid and unpaid staff.

This Master thesis also has practical contributions, as it gives an idea of how PM practices influence the attitudes and behaviours of volunteers and managers, which practices for volunteer PM create a more motivating volunteer experience and what volunteers and managers suggest improving these practices. Moreover, the thesis highlights the importance of good relationships between managers and volunteers, as they are the basis for successfully implementing PM practices. This thereby allows managers and other NPOs to reflect on their PM practices and get ideas on how volunteers can be performance managed and what challenges might be. 


\subsection{Practical Implications}

This thesis provides a valuable knowledge base to NPOs in designing and implementing PM for volunteers. From the findings three main implications can be drawn which shall help NPOs to reflect on their practices.

First, now that the findings have been presented and discussed, it should be reflected if PM for volunteers is a suitable concept for NPOs. The research process has shown how much managers and volunteers struggle with the idea of applying traditional managerial concepts, such as PM, to a volunteering context. Although studying the holistic PM process allowed the researcher to discover accepted, not accepted practices and a grey area, it seems that the individual practices fit better with the concept of volunteering than the whole PM system. A reason could be that most individual PM practices were applied at the OSD, but under the umbrella term support or VM. The PM system, though, should still not be declared unsuitable for NPOs, as the principles of PM can have much value for them. Addressing the semantic problem seems to be crucial in this case by labelling PM differently. Thereby, PM is concealed from managers and volunteers, similarly to the manager's idea of hiding certain practices behind social gatherings (section 5.3.3).

Second, NPOs must carefully align professionalism in process and policy designs with volunteer motivations and their own objectives. NPOs should be aware that volunteers are interested in having more regular practices, but do not want to experience the same environment as in their paid work. Thus, managers have to find a good balance between formalising the practices, while still keeping the special characteristics of volunteering. Good volunteer-manager relationships can thereby facilitate the implementation of management practices for volunteers. Moreover, to improve VM and the process around poor performances, managers have to set up agreements on the management of volunteers (e.g. which goals to measure) and create some guidelines and policies around that which give guidance to managers and help to avoid ambiguities about the responsibility of managing volunteers (section 5.7). The divisional CEO affirmed that these tasks would be addressed in the subsequent months, as she had just started her work for the OSD a month prior to the interview. 
Third, managers' and volunteers' improvement suggestions (section 5.6) present opportunities for development to the OSD. One improvement idea, namely more and better communication, was requested by both managers and volunteers and should therefore be tackled first. While resource constraints might not allow managers to have one-on-one sessions with each volunteer, a more effective use of social media channels, as proposed by some participants, could possibly improve some of the communication and information flow.

\subsection{Suggestions for Future Research}

This thesis opens opportunities for future research on volunteer PM in NPOs. While this study focused on one division of the CS, a national federated organisation (section 1.5), independent NPOs may not display the same characteristics and, therefore, are worthwhile studying. Moreover, other divisions of the CS could be investigated and compared to the findings from the OSD to find out if they share communalities. Further research of the OSD may also provide good insights into the degree to which the change of CEO has impacted the PM of volunteers and continued comparisons of volunteers' and employees' PM practices might allow for a better understanding of the differences between the PM of both staff groups and the reasons behind these variations.

Additionally, it is suggested to examine NPOs from different contexts, such as several sectors, sizes, and geographical areas, to reveal similarities and differences between the PM practices used for volunteers and to identify patterns which can help organisations to better understand and improve their PM systems. An investigation of NPOs in the various sectors might also shed light on some challenges or rules which are only applicable to a specific context. Similarly, NPOs with a variety of purposes should be investigated, as the type of work the organisation does and the motivation of the volunteers may also influence the PM practices used for volunteers. Especially differences in management might occur between ad-hoc and continuous volunteers. Moreover, future researchers should conduct longitudinal studies which follow NPOs and volunteers through different stages in the implementation of PM practices for volunteers. 
Finally, although this thesis' updated PM process and practices model (figure 4) serves as a valuable starting point for research on PM practices for volunteers and employees, it needs further investigation and refining, e.g. this model could be used as basis for case studies in NPOs from different sectors, sizes and with a variety of volunteer roles. Future research may also consider other factors such as the relationships between managers and volunteers and the communication style which influence the volunteers' acceptance of PM practices. Moreover, research of the volunteer managers' role and capacity and the influence of higher leadership in creating effective volunteer PM practices could advance knowledge of PM in NPOs.

\subsection{Concluding Remarks}

It is hoped that this research has given the OSD's managers and volunteers some opportunities for reflecting on their PM practices. It is worth remembering that NPOs, and therefore also the OSD, have first and foremost a mission to achieve with which PM can help. Thus, the final words of this thesis are given to the volunteers who can best express what their volunteer experience with the OSD means to them:

"They are just such amazing people. You really feel if you have anything to do with the Cancer Society or being involved with them, [...] they treat you for who you are, not as a number. You get so much...support, genuine support...They are all very compassionate people. It's such a great organisation. I could never say that there was anybody I came across within the Cancer Society that hasn't been amazing to talk to and supportive..."

(Alice, Volunteer)

"I've learnt a lot, l've loved meeting lots of new people...it has been incredible. They saw potential in me and [...] have nurtured me and really pushed me to grow and I have just learnt so much. [...] It's awesome how much trust they invest and they really allow you to develop and try things out."

(Lilly, Volunteer) 


\section{References:}

Aguinis, H. (2009). Performance management: Pearson Prentice Hall Upper Saddle River, NJ.

Akinlade, D., \& Shalack, R. (2016). Strategic Human Resource Management in Nonprofit Organizations: A Case For Mission-Driven Human Resource Practices. Paper presented at the Allied Academies International Conference. Academy of Organizational Culture, Communications and Conflict. Proceedings.

Alfes, K., Shantz, A., \& Bailey, C. (2016). Enhancing volunteer engagement to achieve desirable outcomes: What can non-profit employers do? VOLUNTAS: International Journal of Voluntary and Nonprofit Organizations, 27(2), 595-617.

Armstrong, M. (2006). Performance management: Key strategies and practical guidelines. London: Kogan Page.

Baines, D., Charlesworth, S., \& Cunningham, I. (2014). Fragmented outcomes: International comparisons of gender, managerialism and union strategies in the nonprofit sector. Journal of Industrial Relations, 56(1), 24-42.

Barnes, M. L., \& Sharpe, E. K. (2009). Looking beyond traditional volunteer management: A case study of an alternative approach to volunteer engagement in parks and recreation. VOLUNTAS: International Journal of Voluntary and Nonprofit Organizations, 20(2), 169-187.

Bartram, T., Hoye, R., \& Cavanagh, J. M. (2014). Special issue on human resource management in the NGO, volunteer and not-for-profit sector. The International Journal of Human Resource Management, 25(22), 3178-3180.

Ben-Ner, A. (2004). Book Review: The Governance of Not-For-Profit Organizations. Nonprofit and Voluntary Sector Quarterly, 33(4), 739-748.

Bititci, U., Cocca, P., \& Ates, A. (2016). Impact of visual performance management systems on the performance management practices of organisations. International Journal of Production Research, 54(6), 1571-1593.

Boezeman, E. J., \& Ellemers, N. (2007). Volunteering for charity: pride, respect, and the commitment of volunteers. Journal of Applied Psychology, 92(3), 771.

Boezeman, E. J., \& Ellemers, N. (2009). Intrinsic need satisfaction and the job attitudes of volunteers versus employees working in a charitable volunteer organization. Journal of Occupational and Organizational Psychology, 82(4), 897-914.

Bouskila-Yam, O., \& Kluger, A. N. (2011). Strength-based performance appraisal and goal setting. Human Resource Management Review, 21(2), 137-147.

Braun, V., \& Clarke, V. (2006). Using thematic analysis in psychology. Qualitative research in psychology, 3(2), 77-101.

Brewis, G., Hill, M., \& Stevens, D. (2010). Valuing volunteer management skills. Institute for Volunteering Research.

Bryman, A. (2003). Quantity and quality in social research: Routledge.

Buckingham, M., \& Goodall, A. (2015). Reinventing performance management: how one company is rethinking peer feedback and the annual review, and trying to design a system to fuel improvement. Harvard Business Review, 93(4), 40. 
Bussell, H., \& Forbes, D. (2002). Understanding the volunteer market: The what, where, who and why of volunteering. International Journal of Nonprofit and Voluntary Sector Marketing, 7(3), 244-257.

Bussell, H., \& Forbes, D. (2006). Developing Relationship Marketing in the Voluntary Sector. Journal of Nonprofit \& Public Sector Marketing, 15(1-2), 151-174.

Bussin, M. (2013). Performance Management for Government, Universities, Schools and NGOs : A practical and Informative Textbook for Managing Performancein service delivery-orientated organisations. Randburg, ZA: Knowres Publishing.

Carey, W., Philippon, D. J., \& Cummings, G. G. (2011). Coaching models for leadership development: An integrative review. Journal of Leadership Studies, 5(1), 51-69.

Carter, D. E., \& Porter, S. (2000). Validity and Reliability Fourth edition. Blackwell Sciences, Oxford.

Carvalho, A., \& Sampaio, M. (2017). Volunteer management beyond prescribed best practice: a case study of Portuguese non-profits. Personnel Review, 46(2), 410428.

Castka, P., Bamber, C., \& Sharp, J. (2003). Measuring teamwork culture: the use of a modified EFQM model. Journal of Management Development, 22(2), 149-170.

Cavana, R. Y., Delahaye, B. L., \& Sekaran, U. (2001). Applied business research: Qualitative and quantitative methods: John Wiley \& Sons Australia.

Cnaan, R. A., \& Cascio, T. A. (1998). Performance and commitment: Issues in management of volunteers in human service organizations. Journal of Social Service Research, 24(3-4), 1-37.

Cnaan, R. A., Handy, F., \& Wadsworth, M. (1996). Defining who is a volunteer: Conceptual and empirical considerations. Nonprofit and Voluntary Sector Quarterly, 25(3), 364-383.

Corporate Leadership Council. (2004). Driving employee performance and retention through engagement: $A$ quantitative analysis of the effectiveness of employee engagement strategies. Paper presented at the Corporate Leadership Council, Washington, DC.

Creative NZ. (2014). Volunteer Management Toolkit - A resource for arts organisations. Retrieved from http://www.creativenz.govt.nz/development-andresources/volunteer-management-toolkit

Creswell, J. W. (2013). Qualitative inquiry and research design : choosing among five approaches / John W. Creswell (3rd ed.). Los Angeles: SAGE Publications.

Cuskelly, G., Taylor, T., Hoye, R., \& Darcy, S. (2006). Volunteer management practices and volunteer retention: A human resource management approach. Sport Management Review, 9(2), 141-163.

DeNisi, A. (2000). Performance appraisal and performance management. Multilevel Theory, Research, and Methods in Organizations: Foundations, Extensions and New Directions. San Francisco, CA: Jossey-Bass, 121-156.

DeNisi, A. (2011). Managing performance to change behavior. Journal of Organizational Behavior Management, 31(4), 262-276. 
DeNisi, A., \& Smith, C. E. (2014). Performance appraisal, performance management, and firm-level performance: a review, a proposed model, and new directions for future research. The Academy of Management Annals, 8(1), 127-179.

Department of Internal Affairs. (2014). Quarterly Volunteering and Donating Indicators (to September 2014) [Press release]

Devaro, J., \& Brookshire, D. (2007). Promotions and incentives in nonprofit and forprofit organizations. Industrial \& Labor Relations Review, 60(3), 311-339.

Dhebar, B. B., \& Stokes, B. (2008). A nonprofit manager's guide to online volunteering. Nonprofit Management and Leadership, 18(4), 497-506.

Drucker, P. F. (1989). What business can learn from nonprofits. Harvard Business Review, 67(4), 88-93.

Dwiggins-Beeler, R., Spitzberg, B., \& Roesch, S. (2011). Vectors of volunteerism: Correlates of volunteer retention, recruitment, and job satisfaction. Journal of Psychological Issues in Organizational Culture, 2(3), 22-43.

Ellis, S. J., \& Noyes, K. H. (1990). By the people: A history of Americans as volunteers: Jossey-Bass.

Frumkin, P., \& Andre-Clark, A. (2000). When missions, markets, and politics collide: Values and strategy in the nonprofit human services. Nonprofit and Voluntary Sector Quarterly, 29(suppl 1), 141-163.

Garner, J., \& Garner, L. (2011). Volunteering an Opinion: Organizational Voice and Volunteer Retention in Nonprofit Organizations. Nonprofit and Voluntary Sector Quarterly, 40(5), 813.

Gill, P., Stewart, K., Treasure, E., \& Chadwick, B. (2008). Methods of data collection in qualitative research: interviews and focus groups. Br Dent J, 204(6), 291295.

Gray, D. E. (2013). Doing research in the real world: Sage.

Gruman, J. A., \& Saks, A. M. (2011). Performance management and employee engagement. Human Resource Management Review, 21(2), 123-136.

Hager, M., \& Brudney, J. L. (2004). Volunteer management practices and retention of volunteers. Washington, DC.: The Urban Institute.

Hager, M. A., \& Brudney, J. L. (2011). Problems recruiting volunteers: Nature versus nurture. Nonprofit Management and Leadership, 22(2), 137-157.

Handy, F., \& Srinivasan, N. (2004). Valuing volunteers: An economic evaluation of the net benefits of hospital volunteers. Nonprofit and Voluntary Sector Quarterly, 33(1), 28-54.

Hartenian, L. S. (2007). Nonprofit agency dependence on direct service and indirect support volunteers: An empirical investigation. Nonprofit Management and Leadership, 17(3), 319-334.

Haski-Leventhal, D., \& Bargal, D. (2008). The volunteer stages and transitions model: Organizational socialization of volunteers. Human Relations, 61(1), 67-102.

Hatch, J. A. (2002). Doing qualitative research in education settings / J. Amos Hatch. Albany : State University of New York Press. 
Henning, E., Van Rensburg, W., \& Smit, B. (2004). Finding your way in qualitative research: Van Schaik Pretoria.

Hollway, W., \& Jefferson, T. (1997). Eliciting narrative through the in-depth interview. Qualitative Inquiry, 3, 53+.

Holmes, K. (2009). The value of volunteering: The volunteer's story. Australian Journal on Volunteering, 14, 50.

Hotchkiss, R. B., Fottler, M. D., \& Unruh, L. (2009). Valuing volunteers: the impact of volunteerism on hospital performance.(Report). Health Care Management Review, 34(2), 119.

Houghton, C. E., Casey, D., \& Murphy, K. (2012). Rigour in qualitative case study research. Nurse researcher, 20(4), 12-17.

Hudson, L. A., \& Ozanne, J. L. (1988). Alternative ways of seeking knowledge in consumer research. Journal of consumer research, 508-521.

Hughes, L. (2006). A Guide for training volunteers (Part A). Melbourne: Volunteering

Jennings, G. (2001). Tourism research: John Wiley and sons Australia, Ltd.

Joffe, H. (2012). Thematic analysis (Vol. 1): John Wiley \& Sons, Chichester.

Kellner, A., Townsend, K., \& Wilkinson, A. (2016). 'The mission or the margin?'A highperformance work system in a non-profit organisation. The International Journal of Human Resource Management, 1-22.

Kenny, S., McNevin, A., \& Hogan, L. (2008). Voluntary activity and local government: managing volunteers or facilitating active citizenship? Social Alternatives, 27(2), 45.

Kinicki, A. J., Jacobson, K. J., Peterson, S. J., \& Prussia, G. E. (2013). Development and validation of the performance management behavior questionnaire. Personnel psychology, 66(1), 1-45.

Kreutzer, K., \& Jäger, U. (2011). Volunteering versus managerialism: Conflict over organizational identity in voluntary associations. Nonprofit and Voluntary Sector Quarterly, 40(4), 634-661.

Leat, D. (1993). Managing across sectors: Similarities and differences between forprofit and voluntary non-profit organisations: City University Business School London.

Lee, B., Collier, P. M., \& Cullen, J. (2007). Reflections on the use of case studies in the accounting, management and organizational disciplines. Qualitative Research in Organizations and Management: An International Journal, 2(3), 169-178.

Leonard, R., Onyx, J., \& Hayward-Brown, H. (2004). Volunteer and coordinator perspectives on managing women volunteers. Nonprofit Management and Leadership, 15(2), 205-219.

Lincoln, Y. S., \& Guba, E. G. (1985). Naturalistic inquiry (Vol. 75). Beverley Hills, CA.: Sage.

Lockyer, A. (2014). Proposed empirical research concerning the performance management in the New Zealand Not For Profit Sector. Paper presented at 
World Business Finance and Management Conference, Auckland, New Zealand

Lynch, S., \& Smith, K. (2009). The dilemma of judging unpaid workers. Personnel Review, 39(1), 80-95.

Lyons, M. (2001). Third Sector: The contribution of nonprofit and cooperative enterprises in Australia: Allen \& Unwin.

Machin, J., \& Paine, A. E. (2008). Management matters: a national survey of volunteer management capacity. London: Institute for Volunteering Research.

McHargue, S. K. (2003). Learning for performance in nonprofit organizations. Advances in Developing Human Resources, 5(2), 196-204.

Mohiuddin, M., \& Dulay, G. (2015). Employee Motivation in Non-Profit: Evidence from a Community Based Voluntary Organization. International Journal of Business and Management, 10(11), 74.

Mone, E., \& London, M. (2009). Employee engagement through effective performance management: a manager's guide. New York: Routledge.

Moore, M. H. (2000). Managing for value: Organizational strategy in for-profit, nonprofit, and governmental organizations. Nonprofit and Voluntary Sector Quarterly, 29(suppl 1), 183-208.

Moreton, S. (2006). Are 'professional' HR practices compatible with volunteer management? Retrieved from http://www.attend.org.uk/sites/default/files/HR\% 20and\%20Volunteer\%20Management\%20-\%20True\%20Affinity\%20and\%20 Beyond..._0.pdf:

Nankervis, A., \& Stanton, P. (2010). Managing employee performance in small organisations: challenges and opportunities. International Journal of Human Resources Development and Management, 10(2), 136-151.

National Organization for Human Services. (2016). What is Human Services? Retrieved from http://www.nationalhumanservices.org/what-is-human-services

Nencini, A., Romaioli, D., \& Meneghini, A. M. (2016). Volunteer motivation and organizational climate: Factors that promote satisfaction and sustained volunteerism in NPOs. VOLUNTAS: International Journal of Voluntary and Nonprofit Organizations, 27(2), 618-639.

Nesbit, R., Rimes, H., Christensen, R. K., \& Brudney, J. L. (2016). Inadvertent Volunteer Managers: Exploring Perceptions of Volunteer Managers' and Volunteers' Roles in the Public Workplace. Review of Public Personnel Administration, 36(2), 164-187.

New Zealand Government. (2016). Non-profit glossary. Retrieved from http://www.ird.govt.nz/non-profit/np-glossary/np-glossary.html\#np

Newton, C., Becker, K., \& Bell, S. (2014). Learning and development opportunities as a tool for the retention of volunteers: A motivational perspective. Human Resource Management Journal, 24(4), 514-530.

O'Brien, M., Sanders, J., \& Tennant, M. (2009). The New Zealand Non-Profit Sector And Government Policy. Retrieved from https://www.parliament.nz/resource 
O’Boyle, I., \& Hassan, D. (2015). Applying Performance Management Practices Within Non-Profit Sport Organisations: A Case Study Of New Zealand. International Journal of Sport Management, 16, 1-24.

O'Leary, Z. (2014). The essential guide to doing your research project / Zina O'Leary (2nd edition.. ed.): London SAGE.

Ochurub, M., Bussin, M., \& Goosen, X. (2012). Organisational readiness for introducing a performance management system. SA Journal of Human Resource Management, 10(1), 1-11.

Ogden, J., \& Cornwell, D. (2010). The role of topic, interviewee and question in predicting rich interview data in the field of health research. Sociology of health \& illness, 32(7), 1059-1071.

Otago Southland Cancer NZ. (2017). Our Vision, Mission and Committments. Retrieved from https://otago-southland.cancernz.org.nz/en/about-us/aboutus/vision-and-mission/

Paton, R., \& Cornforth, C. (1992). What's different about managing in voluntary and nonprofit organizations? In J. Batsleer, C. Cornforth, \& R. Paton (Eds.), Issues in voluntary and nonprofit management (pp. 36-46). Addison-Wesley, Wokingham.

Paull, M., Holloway, D., \& Burnett, H. (2010). Volunteer Involving Organisations: Comparing the management of volunteers in Western Australia in 1994 and 2009: Perth: Murdoch University.

Platt, J. (2007). Case Study. In Outhwaite, W. \& Turner, S. P. The SAGE handbook of social science methodology (pp. 102-120). : SAGE Publications Ltd.

Pulakos, E. D. (2004). Performance Management: A roadmap for developing, implementing and evaluating performance management systems. USA: SHRM Foundation.

Pulakos, E. D. (2009). Performance management: $A$ new approach for driving business results: John Wiley \& Sons.

Pulakos, E. D., Hanson, R. M., Arad, S., \& Moye, N. (2015). Performance management can be fixed: An on-the-job experiential learning approach for complex behavior change. Industrial and Organizational Psychology, 8(01), 51-76.

Pulakos, E. D., \& O'Leary, R. S. (2011). Why is performance management broken? Industrial and Organizational Psychology, 4(2), 146-164.

Reinharz, S., \& Davidman, L. (1992). Feminist methods in social research: Oxford University Press.

Risher, H. (2011). Getting performance management on track. Compensation \& Benefits Review, 273-281.

Selden, S., \& Sowa, J. E. (2011). Performance management and appraisal in human service organizations: Management and staff perspectives. Public Personnel Management, 40(3), 251-264.

Shah, S. K., \& Corley, K. G. (2006). Building better theory by bridging the quantitativequalitative divide. Journal of Management Studies, 43(8), 1821-1835. 
Shuy, R. W. (2001). Handbook of interview research : context \& methods / [edited] by Jaber F. Gubrium and James A. Holstein. Thousand Oaks, Calif.: Sage Publications.

Sillup, G. P., \& Klimberg, R. (2010). Assessing the ethics of implementing performance appraisal systems. Journal of Management Development, 29(1), 38-55.

Souza, K. A., \& Dhami, M. K. (2008). A study of volunteers in community-based restorative justice programs. Canadian Journal of Criminology and Criminal Justice, 50(1), 31-57.

Spence, J. R., \& Keeping, L. (2011). Conscious rating distortion in performance appraisal: A review, commentary, and proposed framework for research. Human Resource Management Review, 21(2), 85-95.

Statistics New Zealand. (2007). Counting Non-profit Institutions in New Zealand 2005. Retrieved from http://www.stats.govt.nz/browse_for_stats /people_and_communities/Households/Non-ProfitInstitutionsSatelliteAccount _HOTP2005/Commentary.aspx

Statistics New Zealand. (2015). Non-profit institutions satellite account: 2013. Retrieved from www.stats.govt.nz

Studer, S., \& von Schnurbein, G. (2013). Organizational factors affecting volunteers: A literature review on volunteer coordination. VOLUNTAS: International Journal of Voluntary and Nonprofit Organizations, 24(2), 403-440.

Taylor, T., Darcy, S., Hoye, R., \& Cuskelly, G. (2006). Using psychological contract theory to explore issues in effective volunteer management. European Sport Management Quarterly, 6(2), 123-147.

Taylor, T., Mallinson, C., \& Bloch, K. (2008). "Looking for a Few Good Women": Volunteerism as an Interaction in Two Organizations. Nonprofit and Voluntary Sector Quarterly, 37(3), 389.

Taylor, T., \& McGraw, P. (2006). Exploring human resource management practices in nonprofit sport organisations. Sport Management Review, 9(3), 229-251.

Tennant, M., Sanders, J., O’Brien, M., \& Castle, C. (2006). Defining the Nonprofit Sector: New Zealand. Retrieved from https://www.parliament.nz/resource/0000115088:

The Economist. (2016). The measure of a man Out of ammo? Retrieved from http://www.economist.com/printedition/2016-02-20

Tucker, B., \& Thorne, H. (2013). Performance on the right hand side. Organizational performance as an antecedent to management control. Qualitative Research in Accounting \& Management, 10(3/4), 316-346.

UN Volunteers. (2015). 2015 State of the World's Volunteerism Report. Retrieved from http://www.volunteeractioncounts.org/en/swvr-2015.html

United Nations General Assembly. (2002). Recommendations on support for volunteering (A/RES/56/38). Paper presented at the Resolution adopted by the General Assembly at the fifty-sixth session - Agenda item 108.

van Ingen, E., \& Wilson, J. (2016). I Volunteer, Therefore I am? Factors Affecting Volunteer Role Identity. Nonprofit and Voluntary Sector Quarterly, 1-18. 
Vecina, M. L., Chacón, F., Sueiro Abad, M. J., \& Barrón, A. (2012). Volunteer Engagement: Does Engagement Predict the Degree of Satisfaction among New Volunteers and the Commitment of Those who have been Active Longer? Applied Psychology, 61(1), 130-148.

Volunteering NZ. (2016). A Volunteering New Zealand Summary Report - State of the World's Volunteerism Report Retrieved from http://www.volunteeringnz.org.nz/wp-content/uploads/2016SOWVR.pdf

Waikayi, L., Fearon, C., Morris, L., \& McLaughlin, H. (2012). Volunteer management: an exploratory case study within the British Red Cross. Management Decision, 50(3), 349-367.

Walk, M., Schinnenburg, H., \& Handy, F. (2014). Missing in action: Strategic human resource management in German nonprofits. VOLUNTAS: International Journal of Voluntary and Nonprofit Organizations, 25(4), 991-1021.

Walk, T. (2012). Employee Engagement: Tools for Analysis, Practice, and Competitive Advantage by William H. Macey, Benjamin Schneider, Karen M. Barbera, and Scott A. Young. Personnel psychology, 65(1), 207-210.

Wilson, J. (2000). Volunteering. Annual review of sociology, 26(1), 215-240.

Wilson, J. (2012). Volunteerism research: A review essay. Nonprofit and Voluntary Sector Quarterly, 41(2), 176-212.

Wolfe, R., Wright, P. M., \& Smart, D. L. (2006). Radical HRM innovation and competitive advantage: The Moneyball story. Human Resource Management, 45(1), 111-145.

Yin, R. K. (2009). Case study research : design and methods / Robert K. Yin (Fourth edition. ed. Vol. 5): Los Angeles : SAGE. 


\section{APPENDICES}

Appendix A: Information Sheets
1) Volunteers
2) Managers

Appendix B: Research Agreements
1) Volunteers
2) Managers

Appendix C: Interview Schedules
1) Volunteers
2) Managers
3) CEO 
Appendix A (1):

\section{Exploring Performance Management of Volunteers in Non-Profit Organisations in New Zealand's Human Service Sector}

\section{VOLUNTEERS: INFORMATION SHEET}

Thank you for your interest in this project. This handout aims to give you information about the project and your rights to confidentiality, so that you can decide whether you are willing to participate in the interview.

My name is Magdalena Weber and I am a Masters student in Management at Victoria University of Wellington. I volunteered and worked with volunteers for several years which is where my interest for this research stems from. Among others I worked as a volunteer with street children in Romania and most recently I worked for the Jesuit mission in Austria. This research project is work towards my thesis on volunteer management in New Zealand's non-profit human service sector.

The purpose of this study is to get a sense of which organisational practices non-profit organisations can use to create a motivating volunteer experience. I am interested in learning about your experiences with volunteering with the Cancer Society's Otago Southland division, including how the Otago Southland division reviews the performance of its volunteers. However, this is not about your performance, but rather your thoughts, experiences and opinions about the Otago Southland division's practices. The Otago Southland division has agreed to be the case study for my project. For my research I plan to conduct a series of interviews with volunteers, the volunteer manager/s and other managers from the Otago Southland division.

You have been approached as one of a range of currently active volunteers. If you agree to take part, I will interview you at a time that suits you and in a place that is convenient for you, such as at the Otago Southland division or a public place such as a café. I will ask you questions about your experiences, thoughts and opinions about the Otago Southland division and its organisational practices, such as feedback, rewards or training. The interview will take about 1 hour and will be audio recorded. Should you feel uncomfortable with any of the question(s), you can decline to answer. Moreover, you can stop the interview at any time, without giving a reason. I can provide you with a transcript of the interview which you can review and return to me within two weeks. Furthermore, you can withdraw from the study up to four weeks after the interview. If you withdraw, the information you provided will be destroyed or returned to you. This research is intended to be used as part of my Master thesis which will be submitted to Victoria University of Wellington. The findings may also be used for academic publications, conference presentations, and public reports.

\section{Confidentiality:}

All information from the interviews will be kept confidential to the researcher and the supervisor of the project. You might be quoted directly in the final thesis. Your name will not be used in any publications and everything will be done to keep the information you supplied during the interview confidential. 
However, the Cancer Society will be named and others in the Otago Southland division might know that you participated in the research or might be able to identify quotes of your interview in the final thesis. No data about individual performance will be reported. The interview transcripts, summaries and any recordings will be kept securely and destroyed 5 years after the research ends [April 2022].

\section{What does this mean for you?}

You are under no obligation to be interviewed but if you agree to participate, I will ask you to fill in a research agreement that, together with this information sheet, outlines your role in this research and how I will respect your rights as a research participant.

If you do decide to participate, you have the right to:

- $\quad$ choose not to answer any question;

- $\quad$ ask for the recorder to be turned off at any time during the interview;

- $\quad$ withdraw from the study up until four weeks after your interview;

- $\quad$ ask any questions about the study at any time;

- $\quad$ receive a copy of the interview transcript to review and return within 2 weeks;

- $\quad$ agree on another name for me to use rather than your real name;

- read any reports of this research by ticking the box in the research agreement and filling in your email address;

Thank you very much for your time and help in making this study possible. Please do not hesitate to contact the researcher or supervisor if you have any questions.

Approval for the research has been granted by the Victoria University of Wellington Human Ethics Committee with approval number 23441. If you have any concerns about the ethical conduct of the research you may contact the Victoria University HEC Convener: Associate Professor Susan Corbett. Email susan.corbett@vuw.ac.nz or telephone +64-4-463 5480.

\section{Researcher:}

Magdalena Weber, School of Management, Victoria University of Wellington,

Email: webermagd@myvuw.ac.nz

\section{Supervisor:}

Prof. Karen Smith, School of Management, Victoria University of Wellington,

Phone: 044635721

Email: Karen.smith@vuw.ac.nz 
Appendix A (2):

\section{Exploring Performance Management of Volunteers in Non-Profit Organisations in New Zealand's Human Service Sector}

\section{MANAGERS: INFORMATION SHEET}

Thank you for your interest in this project. This handout aims to give you information about the project and your rights to confidentiality, so that you can decide whether you are willing to participate in the interview.

My name is Magdalena Weber and I am a Masters student in Management at Victoria University of Wellington. This research project is work towards my thesis on performance management of volunteers in New Zealand's non-profit human service sector.

The purpose of this case study is to get a sense of which performance management practices non-profit organisations can use to create a motivating volunteer experience. I am interested in how the Cancer Society applies performance management practices to its volunteers and employees, how these measures influence the attitudes and behaviours of volunteers and managers and what volunteers and managers suggest to improve these practices of their organisation. Moreover, I would like to compare the performance management practices applied to employees and volunteers at the Cancer Society. The Cancer Society has agreed to be the case study for my project. For my research I plan to conduct a series of interviews with volunteers, the person responsible for volunteers and other managers from the Cancer Society. Participating in this research will give you and the Cancer Society an opportunity to reflect on the organisation's performance management practices and to get a sense of how volunteers perceive these practices.

If you agree to take part, I will interview you at a time that suits you and in a place that is convenient for you, such as your place of work, a public place such as a café, or at the university. I will ask you questions about your experiences, thoughts and opinions about policies, organisational values and performance management practices applied at the Cancer Society, such as feedback, rewards or training. The interview will take about 1 hour and will be audio recorded. Should you feel uncomfortable with any of the question(s), you can decline to answer. Moreover, you can stop the interview at any time, without giving a reason. I can provide you with a transcript of the interview which you can review and return to me within two weeks. Furthermore, you can withdraw from the study up to four weeks after the interview. If you withdraw, the information you provided will be destroyed or returned to you. This research is intended to be used as part of my Master thesis which will be submitted to Victoria University of Wellington. The findings may also be used for academic publications, conference presentations, and public reports.

\section{Confidentiality:}

All information from the interviews will be kept confidential to the researcher and the supervisor of the project. You might be quoted directly in the final thesis. With your written consent, your job title will be named in the final thesis. Furthermore, your organisation will be named which might allow others to 
identify you in the final thesis. While the findings will be shared with the Cancer Society, none of the transcripts or individual interview data will be reported. The interview transcripts, summaries and any recordings will be kept securely and destroyed 5 years after the research ends [April 2022].

\section{What does this mean for you?}

You are under no obligation to be interviewed but if you agree to participate, I will ask you to fill in a research agreement that, together with this information sheet, outlines your role in this research and how I will respect your rights as a research participant.

If you do decide to participate, you have the right to:

- $\quad$ choose not to answer any question;

- $\quad$ ask for the recorder to be turned off at any time during the interview;

- $\quad$ withdraw from the study up until four weeks after your interview;

- $\quad$ ask any questions about the study at any time;

- $\quad$ receive a copy of the interview transcript to review and return within 2 weeks;

- $\quad$ agree on not naming your job title

- read any reports of this research by ticking the box in the research agreement and filling in your email address;

Thank you very much for your time and help in making this study possible. Please do not hesitate to contact the researcher or supervisor if you have any questions.

Approval for the research has been granted by the Victoria University of Wellington Human Ethics Committee with approval number 23441. If you have any concerns about the ethical conduct of the research you may contact the Victoria University HEC Convener: Associate Professor Susan Corbett. Email susan.corbett@vuw.ac.nz or telephone +64-4-463 5480.

\begin{tabular}{|l|l|}
\hline Researcher: & Supervisor: \\
Magdalena Weber, School of Management, & Prof. Karen Smith, School of Management, \\
Victoria University of Wellington, & Victoria University of Wellington, \\
Email: webermagd@myvuw.ac.nz & Phone: 044635721 \\
& Email: Karen.smith@vuw.ac.nz \\
\hline
\end{tabular}


Appendix B (1):

\section{Exploring Performance Management of Volunteers in Non-Profit Organisations in New Zealand's Human Service Sector}

\section{VOLUNTEERS: RESEARCH AGREEMENT}

I have read the Participant Information Sheet and understand the nature of the research. I have had the opportunity to ask any questions and have them answered to my satisfaction. I understand that I can ask further questions at any time.

I agree to take part in one audio-recorded semi-structured interview. This consent form will be held for 5 years.

I understand that:

- My participation is completely voluntary. I understand that I am free to decline to answer any question during the interview if I prefer not to provide an answer or ask for the recorder to be turned off at any time during the interview.

- I agree to being directly quoted in the final thesis. My name will not be used in any publications. Everything will be done to keep the information I supplied during the interview confidential. However, the Cancer Society will be named and others in the Otago Southland division might be able to identify me or my quotes in the final thesis.

- I may withdraw from this study until four weeks after the interview without giving an explanation, and any information that I have provided will be returned to me or destroyed.

- The data will be securely kept for a period of up to five years after the completion of this project [April 2022] and then destroyed.

- No-one will have access to the recordings or any notes except the researcher and the supervisor.

- I understand that the results will be used for a Master thesis. The findings may also be used for academic publications, conference presentations, and public reports.

- I may read any reports of this research by ticking the box on page two of this agreement and filling in my email address.

In publications I would like to be identified as:

A self-identified pseudonym 
I agree to take part in this research:

Name:

Signature:

Date:

$\square$ I wish to receive a copy of the transcript to review and return within 2 weeks

$\square$ I wish to receive a summary of the research (not before April 2017)

$\square$ I wish to receive an electronic copy of the thesis (not before April 2017)

Contact Details (Email):

Researcher:

Magdalena Weber, School of Management,

Victoria University of Wellington,

Email: webermagd@myvuw.ac.nz

\section{Supervisor:}

Prof. Karen Smith, School of Management, Victoria University of Wellington,

Phone: 044635721

Email: Karen.smith@vuw.ac.nz 
Appendix B (2):

\section{Exploring Performance Management of Volunteers in Non-Profit Organisations in New Zealand's Human Service Sector}

\section{MANAGERS: RESEARCH AGREEMENT}

I have read the Participant Information Sheet and understand the nature of the research. I have had the opportunity to ask any questions and have them answered to my satisfaction. I understand that I can ask further questions at any time.

I agree to take part in one audio-recorded semi-structured interview. This consent form will be held for 5 years.

I understand that:

- My participation is completely voluntary. I am free to decline to answer any question during the interview if I prefer not to provide an answer or ask for the recorder to be turned off at any time during the interview.

- I agree to being directly quoted and identified by my job title in the final thesis.

- While the findings will be shared with the Cancer Society, none of the transcripts or data about the individual interview or individual performances will be reported.

- I may withdraw from this study until four weeks after the interview without giving an explanation, and any information that I have provided will be returned to me or destroyed.

- The data will be securely kept for a period of up to five years after the completion of this project [April 2022] and then destroyed.

- No-one will have access to the recordings or any notes except the researcher and the supervisor.

- The results will be used for a Master thesis. The findings may also be used for academic publications, conference presentations, and public reports.

- I may read any reports of this research by ticking the box on page two of this agreement and filling in my email address.

In publications I would like to be identified as:

A position descriptor: 
I agree to take part in this research:

Name:

Signature:

Date:

I wish to receive a copy of the transcript to review and return within 2 weeks

$\square$ I wish to receive a summary of the research (not before April 2017)

I wish to receive an electronic copy of the thesis (not before April 2017)

Contact Details (Email):

\section{Researcher:}

Magdalena Weber, School of Management,

Victoria University of Wellington,

Email: webermagd@myvuw.ac.nz

\section{Supervisor:}

Prof. Karen Smith, School of Management,

Victoria University of Wellington,

Phone: 044635721

Email: Karen.smith@vuw.ac.nz 
Appendix C (1):

\section{VOLUNTEERS: INTERVIEW SCHEDULE}

First of all, I'd like to thank you for participating in my Master research regarding performance management for volunteers. Please feel free to interrupt or ask for clarification any time during the interview. I'm mainly interested in your opinions and personal experiences. Do you have any questions before we start?

Opening Question:

\section{1.) Can you tell me about your volunteer occupation?}

Performance Management:

2.) How would you describe your volunteer experience with this organisation?

Prompts: commitment, most/least value

3.) What do you understand by the term "performance management" in relation to volunteers? Prompts: which practices, organisation's core values, policies

4.) Can you tell me more about...

Planning:

- ...how you know what is expected of you at "organisation"?

- ...how you feel about the communication and decision making process in the organisation?

- ...how you set goals together with your volunteer manager or supervisor?

- ...if you would like to change anything about the goal setting process or communication with your volunteer manager/supervisor?

Monitoring and Developing:

- ...how you receive feedback about your performance? Would you prefer to receive feedback in a different way?

- ...if you feel confident about performing your assigned tasks? Did you receive any kind of training on how to perform the task?

- ...if there has been a time when you felt unqualified or overwhelmed with your tasks?

- ...how you are encouraged by your volunteer manager/supervisor? Would you like to receive more/less encouragement?

- ....if you have the opportunity to advance in your current volunteer position or to receive any kind of training? Would you like to receive more/less or different trainings?

Rewarding:

- ...what you have experienced in terms of recognition or rewards at the organisation? Would you prefer to be appreciated/recognized in a different way? 
5.) Can you tell me about a positive experience you had in regard to these practices with "organisation"?

6.) Can you tell me about a negative experience you had in regard to these practices with "organisation"?

7.) If you could, is there anything about the performance management practices at "organisation" you would like to improve?

8.) What recommendation would you make to the organisation regarding the management of volunteers?

- Which practices do you think would increase the volunteers' commitment and retention?

9.) Is there anything you would like to add to this interview?

This concludes our interview. Thank you for your participation in this study. 
Appendix C (2):

\section{VOLUNTEER MANAGER: INTERVIEW SCHEDULE}

First of all, l'd like to thank you for participating in my Master research regarding performance management for volunteers. Please feel free to interrupt or ask for clarification any time during the interview. I'm mainly interested in your opinions and personal experiences. Do you have any questions before we start?

Opening Question:

1.) Can you give me an overview of how volunteers are important to your organisation?

- What kind of functions do volunteers execute for your organisation?

Volunteer Management:

2.) Is there a formal framework within "organisation" for the management of volunteers? Please describe how it works.

- How do you ensure that volunteers are placed in areas and with work that is appropriate to their skills and interests?

Performance Management:

3.) What are the purposes of performance management practices for volunteers at "organisation"?

- Prompts: expectations, organisation's core values, philosophy, manager's role

4.) What kind of performance management policies and/or practices does "organisation" have in place for volunteers?

5.) How do the obligations under the Treaty of Waitangi inform your performance management practices?

- Do you have certain policies, trainings or interview procedures especially for Maori?

- Do you have certain policies, trainings or interview procedures which shall ensure a better collaboration between volunteers who work with Maori?

6.) Can you tell me more about...

Planning:

- ...how you communicate the objectives of "organisation" to your volunteers?

- ...how you set goals with your volunteers?

Monitoring and Developing:

- ...how the individual volunteers receive feedback?

- ...what kind of training and development opportunities you offer for your volunteers?

Rewarding:

- ...how you reward and recognize your volunteers? 
7.) What do you think are benefits and strengths of these performance management practices?

8.) What do you think are some of the limitations with your system?

9.) How do you deal with volunteers who perform poorly?

- Who is seen as performing poorly?

- Are you aware of any barriers which might keep you from solving the performance issues?

10.)How do you deal with volunteers who exceed expectations?

- Who is seen as performing well?

11.)To what extent are the volunteer performance management practices similar to the HR management practices of "organisation"?

12.) What do you believe the volunteers think of the performance management system?

13.) What improvements could be made to your performance management practices?

14.) What do you think good performance management practices for volunteers ought to look like in a non-profit organisation?

15.) Is there anything you would like to add to this interview?

This concludes our interview. Thank you for your participation in this study. 
Appendix C (3):

\section{CEO: INTERVIEW SCHEDULE}

First of all, I'd like to thank you for participating in my Master research regarding performance management for volunteers. Please feel free to interrupt or ask for clarification any time during the interview. I am going to ask you about the volunteer policies and performance management practices and how they contrast to the policies and practices for employees. Do you have any questions before we start?

Opening Question:

1.) Can you give me an overview of how volunteers are important to your organisation?

- What kind of functions do volunteers execute for your organisation?

- Do employees in your organisation execute similar jobs?

Volunteer Management:

2.) Is there a formal framework within "organisation" for the management of volunteers? Please describe how it works.

- How do you ensure that volunteers are placed in areas and with work that is appropriate to their skills and interests?

- How is this framework different to the formal framework you have in place for employees?

Performance Management:

3.) What are the purposes of performance management practices for volunteers at "organisation"?

- Prompts: expectations, organisation's core values, philosophy, manager's role

$\rightarrow$ always compared to paid staff

4.) What kind of performance management policies and/or practices does "organisation" have in place for volunteers?

5.) How do the obligations under the Treaty of Waitangi inform your performance management practices?

- Do you have certain policies, trainings or interview procedures especially for Maori?

- Do you have certain policies, trainings or interview procedures which shall ensure a better collaboration between volunteers or employees who work with Maori?

6.) Can you tell me more about...

Planning:

- ...how you communicate the objectives of "organisation" to your volunteers? How does this differ from the way you communicate the objectives of "organisation" to your employees?

- ...how you set goals with your volunteers? How does this contrast to the goal setting process with employees?

Monitoring and Developing:

- ...how the individual volunteers receive feedback? How does this relate to or differ from the feedback process for employees?

- ...what kind of training and development opportunities you offer for your volunteers? How does this relate to or differ from the training and development opportunities for employees? 
Rewarding:

- ...how you reward and recognize your volunteers? How does this relate to or differ from the rewards and recognition which is provided to employees?

7.) What do you think are benefits and strengths of these performance management practices?

- Are the benefits and strengths of these practices the same for employees?

8.) What do you think are some of the limitations with your system?

- Are the limitations the same for your employees?

9.) How do you deal with volunteers who perform poorly?

- Who is seen as performing poorly?

- How does the process of dealing with poor performance differ between volunteers and employees?

10.)How do you deal with volunteers who exceed expectations?

- Who is seen as performing well?

- How does the process of dealing with good performance differ between volunteers and employees?

11.)To what extent are the volunteer performance management practices similar to the HR management practices of "organisation"?

12.) What do you believe the volunteers think of the performance management system?

13.) What improvements could be made to your performance management practices?

14.) What do you think good performance management practices for volunteers ought to look like in a non-profit organisation?

- How do these practices differ from good performance management practices for employees?

15.) Is there anything you would like to add to this interview?

This concludes our interview. Thank you for your participation in this study. 